\title{
ESPÉCIES DE PARASITÓIDES (HYMENOPTERA: BRACONIDAE) DE MOSCAS-DAS-FRUTAS (DIPTERA: TEPHRITIDAE) NO ESTADO DE SÃO PAULO: CARACTERIZAÇÃO TAXONÔMICA, DISTRIBUIÇÃO GEOGRÁFICA E PERCENTAGEM DE PARASITISMO
}

\author{
CláUdia Fidelis MARINHO
}

Dissertação apresentada à Escola Superior de Agricultura "Luiz de Queiroz", Universidade de São Paulo, para obtenção do título de mestre em Ciências, Área de Concentração: Entomologia.

P I R A C I C A B A

Estado de São Paulo - Brasil

Fevereiro - 2004 


\title{
ESPÉCIES DE PARASITÓIDES (HYMENOPTERA: BRACONIDAE) DE MOSCAS-DAS-FRUTAS (DIPTERA: TEPHRITIDAE) NO ESTADO DE SÃO PAULO: CARACTERIZAÇÃO TAXONÔMICA, DISTRIBUIÇÃO GEOGRÁFICA E PERCENTAGEM DE PARASITISMO
}

\author{
CláUdia Fidelis MARINHO \\ Bióloga
}

Orientador: Prof. Dr. ROBERTO ANTONIO ZUCCHI

\begin{abstract}
Dissertação apresentada à Escola Superior de Agricultura "Luiz de Queiroz", Universidade de São Paulo, para obtenção do título de mestre em Ciências, Área de Concentração: Entomologia.
\end{abstract}

P I R A C I C A B A

Estado de São Paulo - Brasil

Fevereiro - 2004 
Dados I nt ernaci onai s de Cat al ogação na Publi cação ( Cl P) DI VI SÃO DE BI BLI OTECA E DOCUMENTAÇÃO - ESALQI USP

Marinho, Cláudia Fidelis

Espécies de parasitódes (Hymenoptera : Braconidae) de moscas-das-frutas

(Diptera : Tephritidae) no Estado de São Paulo: caracterização taxonômica, distribuição geográfica e percentagem de parasitismo / Piracicaba, 2004.

88 p. : il.

Dissertação (mestrado) - - Escola Superior de Agricultura Luiz de Queiroz, 2004. Bibliografia.

1. Braconideo 2. Classificação (Biologia) 3. Controle biológico 4. Distribuição geográfic 5. Inseto-parasitóide 6. Mosca-das-frutas 7. Parasitismo I. Título

CDD 632.774

"Permi tida a cópia total ou parcial deste documento, desde que citada a fonte - O aut or" 
Com todo amor

\title{
Agradeço e Dedico
}

\author{
Aos meus pais, \\ José Carlos Marinho e Maria Luci Fidelis Marinho, \\ Que sempre me apoiaram e incentivaram nas minhas escolhas e pelos esforços \\ ilimitados para minha formação pessoal e profissional
}

$\mathcal{L}$

Aos meus irmãos

Píer Angeli, Marilucy e Roney

Pelo grande apoio, companheirismo e amizade

Ofereço 


\section{AGRADECIMENTOS}

A autora expressa seus agradecimentos a todas as pessoas que, direta ou indiretamente, contribuíram para a realização deste trabalho, em especial:

Ao Prof. Dr. Roberto Antonio Zucchi, pela orientação, oportunidade e aprendizagem durante o mestrado;

Ao Departamento de Entomologia, Fitopatologia e Zoologia Agrícola da ESALQ/USP pela oportunidade de realizar este curso;

A Capes (Coordenação de Aperfeiçoamento de pessoal de Nível Superior), pela concessão da bolsa de estudos;

Ao Dr. Adalton Raga pelo material cedido para a realização deste trabalho;

Prof ${ }^{a} \mathrm{Dr}^{\mathrm{a}}$ Marinéia Lara Haddad em especial ao Prof. Dr. Sinval Silveira Neto pelos esclarecimentos quanto aos dados;

Ao Prof. Dr. José Roberto Postali Parra pelo uso dos equipamentos do Laboratório de Biologia de Insetos (ESALQ/USP), e a Dori Edson Nava pelo auxílio dos mesmos;

Ao Dr. Jorge Anderson Guimarães e M. Sc. Miguel Francisco de Souza Filho pela ajuda durante o mestrado e pelas valiosas sugestões dadas a este trabalho; 
Ao Biólogo Heraldo Negri de Oliveira pelas fotos utilizadas para a formação das pranchas das asas e parasitóides;

À Bióloga M. Sc. Patrícia Milano pelas ilustrações do mesossoma, metassoma e asas dos parasitóides;

Ao Prof. Elliot. W. Kitajima e a Francisco André O. Tanaka, do Núcleo de Apoio a Microscopia Eletrônica da ESALQ-USP (NAP/MEPA - ESALQ/USP), pela orientação e auxílio na parte de Microscopia;

Ao Prof. Dr. Celso Omoto, pela revisão do Summary;

As grandes amigas Márcia d’Ávila e Vanessa Pires da Rosa pela grande amizade e companheirismo, e que me deram tanto apoio nos momentos mais alegres aos mais difíceis, não esquecendo da "Nina”;

Aos amigos Jerson Vanderlei C. Guedes, Geni da Silva Sodré, Isabel Aparecida Custódio e Ranyse B. Querino da Silva, Cristiane M. Feniman em especial a Keiko Uramoto e Clarisse Diniz Alvarenga pelo grande incentivo, apoio, compreensão e amizade e aos demais amigos do Departamento;

Aos Professores do Departamento de Entomologia, Fitopatologia e Zoologia Agrícola da ESALQ/USP por todo conhecimento compartilhado;

E a Deus, razão maior de nossa existência e por estar comigo em todos os momentos. 


\section{SUMÁRIO}

\section{Página}

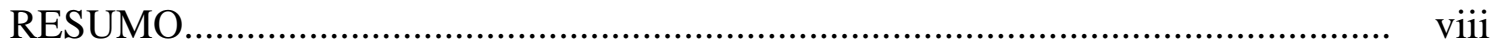

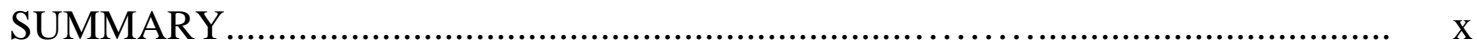

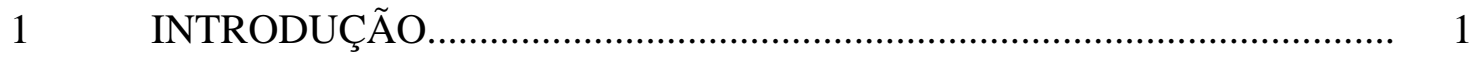

2 REVISÃO DE LITERATURA........................................................... 2

$2.1 \quad$ Taxonomia de Braconidae.................................................................... 2

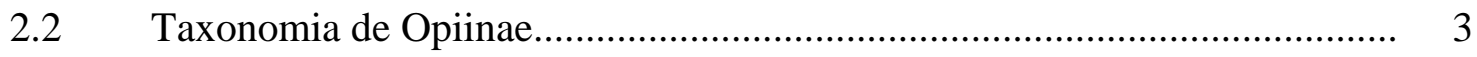

2.3 Taxonomia de Alysiinae.................................................................. 4

2.4 Alguns gêneros da família Braconidae, parasitóides de moscas-das-frutas

(Diptera: Tephritidae), no Brasil............................................................. 6

2.5 Distribuição de parasitóides no Brasil....................................................... 8

2.6 Controle biológico........................................................................ 10

$2.7 \quad$ Aspectos biológicos....................................................................... 10

2.8 Percentagem de parasitismo............................................................. 11

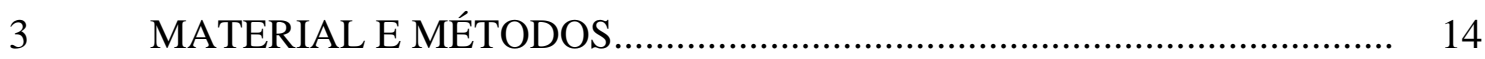

Obtenção das amostras..................................................................... 14

Identificação dos parasitóides............................................................ 15

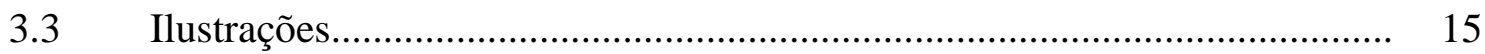

3.4 Caracterização das espécies............................................................... 15

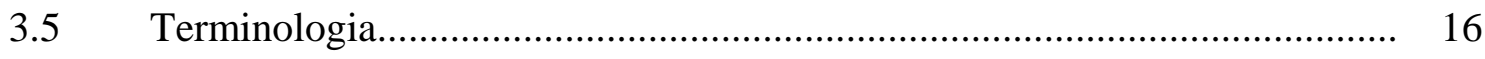

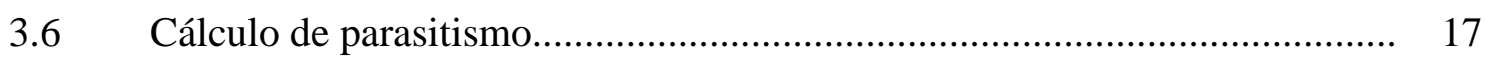


3.7 Cálculo da Intensidade de infestação (I.I.) e percentagem de intensidade de infestação (\%I.I.) de moscas-das-frutas.................................................... 18

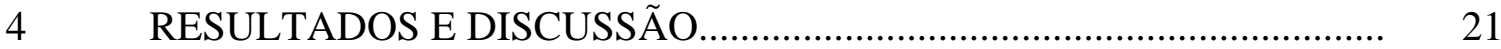

4.1 Espécies de Braconidae......................................................................... 21

4.2 Chave para as espécies de parasitóides (Hymenoptera: Braconidae) de larvas frugívoras (Diptera: Tephritidae) coletadas..................................... 31

4.3 Caracterização das espécies de parasitóides (Hymenoptera: Braconidae) de larvas frugívoras (Diptera: Tephritidae)................................................... 33

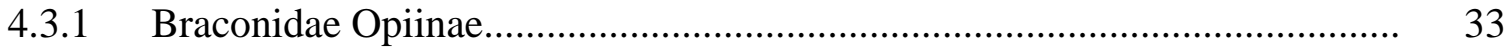

4.3.2 Braconidae Alysiinae........................................................................ 51

4.4 Associação parasitóides/insetos hospedeiros/ plantas associadas.................. 57

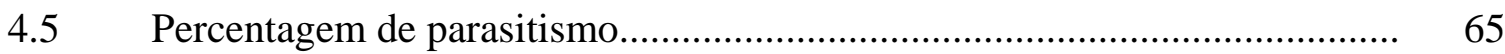

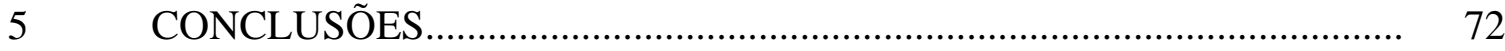

REFERÊNCIAS BIBLIOGRÁFICAS.................................................................. 


\section{ESPÉCIES DE PARASITÓIDES (HYMENOPTERA: BRACONIDAE) DE MOSCAS-DAS-FRUTAS (DIPTERA: TEPHRITIDAE) NO ESTADO DE SÃO PAULO: CARACTERIZAÇÃO TAXONÔMICA, DISTRIBUIÇÃO GEOGRÁFICA E PERCENTAGEM DE PARASITISMO}

Autora: CLÁUDIA FIDELIS MARINHO

Orientador: Prof. Dr. ROBERTO ANTONIO ZUCCHI

\section{RESUMO}

A partir de 148 amostras com parasitóides da família Braconidae, provenientes de levantamentos realizados com as moscas-das-frutas no Estado de São Paulo, foi feito estudo taxonômico, de distribuição e de associação com as moscas hospedeiras e fruteiras. Em 33 municípios, foram coletados 3.009 exemplares. A subfamília Opiinae foi a mais abundante com 96,2\% dos exemplares. Apenas 3,8\% dos parasitóides pertenciam à subfamília Alysiinae. Foram coletadas seis espécies de braconídeos: Doryctobracon areolatus (Szépligeti), Doryctobracon brasiliensis (Szépligeti), Utetes anastrephae (Viereck), Opius bellus (Wesmael) e Opius sp. (Wesmael), além do alisiíneo Asobara anastrephae (Muesebeck). A maior parte dos braconídeos (77,5\%) pertencia a $D$. areolatus. Esta espécie foi associada ao maior número de espécies frutíferas (26), em 7 famílias, e ocorreu na maioria dos municípios amostrados (30). Foi associada a Anastrepha fraterculus (Wied.), A. obliqua (Macquart) e A. amita Zucchi, sendo obtida pela primeira vez de larvas de moscas em frutos de wampi, Clausena lansium (Lour) Skeels, e de canela-batalha, Cryptocarya aschersoniana Mez. 
Doryctobracon brasiliensis foi associada apenas A. fraterculus, sendo registrado pela primeira vez em ameixa-japonesa, Prunus salicina Lindl. Não foi possível associar as demais espécies de parasitóides às moscas-das-frutas. Opius sp. foi associada às larvas em canela-batalha (primeiro registro de planta associada). A percentagem de parasitismo de tefritídeos nos 33 municípios foi de 7,75\%, variando de 0,02\% a 40\%. Foi elaborada uma chave de identificação para as espécies. 


\section{BRACONID PARASITOIDS (HYMENOPTERA) OF FRUIT FLIES (DIPTERA: TEPHRITIDAE) IN THE STATE OF SÃO PAULO: TAXONOMIC CHARACTERIZATION, GEOGRAPHIC DISTRIBUTION AND PERCENTAGE OF PARASITISM}

Author: CLAUDIA FIDELIS MARINHO Adviser: Prof. Dr. ROBERTO ANTONIO ZUCCHI

\section{SUMMARY}

This work presents the results of a survey of braconid fruit fly parasitoids from 33 localities in the State of São Paulo. In addition to the taxonomic studies, data of geographical distribution and association of braconid species to insect hosts and associated plants were also performed. A total of 3,009 specimens were colleted. The subfamily Opiinae was the most abundant with $96.2 \%$ of specimens colleted, and only 3.8\% of the parasitoids belonged to the subfamily Alysiinae. Six species of braconids were collected: Doryctobracon areolatus (Szépligeti), Doryctobracon brasiliensis (Szépligeti), Utetes anastrephae (Viereck), Opius bellus (Wesmael) and Opius sp. (Wesmael), beyond the alisiíneo Asobara anastrephae (Muesebeck). Most of the braconids $(77.5 \%)$ belonged to $D$. areolatus. This species was associated with the highest number of fruit tree species (26), in 7 families, and occurred in the majority of the cities sampled (30). It was associated to Anastrepha fraterculus (Wied.), A. obliqua (Macquart) and A. amita Zucchi, and it is recorded for the first time from fruit fly larvae in wampi, Clausena lansium (Lour) Skeels, and in “canela-batalha” fruits, Cryptocarya 
aschersoniana Mez. Doryctobracon brasiliensis was associated only to A. fraterculus, and it is recorded for the first time in fruit fly larvae in plum, Prunus salicina Lindl. It was not possible to associate the other parasitoid species to the fruit fly species. Opius sp. was associated with the fruit fly larvae in "canela-batalha" (first record of associate plant). The percentage of tephritid parasitism in the 33 cities was of $7.75 \%$, varying from $0.02 \%$ to $40 \%$. A key to identification for the braconid species was elaborated. 


\section{INTRODUÇÃO}

A família Braconidae é a segunda maior família da Ordem Hymenoptera (Wharton, 1997). As espécies das subfamílias Opiinae e Alysiinae parasitam larvas de moscas-das-frutas (Tephritidae) incluindo espécies dos gêneros Anastrepha e Ceratitis.

Os braconídeos, principalmente as espécies da subfamília Opiinae, são os mais utilizados no controle biológico de moscas-das-frutas no mundo, devido à sua especificidade (parasitóides coinobiontes de dípteros ciclorrafos) e pela facilidade de criação de algumas espécies em laboratório, como Diachasmimorpha longicaudata (Ashmead), que se adapta facilmente aos ambientes onde são liberados (Carvalho et al., 2000). Esta espécie tem sido utilizada com sucesso na maioria dos programas de liberações inundativas contra populações de Anastrepha no Novo Mundo. No México, há o projeto de controle biológico das moscas-das-frutas com excelentes resultados (Programa MOSCAMED) (Carvalho et al., 2000).

Para o sucesso na liberação destes parasitóides e conseqüentemente o controle das moscas-das-frutas, torna-se indispensável a realização de estudos taxonômicos, biológicos, de interações tritróficas, de distribuição, além de levantamentos das espécies com o objetivo de conhecer a praga e seu parasitóide (Wharton, 1989; Leonel et al., 1995).

Assim, este trabalho teve como objetivo desenvolver um estudo taxonômico das espécies de parasitóides de moscas-das-frutas coletadas no Estado de São Paulo; elaborar uma chave ilustrada de identificação para as espécies coletadas; ilustrar os caracteres taxonômicos por meio de microscopia eletrônica de varredura (MEV); estudar a distribuição das espécies de braconídeos no Estado de São Paulo e estabelecer as frutíferas, associando-as com os insetos hospedeiros e respectivos parasitóides. 


\section{REVISÃO DE LITERATURA}

\subsection{Taxonomia de Braconidae}

A família Braconidae possui cerca de 14.890 espécies descritas e 40.000 espécies estimadas que se distribuem em diversas regiões do mundo (Wharton, 1997). A maioria

é parasitóide de outros insetos, principalmente larvas de Lepidoptera, Coleoptera e Diptera, podendo ser ecto ou endoparasitóides. O reconhecimento desta família é baseado em uma combinação de caracteres, tais como, ausência da célula costal; nervura costal, subcostal e radial fundidas, ou assim até a metade basal da asa anterior; fusão do segundo e terceiro tergos metassomais; trocanter com dois segmentos e ausência da nervura $2 \mathrm{~m}$-cu (freqüentemente chamada de segunda nervura recurrente) (Wharton, 1997).

As subfamílias Opiinae e Alysiinae formam um grupo monofilético que parasitam larvas de moscas frugívoras (Wharton, 1993; 1997a). Estes parasitóides são em geral de coloração castanha, asas transparentes e com constrição entre o abdome e o tórax. A identificação é baseada na venação alar, esculturação do propódeo e disposição das mandíbulas (Wharton, 1997).

Vários trabalhos abordam a filogenia e classificação da família Braconidae (Tobias, 1967; Capek, 1969; 1970; Achterberg, 1976; 1984; Gaudl \& Bolton, 1988; Quicke \& Achterberg, 1990; Wharton, 1993), que se divide em 34 subfamílias e 404 gêneros (Wharton, 1997). Os caracteres usados na Taxonomia dos Braconidae e chaves para a sua classificação foram apresentadas por Marsh (1963), Griffithis (1964) e Achterberg (1976).

As espécies de parasitóides mais importantes de moscas-das-frutas pertencem à 
subfamília Opiinae, com 40 espécies utilizadas em programas de controle biológico em todo o mundo (Wharton \& Gilstrap, 1983).

Os primeiros estudos taxonômicos na região Neotropical foram realizados por Costa Lima $(1937 ; 1938)$, que listou e apresentou uma chave para todas as espécies de Opius, com descrição de várias espécies.

Uma revisão das espécies de parasitóides de Tephritidae, indo-australianas introduzidas no Havaí foi realizada por Fullaway (1951). De acordo com Wharton (1989), há problemas não solucionados, envolvendo a nomenclatura de parasitóides de moscas-das-frutas usados em programas de controle biológico. Wharton (1997) apresentou um manual de identificação para todas as subfamílias de Braconidae do Novo Mundo, incluindo chaves e ilustrações para todos os gêneros, além de discussões sobre a biologia, classificação, terminologia e morfologia.

\subsection{Taxonomia de Opiinae}

A subfamília Opiinae apresenta uma grande variedade de espécies, com aproximadamente 1.300 descritas (Wharton, 1997b). Esta subfamília é caracterizada por apresentar mandíbulas do tipo endodontes, ou seja, ápices voltados para dentro, quase se tocando quando fechadas (Fig. 4C). Porém, Exodontiella Wharton e algumas espécies de Paroligoneurus Muesebeck (Ichneutinae) apresentam mandíbulas exodontes, mas são separadas dos Alysiinae do Novo Mundo pelo distinto padrão de venação alar e ausência da sutura crenulada médio-ventral no mesotórax. Os membros da subfamília Opiinae apresentam também outras características importantes para a identificação, tais como, morfologia da glândula tergal, deslocamento da veia radial (r) da asa anterior (Fig. 2B), perda da carena epicnemial e pelo menos parte da carena occipital (Wharton, 1997b). Na região Neotropical, inclui-se nesta subfamília as espécies exóticas do gênero Fopius Wharton e Psyttalia Walker e espécies nativas do gênero Doryctobracon Szépligeti, Utetes Foerster e Opius Wesmael (Ovruski et al., 2000). O gênero Diachasmimorpha Ashmead contém espécies introduzidas em vários países e espécies que se distribuem da parte norte da região Neártica à região Neotropical (Ovruski et al., 2000). 
As relações entre os gêneros e os subgêneros desta subfamília têm sido pouco estudadas, sendo sua classificação não definida. O primeiro trabalho com uma síntese do grupo foi realizado por Thompson (1895), citado por Wharton (1988).

Fischer (1972), apud Tobias (1977), propôs a maior reclassificação do grupo empregando 63 gêneros e subgêneros, porém esta se tornou inconsistente em razão das dúvidas quanto a monofilia das espécies.

Wharton (1987) realizou modificações na nomenclatura e classificação de algumas espécies de Opiinae. Designou lectótipos para 13 espécies de Opiinae e um neótipo para Bracon carbonarius Nees von Esenbeck, 1834, além de transferir dois gêneros de Rogadinae (Baeocentrum Schulz e Coeloreuteus Roman) e um de Helconinae (Neodiospilus Szépligeti) para Opiinae. Renomeou quatro espécies de Opius e descreveu Rhynchosteres silvestrii, parasitóide de Tephritidae. Wharton (1999) descreveu duas novas espécies do Velho Mundo no gênero Fopius: F. ceratitivorus (Quênia) e F. schlingeri (Austrália), parasitando respectivamente moscas dos gêneros Ceratitis e Bactrocera. Kimani-Njogu \& Wharton (2002) descreveram duas espécies de Opiinae - Rhynchosteres mandibularis e Fopius okekai - criadas em pupários de ceratitidini (Tephritidae) coletados na região ocidental do Quênia. Estas espécies foram discutidas com ênfase na forma de seus clípeos.

\subsection{Taxonomia de Alysiinae}

A subfamília Alysiinae possui mais de 1.000 espécies descritas em 41 gêneros (Wharton, 1997a). É caracterizada, por apresentar mandíbulas do tipo exodontes (ápices não se tocam quando fechadas) (Fig. 12C). As mandíbulas, geralmente, apresentam três dentes, sendo a maioria com quatro e poucos apresentando entre dois ou cinco dentes. Estes dentes são usados na identificação dos Alysiinae. Em todas as espécies desta subfamília, faltam as carenas occipital e epicnemial e a sutura longitudinal, que passa médio-ventralmente ao longo do mesotórax, é freqüentemente crenulada. A maioria é parasitóide de Agromyzidae, sendo dividida em duas tribos: Alysiini (mais heterogênea

e confusa em sua classificação, parasitando mais de 20 famílias de dípteros) e Dacnusini 
(mais homogênea atacando principalmente moscas minadoras). Algumas espécies da subfamília Alysiinae são solitárias, no entanto, algumas espécies de Aphaereta Foerster, 1862 são gregárias (Wharton, 1988, 1997a; Griffiths, 1964).

Os gêneros Phaenocarpa Foerster e Asobara Foerster são os mais comumente associados às moscas-das-frutas (Tephritidae), porém o último gênero ainda necessita ser revisto; parte de suas espécies é parasitóide de Drosophilidae (cosmopolita) (Muesebeck, 1958; Wharton \& Gilstrap, 1983; Wharton, 1997a; Ovruski et al., 2000). O gênero Microcrasis Fischer não tem sido estudado e muitas espécies não foram descritas. É considerado endêmico da região Neotropical (Ovruski et al., 2000).

Uma revisão para as espécies de Phaenocarpa da região Oriental foi apresentada por Papp (1967). Na região Neártica, as espécies de Phaenocarpa foram revisadas por Fischer (1974; 1975). Wharton (1980) revisou os gêneros e espécies de Alysiini da região Neártica, apresentando chaves e descrições. Wharton (1994) registrou pela primeira vez três gêneros Paleárticos na América do Norte, descrevendo como novos, dois gêneros da América do Sul e nove espécies do Novo Mundo. Além disso, discutiu a posição de várias espécies do Novo Mundo em três gêneros (Aspilota Foerster, Asobara Foerster e Synelix Foerester). Trostle et al. (1999) descreveram duas espécies de Alysiinae da América do Sul, Phaenocarpa hyalina Trostle e Phaenocarpa pericarpa Wharton \& Carrejo, além de terem registrado Anastrepha distincta Greene, como o primeiro hospedeiro de $P$. pericarpa. Elaboraram uma chave para as espécies de Phaenocarpa da América do Sul.

Espécies da tribo Alysiini da Austrália foram revisadas por Wharton (2002), que apresentou a descrição de dois gêneros e subgêneros; das 49 espécies estudadas 43 eram novas. Apresentou também chaves de identificação para todos os gêneros de Alysiinae conhecidos da Austrália, além de discutir e revisar os gêneros do mundo e suas relações. 


\subsection{Alguns gêneros da família Braconidae, parasitóides de moscas-das-frutas (Diptera: Tephritidae), no Brasil}

No Brasil, são conhecidos cinco gêneros e 13 espécies de braconídeos parasitóides de moscas-das-frutas (Canal \& Zucchi, 2000), mas apenas o parasitóide exótico Diachasmimorpha longicaudata (Ashmead) é utilizado no controle biológico no Brasil (Carvalho et al., 2000).

\section{Subfamília Opiinae}

\section{Gênero Doryctobracon Enderlein, 1920}

Parachasma Fischer, 1967

O gênero Doryctobracon apresenta espécies caracterizadas por apresentar o bordo anterior do clípeo sinuoso; ausência de carena occipital; carena dorsal entre o pronoto e o mesonoto bem desenvolvida; segunda célula cubital curta; nervura recurrente unindo a primeira célula cubital e pós-nervelo desenvolvido (Wharton \& Marsh, 1978; Wharton, 1988, Wharton, 1997c). Desde a década de 80, o nome Doryctobracon tem sido usado, seguindo-se os trabalhos de Fischer $(1972$; 1977) e Wharton \& Marsh (1978). Anteriormente, as espécies eram colocadas nos gêneros Opius, Parachasma Fischer, Bioteres Foerster e, às vezes no gênero Diachasma Foerster (Ovruski et al., 2000).

Este gênero é conhecido quase exclusivamente como parasitóides de espécies de Anastrepha, apresentando algumas espécies pequenas diferenças de coloração. Por essa razão, a separação das espécies é dificultada sendo, portanto, necessárias à realização de mais estudos biológicos (Wharton \& Marsh, 1978; Ovruski et al., 2000). 


\section{Gênero Opius Wesmael, 1835}

As espécies de Opius do Novo Mundo não possuem pós-nervelo (Wharton \& Marsh, 1978). O gênero é reconhecido facilmente pela completa ausência das notaulices e carena occipital; presença de dentes basais largos nas mandíbulas; clípeo completo, escondendo completamente o labro e nervura $\mathrm{R}_{1}$ inserida na porção basal do estigma (Wharton, 1988). Este gênero é bastante complexo e inclui um grande número de diferentes grupos morfológicos, apresentando cerca de 21 sinonímias (Wharton \& Marsh, 1978). Foi dividido em nove subgêneros contando com cerca de 800 espécies (Wharton, 1988). Tobias (1977) discutiu alguns problemas na definição deste gênero. Wharton \& Marsh (1978) afirmaram que os membros do grupo truncatus, subgrupo II, formavam um grupo distinto de parasitóides de tefritídeos, com separação bastante difícil, baseando-se muitas vezes em pequenas diferenças de coloração.

Atualmente estão registradas no gênero Opius oito espécies que parasitam tefritídeos: $O$. baldufi Muesebeck, O. bellus Gahan, O. bucki Costa Lima, O. downesi Gahan, O. froggatti Fullaway, O. hirtus Fischer, O. tafivallensis Fischer, e O. mariae Tobias. Esta espécie Paleártica se mantém numa posição isolada dos Opiinae (Wharton, 1997c). Antigamente o grupo O. bellus Gahan, era incluído em Desmiostoma, porém, as espécies que compunham este grupo não compartilhavam nenhuma característica derivada da espécie-tipo, com exceção da perda da carena occipital (característica homoplásica) (Wharton, 1997c). Opius bellus e O. hirtus pertencem a um complexo de espécies muito próximas, apresentando uma posição subgenérica separada. Os membros de Opius (Bellopius) também são de difícil distinção e é provável que outras espécies deste grupo estejam associadas aos tefritídeos (Ovruski et al., 2000).

\section{Gênero Utetes Foerster, 1862}

No gênero Utetes a carena occipital é variável, presente lateralmente, estendendo-se parcialmente da região dorsal à altura da cabeça, na maioria das espécies, sendo ausente em U. anastrephae (Viereck) espécie da região Neotropical (Wharton, 
1997c). Este gênero ainda apresenta a margem da carena hipostomal bem desenvolvida; sulco malar ausente; pronoto com uma depressão; estigma em forma de cunha com a inserção da $\mathrm{R}_{1}$ levemente deslocada do meio à base; segunda célula cubital alargada e ausência de pós-nervelo (Wharton, 1988). As espécies deste gênero foram consideradas sinonímias de Opius, por um período de 100 anos (Marshall, 1891, citado por Ovruski et al., 2000), porém, o gênero foi dividido em dois subgêneros por Wharton (1988), Bracanastrepha e Utetes, sendo o primeiro definido pela ausência de carena occipital.

\section{Subfamília Alysiinae}

\section{Gênero Asobara Foerster, 1962}

Os caracteres de identificação mais importantes são: segundo flagelômero maior do que o primeiro; nervuras das asas completas, com duas células cubitais; célula braquial fechada, com nervura paralela saindo do centro da célula, algumas vezes intersticial; segundo segmento radial maior do que a primeira intercubital; nervura recurrente intersticial ou unindo-se à segunda célula cubital e sutura médio-ventral do mesotórax raramente ampla e crenulada (Wharton, 1980).

As espécies do gênero Asobara são principalmente parasitóides de Drosofilídeos (Vet et al., 1984, citada por Wharton, 1994). Este gênero é bastante diverso nos trópicos do Velho Mundo e a maioria das espécies não foi ainda descrita (Wharton, 1994).

\subsection{Distribuição dos parasitóides no Brasil}

Os parasitóides da família Braconidae têm sido utilizados largamente no controle biológico de moscas-da-frutas, em vários países (Clausen, 1956; Wharton \& Gilstrap, 1983; Ovruski et al., 2000; Carvalho et al., 2000). Entretanto, para o sucesso na implementação de programas de controle de uma determinada região ou país, é fundamental o conhecimento da dinâmica populacional das moscas-das-frutas, além do conhecimento das espécies de parasitóides locais (nativos) (Araújo, 2002). 
Na região Neotropical, foram relacionadas 41 espécies de opiíneos, parasitóides de espécies de Anastrepha (Wharton \& Marsh, 1978). Para as espécies de Dacus e Ceratitis, foram relacionadas 43 espécies de opiíneos que têm sido usados no controle (Wharton \& Gilstrap, 1983).

No Brasil, o maior número de espécies de parasitóides de larvas frugívoras, coletadas com freqüência, pertence à família Braconidae (Wharton, 1989). Após os trabalhos de Costa Lima (1937; 1938), pouco foi feito com este grupo de insetos. Porém, atualmente levantamentos destes parasitóides têm sido realizados em vários Estados: Amazonas (Canal Daza et al., 1994; 1995), Bahia (Matrangolo et al., 1998), Goiás (Veloso et al., 1996) Mato Grosso do Sul (Uchôa, 1999; Uchôa et al., 2003), Rio de Janeiro (Aguiar-Menezes \& Menezes, 1997), São Paulo (Leonel Jr. et al., 1996; Souza Filho, 1999), Santa Catarina (Nora et al., 1995) e Rio Grande do Sul (Salles, 1996; Kovaleski, 1997).

Leonel Júnior. et al. (1995) relacionaram 10 espécies e Canal \& Zucchi (1996) registraram mais três espécies de parasitóides de Tephritidae totalizando 13 espécies de Braconídeos no Brasil: Asobara anastrephae Muesebeck, Asobara. sp., Doryctobracon areolatus Szépligeti, D. fluminensis Costa Lima, D. brasiliensis Szépligeti, Doryctobracon sp., Microcrasis lonchaeae, Opius bellus Gahan, Opius sp., O. bucki Costa Lima, O. itatiayensis Costa Lima, O. tomoplagiae Costa Lima, Utetes anastrephae Viereck. Dentre essas espécies, seis são de ocorrência comum, sendo Doryctobracon areolatus, a mais abundante (Leonel Jr. et al., 1995; Canal Daza \& Zucchi, 2000). No Estado de São Paulo, ocorrem oito espécies: Asobara anastrephae, Asobara sp., Doryctobracon areolatus, D. brasiliensis, D. fluminensis, Opius bellus, Opius sp. e Utetes anastrephae. A espécie de Asobara coletada em larvas/pupas, no município de Cafeeiros de Pindorama/SP, por meio de levantamentos de moscas-dasfrutas, foi diferenciada de Asobara anastrephae pela coloração escura, sendo ainda não identificada (Canal \& Zucchi, 2000). 


\subsection{Controle biológico}

A iniciativa para o uso de braconídeos em programas de controle biológico de moscas-das-frutas ocorreu em 1902, na Austrália, sem muito sucesso, quando houve uma busca por inimigos naturais no Brasil e na Índia, com o objetivo de controlar Ceratitis capitata (Wharton, 1989). Na década de 40, Diachasmimorpha longicaudata (Ashmead) destacou-se entre 24 espécies liberadas no Havaí para o controle de

Bactrocera dorsalis (Hendel), tornando-se abundante (Bess, 1953). Os resultados promissores deste programa incentivaram projetos análogos em vários países: México (Jimenez-Jimenez, 1963), Austrália (Snowball, 1966), Flórida, EUA (Baranowski, 1974), Trinidad e Tobago (Bennett et al., 1977), Taiwan (Yao, 1989), Espanha (Jimenez \& Castilho, 1992) e recentemente no Brasil. Esta espécie está sendo produzida massalmente pelo CENA/USP, em Piracicaba, SP, em colaboração com o programa internacional para a erradicação da mosca-da-carambola (Carambola Fruit Fly Programe) (Carvalho \& Nascimento, 2001).

No Brasil, foi lançado um programa para a produção de insetos estéries (moscado-mediterrâneo) e do parasitóide exótico D. longicaudata em biofábrica instalada em Juazeiro - BA.

\subsection{Aspectos biológicos}

Os Opiinae e Alysiinae são endoparasitóides de dípteros ciclorrafos que ovipositam em larvas ou ovos de moscas da família Tephritidae e emergem do pupário de seus hospedeiros. As espécies destes gêneros apresentam longos ovipositores que são usados para alcançar as larvas escondidas nos frutos (Wharton, 1993).

As fêmeas freqüentemente buscam em locais distantes e desconhecidos, populações hospedeiras. Portanto, para se reproduzirem estes parasitóides encontram um ambiente apropriado a partir da orientação de parâmetros químicos e físicos, uma vez que a procura é sistemática. Assim, ao iniciarem o forrageamento, uma série de etapas são sucedidas para que ocorra o parasitismo, como a localização do hábitat do 
hospedeiro, localização do hospedeiro; aceitação e suscetibilidade hospedeira (Salt, 1935; Laing, 1938; Flanders, 1953; Doutt, 1964; citado por Vinson, 1976).

Durante o parasitismo, os braconídeos são atraídos para os locais de oviposição a partir de uma pequena linha de voláteis emitidas pela fermentação de frutos em decomposição (estímulos de longa distância). Estando no hábitat do hospedeiro, as fêmeas rapidamente percorrem a superfície do fruto, fazendo movimentos de batida com as antenas (vibrotaxia) a fim de detectar o som produzido pelas larvas, quando se alimentam da polpa. Ao localizar a larva do potencial hospedeiro, o ovipositor é introduzido fortuitamente podendo aceitá-la ou rejeitá-la (apenas a larva não parasitada é aceita). A aceitação implica na colocação de um ou mais ovos no hospedeiro, que continua a se desenvolver mesmo parasitado (parasitóide coinobionte) até seu estágio imaturo completar o desenvolvimento (Greany et al., 1977; Ovruski, 1994; Wharton, 1997; Canale \& Raspi, 2000).

\subsection{Percentagem de parasitismo}

Diversos trabalhos abordam as diferenças nas percentagens de parasitismo, discutidos a partir das características físicas como cor (Leyva et al., 1991), morfológicas, (tamanho) (Leonel Júnior, 1991; Sivinski, 1991, 1997; Aguiar Menezes et al., 2001) e espessura da casca (Salles, 1996), além de químicas, por meio de voláteis emanados de frutos em fermentação (Greany et al., 1977; Messing \& Jang, 1992). Todos estes parâmetros influenciam diretamente na habilidade dos braconídeos em encontrar as larvas nos frutos (Aguiar Menezes, 2000).

A média de parasitismo de larvas/pupas de moscas-das-frutas por braconídeos (Opiinae), nos municípios de Limeira e Piracicaba-SP, foi de 4,8\%, variando de 0,6\% a 11,0\% dependendo da espécie de planta hospedeira. Porém os maiores valores de parasitismo foram obtidos em larvas em carambola (A. carambola) (22,4\%), café (C. arabica) (22,2\%) e pitanga (E. uniflora) (16,4\%), que apresentam características bastante favoráveis à postura dos parasitóides, ou seja, pericarpo fino e mesocarpo raso (Leonel Júnior et al., 1996). Em 94 municípios do Estado de São Paulo, o parasitismo 
variou de $1,1 \%$ a $63,4 \%$, com evidente associação entre as características físicas do fruto com os níveis de parasitismo. A maioria dos parasitóides originou de frutos leves e pequenos como pombeiro (Citharexylum myrianthum Cham.) (1g), cabeluda (Plinia glomerata Berg Amsh.) (3g) e grumixama (Eugenia brasiliensis Lam.) (3g) que apresentaram índices de parasitismo maiores que 20\%, ao contrário de frutos grandes como manga (Mangifera indica L.) (202g), laranja-azeda (Citrus aurantium L.) (152g) e laranja-doce (C. sinensis L Osbeck) (128g), com índices menores de 10\% (Souza Filho, 1999).

Entretanto, Hickel (2002) afirmou que a espessura da polpa (não o tamanho do fruto) atuava como uma barreira a oviposição em larvas de tefritídeos. Constatou que havia correspondência entre a espessura da polpa dos frutos e a incidência de parasitismo. Em frutos com polpa fina, o nível de parasitismo tendeu ao máximo e reduziu em frutos de polpa espessa.

Os níveis de parasitismo variam também em função da densidade de larvas/pupas de moscas-das-frutas e pelo tamanho do ovipositor do parasitóide. Altas densidades larvais e ovipositores maiores contribuem para o aumento no parasitismo (Sivinski et al., $1997 ; 1998)$.

Além dos fatores já mencionados, que contribuem para o aumento no parasitismo das moscas-das-frutas (tamanho dos frutos, casca fina, polpa rasa, tamanho do ovipositor e densidade de larvas/pupas de tefritídeos), o tempo de permanência dos frutos no campo também apresenta uma relação direta com o aumento do parasitismo, ou seja, após a abscisão o nível de parasitismo pode ser aumentado, pois o parasitóide possui um tempo maior para encontrar as larvas das moscas (Purcell et al., 1994). Entretanto, Aguiar-Menezes (2000) observou que o tempo de permanência de goiaba (Psidium guajava L.) e serigüela (Spondias purpurea L.) no solo não resultou em aumento do parasitismo por braconídeos, provavelmente pela diminuição das características químicas, morfológicas e/ou físicas à medida que os frutos tornavam-se senescentes, sendo não mais atrativos às fêmeas de braconídeos.

Aguiar-Menezes \& Menezes (2001) também avaliaram o impacto de opiíneos, determinando sua variação anual na abundância e percentagens de parasitismo, sob a 
influência de fatores climáticos e disponibilidade de frutos hospedeiros. Verificaram que as percentagens de parasitismo de Anastrepha pelas três espécies de opiíneos ( $D$. areolatus, $U$. anastrephae e $O$. bellus), embora não tenham se correlacionado com os fatores climáticos, estes parasitóides exerceram ativamente seu parasitismo nos meses mais quentes e chuvosos (verão), por apresentar maior disponibilidade de frutos. Foi verificado também que as populações de opiíneos foram correlacionadas diretamente com as variações numéricas nas populações de Anastrepha, indicando uma relação dependente da densidade direta. Os opiíneos foram mais efetivos às altas densidades de seus hospedeiros, demonstrando baixa capacidade de localização deles, portanto, não sendo bons candidatos a agentes de controle biológico para estas espécies na região estudada. 


\section{MATERIAL E MÉTODOS}

\subsection{Obtenção das amostras}

Os braconídeos estudados foram provenientes de coletas de frutos realizadas por pesquisadores do Instituto Biológico de Campinas, envolvidos com projetos com as moscas-das-frutas (Diptera: Tephritidae). As coletas foram realizadas em 71 municípios do Estado de São Paulo, no período de agosto/1997 a fevereiro/2003.

Os frutos maduros ou em início de maturação, foram coletados de forma aleatória em diferentes alturas nas árvores e no chão. Portanto, as amostras foram de tamanho variável de acordo com a disponibilidade dos frutos, sendo devidamente etiquetadas. Os frutos foram levados ao Laboratório de Entomologia Econômica do Centro Experimental do Instituto Biológico de Campinas/SP, onde foram pesados e acondicionados em caixas plásticas, contendo uma mistura de areia e argila, para as larvas empuparem. Após 10 a 20 dias, o substrato foi peneirado e os pupários foram contados e transferidos para outro laboratório de ambiente controlado, para a emergência das moscas-das-frutas e parasitóides. Os exemplares foram separados e colocados em frascos com álcool a 70\%, para posterior identificação.

A partir das informações nas etiquetas, foi possível o estabelecimento da distribuição geográfica dos parasitóides no Estado de São Paulo, assim como a associação com os insetos hospedeiros e as frutíferas associadas. A associação entre uma espécie de parasitóide e sua larva hospedeira só foi estabelecida, quando em uma amostra de frutos, emergiram apenas uma espécie de parasitóide e uma espécie de mosca. Os espécimens foram depositados na coleção do Departamento de Entomologia, Fitopatologia e Zoologia Agrícola - ESALQ/USP. 


\subsection{Identificação dos parasitóides}

As espécies da família Braconidae foram identificadas com base nos trabalhos taxonômicos de vários autores (Wharton, 1997; Leonel Júnior, 1991; Souza Filho, 1999) e por comparações com exemplares da coleção do Departamento de Entomologia, Fitopatologia e Zoologia Agrícola - ESALQ/USP.

As espécies de moscas-das-frutas (Tephritidae) foram identificadas pelo Biólogo Rogério Amaro Machado e pelo Eng. Agr. M.Sc. Miguel Francisco de Souza Filho (Instituto Biológico).

\subsection{Ilustrações}

As ilustrações dos braconídeos foram obtidas em Microscopia Eletrônica de Varredura (LEO 435VP) do Núcleo de Apoio à Pesquisa, Microscopia Eletrônica Aplicada à Agropecuária (NAP/MEPA) - ESALQ/USP. Os exemplares, após completamente secos, foram dissecados e montados em bases de alumínio (Stubs), por meio de fita adesiva de dupla face e recobertas por uma fina camada de ouro pelo metalizador utilizado como Sputt Coater, antes de serem examinados.

Para as ilustrações dos parasitóides e das asas anteriores, foi utilizada câmara fotográfica acoplada ao microscópio estereoscópico. Os parasitóides foram mantidos em álcool a 70\% em placa de Petri. As asas foram retiradas dos exemplares e distendidas em lâmina de microscopia, sendo cobertas por lamínula. Os esquemas das asas, mesossoma e metassoma foram elaborados pela Bióloga Patrícia Milano, adaptados de Wharton (1997).

\subsection{Caracterização das espécies}

Foram analisadas séries de 30 exemplares/espécie (15 machos e 15 fêmeas), para a caracterização das espécies. 
Uma ocular micrométrica acoplada ao microscópio estereoscópico foi utilizada para efetuar as seguintes medidas:

1 - Comprimento do corpo

2 - Comprimento do mesossoma

3 - Altura do mesossoma

4 - Largura do mesossoma

5 - Altura da cabeça

6 - Largura da cabeça

7 - Comprimento do ovipositor

8 - Comprimento da asa anterior

9 - Comprimento da $1^{\underline{a}}$ nervura intercubital (m-cu)

10 - Comprimento da $2^{\underline{a}}$ nervura radial $\left(\mathrm{r}_{2}\right)$

\subsection{Terminologia}

Os termos utilizados foram baseados em Wharton (1997).

(1) Bainha do ovipositor: par de bainhas que envolvem o ovipositor (Fig. 1 e 2C).

(2) Carena occipital: Carena localizada posteriormente na cabeça que separa o occipício da têmpora e vértice.

(3) Clípeo: Esclerito médio da cabeça imediatamente acima do labro e delimitado dorso-lateralmente pelo orifício tentorial anterior e dorso-lateralmente pela face (Fig. 4C).

(4) Estigma: Área pigmentada, esclerotizada localizada na metade distal da margem anterior, da asa anterior (Fig. 2B).

(5) Esternelo: Carena que corre desde aproximadamente a base da coxa mediana em direção à margem anterior da mesopleura. Freqüentemente é esculturado (Fig. 10A)

(6) Intercubital 1 (i $\mathbf{i}_{1}$ ): Nervura que divide as células $\mathrm{Cu}_{1}$ e $\mathrm{Cu}_{2}$ (Fig. 2B).

(7) Mesossoma: Conjunto composto de tórax e propódeo (Fig. 2A). 
(8) Mesonoto: Superfície dorsal do metatórax composto de mesoescuto e escutelo (Fig. 2A)

(9) Mesopleura: Esclerito lateral do mesotórax (Fig. 1 e 4A).

(10) Mesoescuto: Esclerito anterior do mesonoto (Fig. 1 e 2A).

(11) Metassoma: Conjunto composto de pecíolo mais gáster (Fig. 2C).

(12) Propódeo: Primeiro segmento do abdome fundido ao metatórax, separado do abdome por constricção (Fig. 1 e 2A)

(13) Radial (r): Nervura que fecha a célula radial na sua margem costal (Fig. 2B).

(14) Radial 2 ( $\left.\mathbf{r}_{2}\right)$ : Nervura que compõe a célula radial (Fig. 2B).

(15) Recurrente (rec): Nervura que divide a célula $d_{1}$ e $d_{2}$ (Fig. 2B).

(16) Sulco escutelar: Depressão transversa do escutelo diretamente posterior ao mesonoto, freqüentemente surgindo como dois grandes orifícios (Fig. 2A).

(17) Sulcos parapsidiais ou notáulices: Par de sulcos que inicia na borda lateral anterior do mesonoto encontrando com o sulco pré-escutelar. Pode apresentarse incompleto e algumas vezes crenulado (Fig. 2A).

(18) Tégula: Esclerito próximo à extremidade da costa da asa anterior, o qual sobrepõe a base da asa (Fig. 1 e 2A).

(19) Têmpora: Área posterior da cabeça localizada acima e atrás dos olhos compostos (Fig. 4A).

\subsection{Cálculo de parasitismo}

A percentagem de parasitismo dos braconídeos sobre larvas/pupas das moscasdas-frutas foi calculada com base em Hernándes-Ortiz et al. (1994):

P\% $=$ № parasitóides emergidos/№ total de pupários obtidos x 100

P\% - Percentagem de parasitismo 


\subsection{Cálculo da intensidade de infestação (I.I.) e percentagem de intensidade de infestação (\% I.I.) de moscas-das-frutas}

O cálculo de intensidade de infestação (I.I.) foi feito contando-se o número de pupários obtidos em relação ao peso total (massa) dos frutos em kg.

A percentagem de intensidade de infestação foi calculada usando-se a intensidade infestação (I.I.) em relação à soma total desta intensidade multiplicada por 100.

(I.I.) = № de pupários / massa $(\mathrm{kg})$

$(\%$ I.I. $)$ intensidade de infestação / soma total de I.I. x 100

I.I. - Intensidade de infestação de moscas-das-frutas

\%I.I. - porcentagem de intensidade de infestação de moscas-das-frutas 


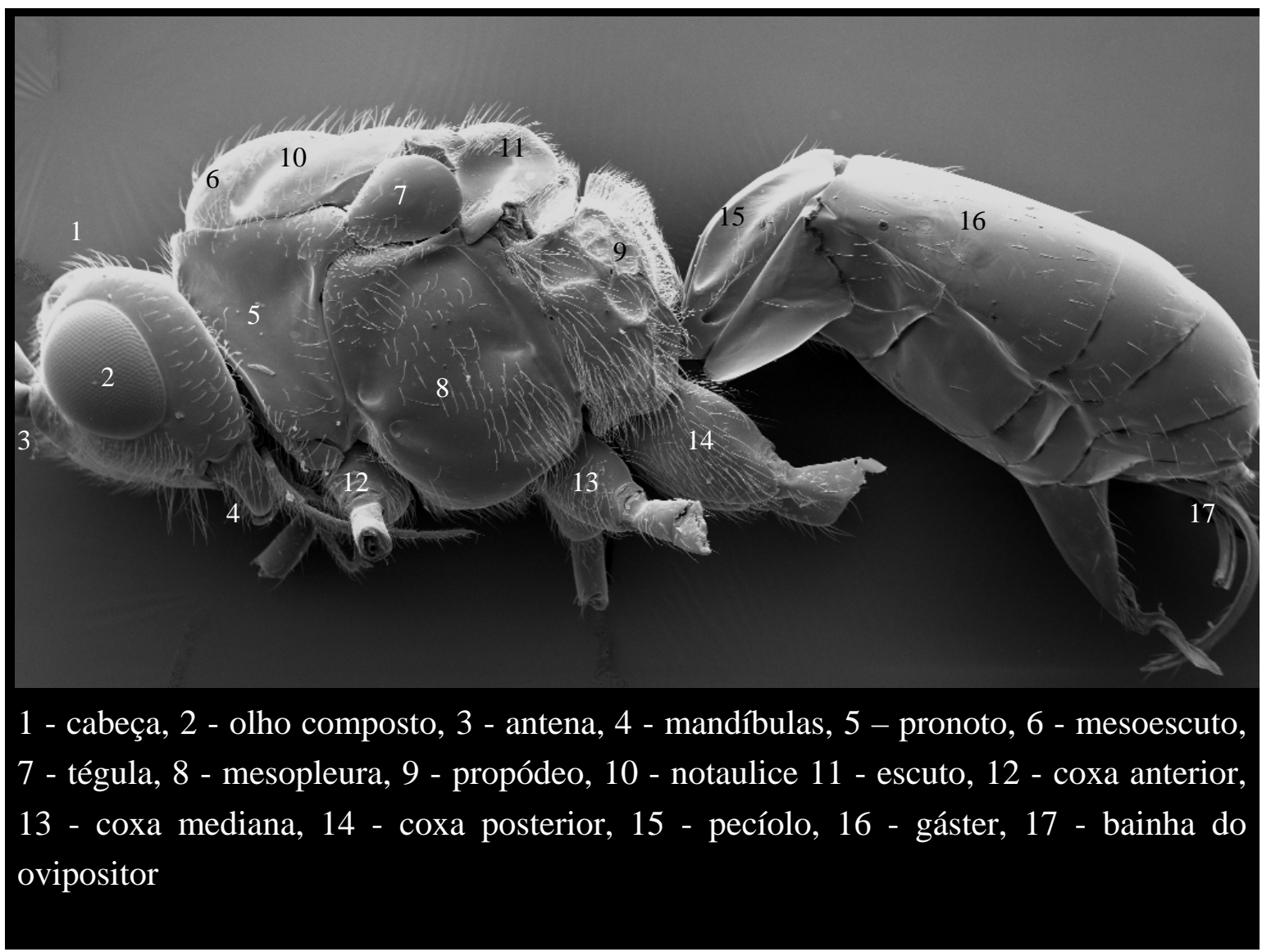

Figura 1 - Doryctobracon areolatus, fêmea - asas retiradas (vista lateral, 68x) 


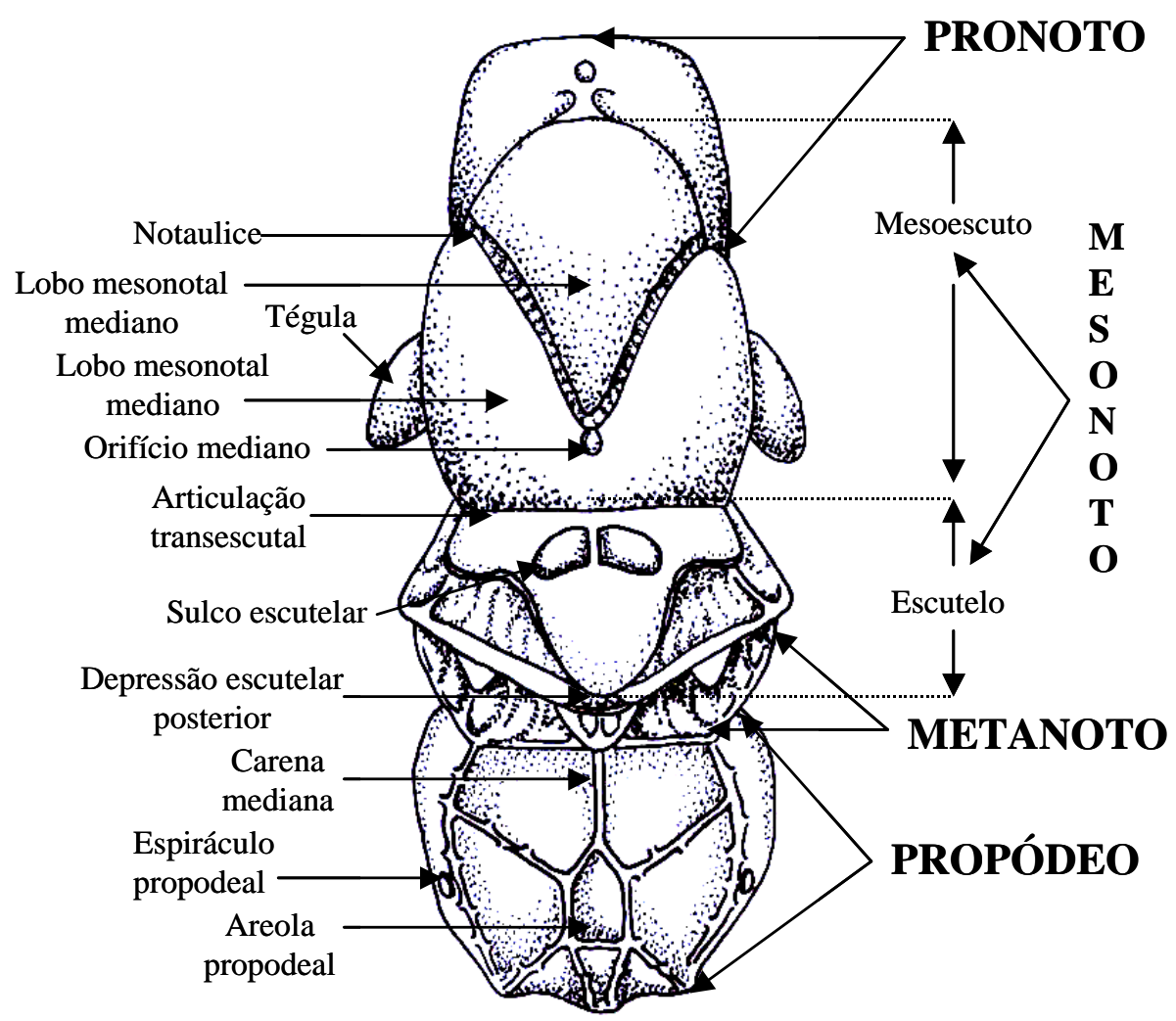

A

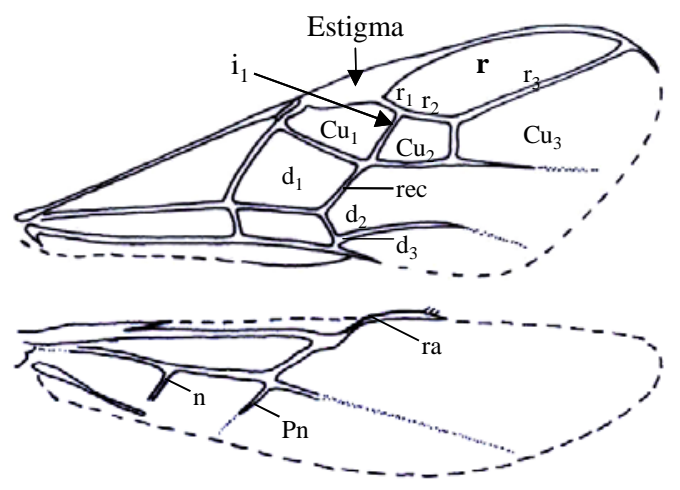

B

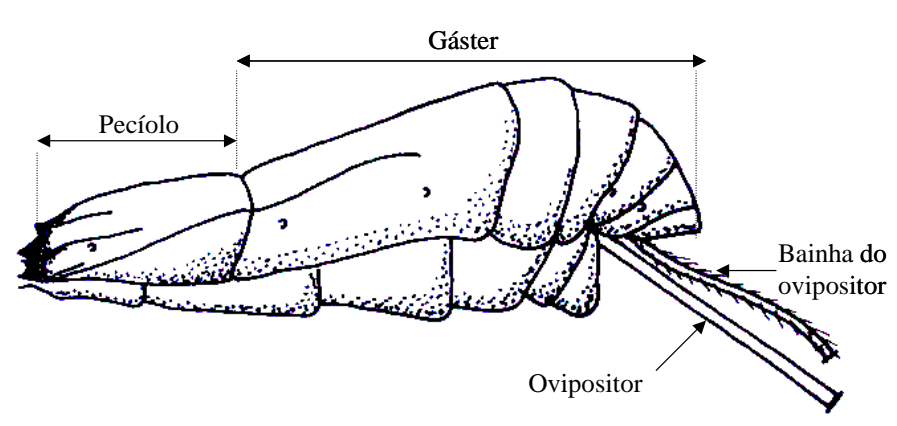

$\mathrm{C}$

Figura 2 - Características morfológicas de Braconidae. A. Mesossoma, em vista dorsal; B. Asa anterior e posterior de Opiinae: $r$, célula radial; $r_{1}, r_{2}$ e $r_{3}\left(1^{\underline{a}}, 2^{\underline{a}}\right.$ e $3^{\underline{a}}$ nervuras

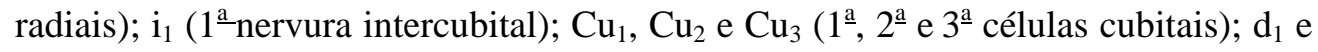
$\mathrm{d}_{2}$ ( $1^{\underline{a}}$ e $2^{\underline{a}}$ células discoidais) e $\mathrm{d}_{3}$ ( $3^{\underline{0}}$ segmento da nervura discoidal); rec, nervura recurrente; ra, radiela; n, nervelo; Pn, pós-nervelo; C. Metassoma, em vista lateral (adaptado de Wharton, 1997) 


\section{RESULTADOS E DISCUSSÃO}

\subsection{Espécies de Braconidae}

Dos 71 municípios amostrados do Estado de São Paulo, em 33 foram obtidas amostras com parasitóides: Avaré, Araraquara, Atibaia, Assis, Anhumas, Bertioga, Campinas, Conchal, Cosmorama, Cordeirópolis, Casa Branca, Florínia, Franca, Juquiá, Jales, Leme, Mococa, Mogi das Cruzes, Monte Alegre do Sul, Monte Mor, Nazaré Paulista, Neves Paulista, Pariquera Açú, Pedreira, Pindorama, Piracicaba, São Bento do Sapucaí, Salto, São Paulo, São Roque, Ubatuba, Vargem e Valinhos (Figura 3). Foram examinadas 148 amostras, totalizando 3.009 parasitóides da família Braconidae, a partir de 38.785 pupários de moscas-das-frutas (Tephritidae). Houve emergência de 21.452 moscas-das-frutas pertencentes ao gênero Anastrepha (85,4\%) (9 espécies) e a Ceratitis capitata (14,6\%) (Tabelas 2 e 3). A subfamília Opiinae foi a mais abundante com 96,2\% dos exemplares, concordando com vários autores, como sendo os principais parasitóides de moscas-das-frutas (Clausen et al., 1965, Wharton \& Gilstrap, 1983, Leonel Júnior et al., 1996). Apenas 3,8\% dos parasitóides pertenciam à subfamília Alysiinae (Tabela 1).

Foram coletadas seis espécies de Braconidae - Doryctobracon areolatus (Szépligeti), Doryctobracon brasiliensis (Szépligeti), Opius bellus (Gahan), Opius sp., Utetes anastrephae (Viereck) e Asobara anastrephae (Muesebeck). A maioria dos braconídeos pertencia a $D$. areolatus com (77,5\%), apresentando ainda o maior número de espécies frutíferas associadas (26) em sete famílias, estando presente na maioria dos municípios amostrados (30) (Tabelas 1 e 6). Estes resultados corroboram com os dados de vários autores (Penteado-Dias, 1987; Leonel Junior et al., 1996; Souza Filho, 1999; 
Matrangolo et al., 1998; Aguiar-Menezes et al., 2001; Uchôa-Fernandes et al., 2003). Esta espécie é também o parasitóide nativo mais comum das espécies de Anastrepha no Novo Mundo, ocorrendo da Argentina ao Sul do Estados Unidos (Wharton \& Marsh, 1978; Wharton, 1997c).

As espécies Opius bellus e Opius sp. apresentaram as menores percentagens de espécimens coletados, respectivamente $1,5 \%$ e $0,8 \%$, contrário aos resultados obtidos por Canal et al., (1994), em Manaus e Iranduba - AM, onde foi constatado 86,1\% de Opius sp. Guimarães e Silva (2002), em duas localidades no estado do Amazonas, encontrou resultados semelhantes, obtendo-se $77 \%$ de Opius sp. (campus da Universidade do Amazonas - UA) e 67\% de O. bellus (Instituto Nacional de Pesquisas da Amazônia - INPA), em frutos de taperebá.

Para as frutíferas amostradas, foram coletados 42.717 frutos distribuídos em 27 espécies frutíferas e 12 famílias, entre nativas e exóticas (Tabela 5). Não foi possível determinar a que família botânica pertencia guapevinha, pela falta de frutos e flores, pelos quais poderia ser identificado, porém acredita-se que esta fruteira pertença à família Sapotaceae.

Tabela 1. Espécies e número de braconídeos coletados em 33 municípios do Estado de São Paulo (agosto/1997 a fevereiro/2003)

\begin{tabular}{lcc}
\hline \multicolumn{1}{c}{ Espécies } & $\mathrm{n}$ & $(\%)$ \\
\hline Opiinae & & $(96,2 \%)$ \\
01. Doryctobracon areolatus (Szépligeti, 1911) & 2.332 & 77,5 \\
02. Doryctobracon brasiliensis (Szépligeti, 1911) & 230 & 7,6 \\
03. Opius bellus Gahan, 1930 & 45 & 1,5 \\
04. Opius sp. & 23 & 0,8 \\
05. Utetes anastrephae (Viereck, 1913) & 265 & 8,8 \\
Alysiinae & & $(3,8 \%)$ \\
06. Asobara anastrephae (Muesebeck, 1958) & 114 & 3,8 \\
Total & 3.009 & 100,0 \\
\hline
\end{tabular}




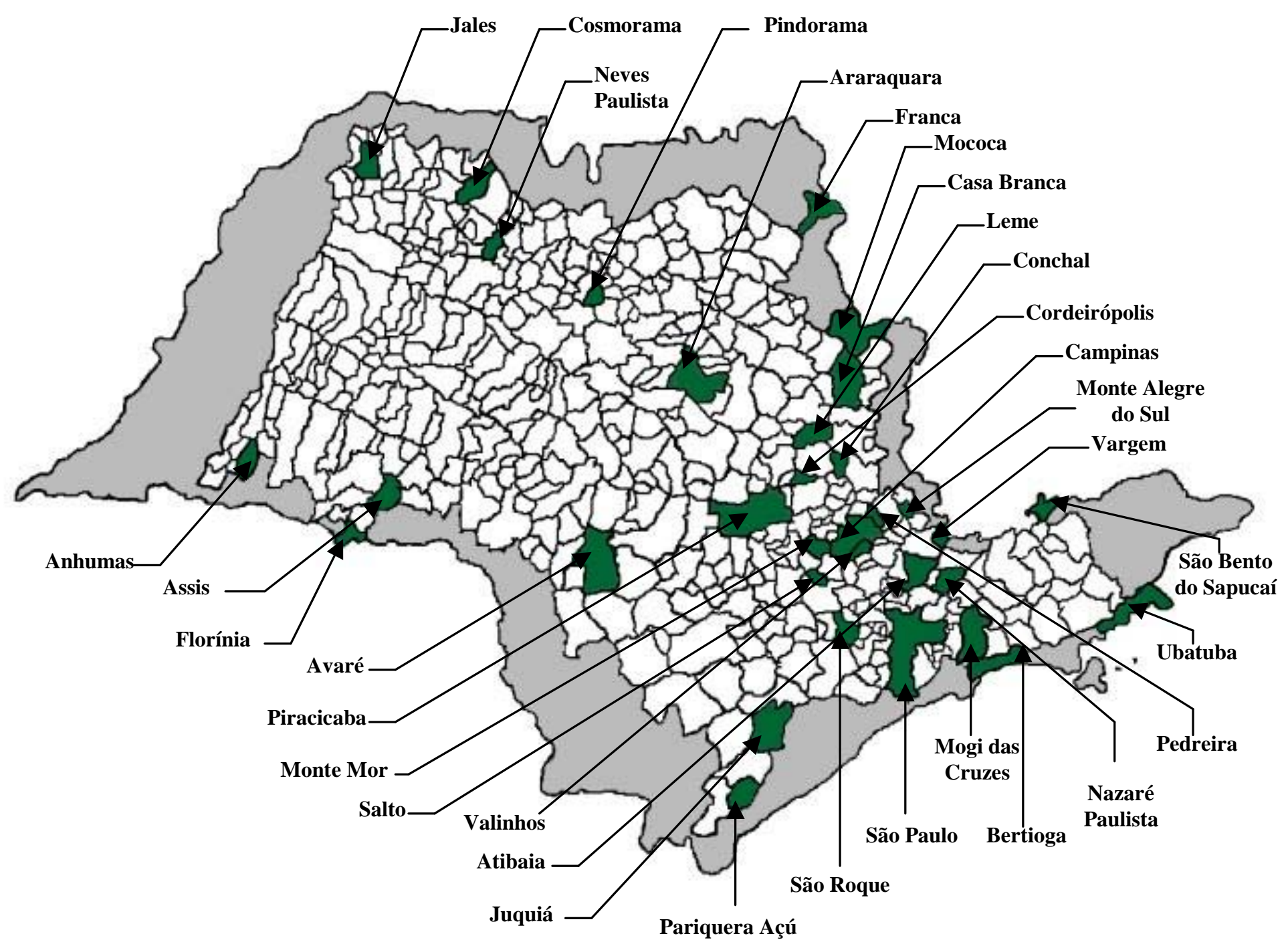

Figura 3 - Municípios do Estado de São Paulo onde foram obtidas amostras com parasitóides de moscas-das-frutas (agosto/1997 a fevereiro/2003) 
Tabela 2. Número de moscas-das-frutas coletados em 33 municípios do Estado de São Paulo (agosto/1997 a fevereiro/2003)

\begin{tabular}{lcccc}
\hline \multicolumn{1}{c}{ Gêneros } & Machos & Fêmeas & Total Geral & Percentagem (\%) \\
\hline Anastrepha & 9.942 & 8.382 & 18.324 & 85,4 \\
Ceratitis & 1.875 & 1.253 & 3.128 & 14,6 \\
\multicolumn{1}{c}{ Total } & 11.817 & 9.635 & 21.452 & 100,0 \\
\hline
\end{tabular}

Tabela 3. Espécies de Anastrepha (fêmeas) e C. capitata (fêmeas) de 33 municípios do Estado de São Paulo (agosto/1997 a fevereiro/2003)

\begin{tabular}{lc}
\hline \multicolumn{1}{c}{ Espécies } & Fêmeas (n) \\
\hline Anastrepha amita Zucchi, 1979 & 604 \\
A. bistrigata Bezzi, 1919 & 9 \\
A. distincta Greene, 1934 & 6.417 \\
A. fraterculus (Wiedemann, 1830) & 37 \\
A. leptozona Hendel, 1914 & 1.090 \\
A. obliqua (Macquart, 1835) & 14 \\
A. sororcula Zucchi, 1979 & 34 \\
A. serpentina (Wiedemann, 1830) & 1 \\
A. turpiniae Stone, 1942 & 1.253 \\
Ceratitis capitata (Wiedemann, 1824) & 9.635 \\
Total & \\
\hline
\end{tabular}


Tabela 4. Distribuição de Braconidae (Opiinae/Alysiinae), parasitóides de moscas-dasfrutas no Estado de São Paulo (agosto/1997 a fevereiro/2003)

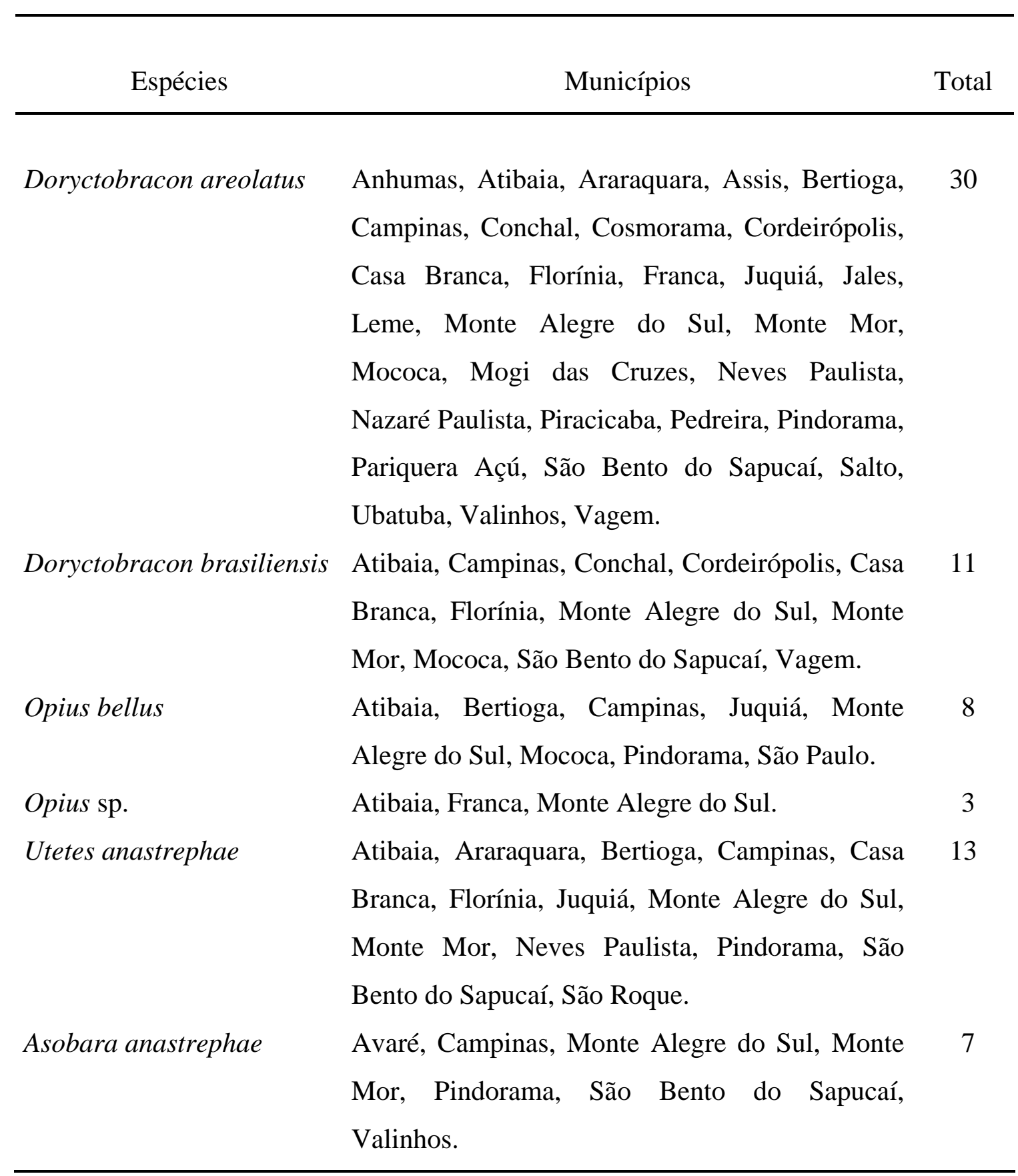


Tabela 5. Espécies de plantas hospedeiras, número de amostras, parasitóides e moscas-das-frutas no Estado de São Paulo (agosto/1997 a fevereiro /2003)

\begin{tabular}{|c|c|c|c|c|c|c|c|c|c|}
\hline \multirow[b]{2}{*}{ Famílias/ espécies } & \multirow[b]{2}{*}{$\begin{array}{l}\text { Nomes } \\
\text { comuns }\end{array}$} & \multirow[b]{2}{*}{ Origens } & \multicolumn{2}{|c|}{ Frutos } & \multirow[b]{2}{*}{$\begin{array}{c}\text { Amostras } \\
\text { (n) }\end{array}$} & \multirow{2}{*}{$\begin{array}{l}\text { Parasitóides } \\
\text { emergidos } \\
\text { (n) }\end{array}$} & \multirow[b]{2}{*}{$\begin{array}{l}\text { Pupários } \\
\text { (n) }\end{array}$} & \multicolumn{2}{|c|}{ Moscas emergidas (n) } \\
\hline & & & $\mathrm{n}$ & $\begin{array}{l}\text { Peso } \\
(\mathrm{kg})\end{array}$ & & & & $\begin{array}{c}\text { C. } \\
\text { capitata }\end{array}$ & $\begin{array}{c}\text { Anastrepha } \\
\text { spp. }\end{array}$ \\
\hline \multicolumn{10}{|l|}{ Anacardiaceae } \\
\hline 1. Mangifera indica L. & Manga & $\mathrm{E}$ & 183 & 23,22 & 7 & 21 & 464 & 0 & 296 \\
\hline 2. Spondias purpúrea L. & Serigüela & $\mathrm{E}$ & 1215 & 7,94 & 5 & 112 & 1084 & 2 & 268 \\
\hline \multicolumn{10}{|l|}{ Clusiaceae } \\
\hline 3. Garcinia brasiliensis & Bacupari & $\mathrm{N}$ & 786 & 6,84 & 4 & 4 & 70 & 48 & 5 \\
\hline \multicolumn{10}{|l|}{ Lauraceae } \\
\hline $\begin{array}{l}\text { 4. Cryptocarya } \\
\text { aschersoniana Mez }\end{array}$ & $\begin{array}{l}\text { Canela- } \\
\text { batalha }\end{array}$ & $\mathrm{N}$ & 275 & 2,20 & 1 & 7 & 52 & 0 & 29 \\
\hline \multicolumn{10}{|l|}{ Malpighiaceae } \\
\hline 5. Malpighia glabra & Acerola & $\mathrm{E}$ & 3390 & 11,20 & 7 & 18 & 669 & 82 & 243 \\
\hline \multicolumn{10}{|l|}{ Mimosaceae } \\
\hline 6. Inga sp. & Ingá & $\mathrm{N}$ & 1448 & 10,50 & 2 & 23 & 677 & 2 & 335 \\
\hline
\end{tabular}


Tabela 5. Espécies de plantas hospedeiras, número de amostras, parasitóides e moscas-das-frutas no Estado de São Paulo (agosto/1997 a fevereiro /2003)

\begin{tabular}{|c|c|c|c|c|c|c|c|c|c|}
\hline \multirow[b]{2}{*}{ Famílias/ espécies } & \multirow[b]{2}{*}{$\begin{array}{l}\text { Nomes } \\
\text { comuns }\end{array}$} & \multirow[b]{2}{*}{ Origens } & \multicolumn{2}{|c|}{ Frutos } & \multirow[b]{2}{*}{$\begin{array}{c}\text { Amostras } \\
\text { (n) }\end{array}$} & \multirow{2}{*}{$\begin{array}{c}\text { Parasitóides } \\
\text { emergidos } \\
\text { (n) }\end{array}$} & \multirow[b]{2}{*}{$\begin{array}{l}\text { Pupários } \\
\text { (n) }\end{array}$} & \multicolumn{2}{|c|}{ Moscas emergidas (n) } \\
\hline & & & $\mathrm{n}$ & $\begin{array}{l}\text { Peso } \\
(\mathrm{kg})\end{array}$ & & & & $\begin{array}{c}\text { C. } \\
\text { capitata }\end{array}$ & $\begin{array}{c}\text { Anastrepha } \\
\text { spp. }\end{array}$ \\
\hline \multicolumn{10}{|l|}{ Myrtaceae } \\
\hline $\begin{array}{l}\text { 7. Campomanesia } \\
\text { guaviroba (DC.) }\end{array}$ & Guabiroba & $\mathrm{N}$ & 793 & 2,98 & 1 & 1 & 37 & 0 & 28 \\
\hline Kiaersk & & & & & & & & & \\
\hline $\begin{array}{l}\text { 8. Eugenia involucrata } \\
\text { DC }\end{array}$ & $\begin{array}{l}\text { Cereja-da- } \\
\text { terra }\end{array}$ & $\mathrm{N}$ & 536 & 1,53 & 2 & 161 & 1696 & 1 & 1033 \\
\hline $\begin{array}{l}\text { 9. Plinia glomerata } \\
\text { (Berg.) Amsh }\end{array}$ & Cabeluda & $\mathrm{N}$ & 865 & 1,89 & 2 & 38 & 448 & 4 & 315 \\
\hline 10. E. brasiliensis La M. & Grumixama & $\mathrm{N}$ & 83 & 0,22 & 1 & 2 & 21 & 1 & 7 \\
\hline 11. E.uniflora L. & Pitanga & $\mathrm{N}$ & 3632 & 6,4 & 15 & 604 & 4082 & 17 & 1979 \\
\hline 12. E. Pyriformis & Uvaia & $\mathrm{N}$ & 1241 & 6,60 & 7 & 59 & 1422 & 0 & 961 \\
\hline 13. Psidium cattleianum & Araçá & $\mathrm{N}$ & 797 & 5,87 & 3 & 156 & 1490 & 0 & 720 \\
\hline Sab. & & & & & & & & & \\
\hline 14. P. guajava L. & Goiaba & $\mathrm{N}$ & 268 & 16,67 & 2 & 17 & 764 & 4 & 176 \\
\hline
\end{tabular}


Tabela 5. Espécies de plantas hospedeiras, número de amostras, parasitóides e moscas-das-frutas no Estado de São Paulo (agosto/1997 a fevereiro /2003)

\begin{tabular}{|c|c|c|c|c|c|c|c|c|c|}
\hline \multirow[b]{2}{*}{ Famílias/ espécies } & \multirow[b]{2}{*}{$\begin{array}{l}\text { Nomes } \\
\text { comuns }\end{array}$} & \multirow[b]{2}{*}{ Origens } & \multicolumn{2}{|c|}{ Frutos } & \multirow[b]{2}{*}{$\begin{array}{l}\text { Amostras } \\
\text { (n) }\end{array}$} & \multirow{2}{*}{$\begin{array}{l}\text { Parasitóides } \\
\text { emergidos } \\
\text { (n) }\end{array}$} & \multirow[b]{2}{*}{$\begin{array}{l}\text { Pupários } \\
\text { (n) }\end{array}$} & \multicolumn{2}{|c|}{ Moscas emergidas (n) } \\
\hline & & & $\mathrm{n}$ & $\begin{array}{l}\text { Peso } \\
(\mathrm{kg})\end{array}$ & & & & $\begin{array}{c}\text { C. } \\
\text { capitata }\end{array}$ & $\begin{array}{l}\text { Anastrepha } \\
\text { spp. }\end{array}$ \\
\hline \multicolumn{10}{|l|}{ Myrtaceae } \\
\hline $\begin{array}{l}\text { 15. Syzygium jambos } \\
\text { (L) Alston }\end{array}$ & Jambo & E & 544 & 10,20 & 7 & 97 & 1759 & 105 & 1009 \\
\hline 16. Plinia edulis & Cambucá & $\mathrm{N}$ & 172 & 1,89 & 1 & 5 & 74 & 0 & 16 \\
\hline $\begin{array}{l}\text { 17. Myrciaria } \\
\text { cauliflora (Mart.) Berg }\end{array}$ & Jabuticaba & $\mathrm{N}$ & 2698 & 21,34 & 7 & 69 & 1004 & 0 & 744 \\
\hline \multicolumn{10}{|l|}{ Oxalidaceae } \\
\hline $\begin{array}{l}\text { 18. Averroa carambola } \\
\text { L. }\end{array}$ & Carambola & E & 1564 & 57,99 & 12 & 339 & 3542 & 3 & 1379 \\
\hline Rosaceae & & & & & & & & & \\
\hline $\begin{array}{l}\text { 19. Eriobotrya japonica } \\
\text { (Thunb) Lindl. }\end{array}$ & Nêspera & $\mathrm{E}$ & 7075 & 84,68 & 23 & 323 & 9898 & 847 & 5739 \\
\hline $\begin{array}{l}\text { 20. Prunus salicina } \\
\text { Lindl. }\end{array}$ & $\begin{array}{l}\text { Ameixa } \\
\text { japonesa }\end{array}$ & E & 19 & 0,49 & 1 & 3 & 40 & 0 & 34 \\
\hline
\end{tabular}


Tabela 5. Espécies de plantas hospedeiras, número de amostras, parasitóides e moscas-das-frutas no Estado de São Paulo (agosto/1997 a fevereiro /2003)

\begin{tabular}{|c|c|c|c|c|c|c|c|c|c|}
\hline \multirow[b]{2}{*}{ Famílias/ espécies } & \multirow[b]{2}{*}{$\begin{array}{l}\text { Nomes } \\
\text { comuns }\end{array}$} & \multirow[b]{2}{*}{ Origens } & \multicolumn{2}{|c|}{ Frutos } & \multirow[b]{2}{*}{$\begin{array}{l}\text { Amostras } \\
\text { (n) }\end{array}$} & \multirow{2}{*}{$\begin{array}{l}\text { Parasitóides } \\
\text { emergidos } \\
\text { (n) }\end{array}$} & \multirow[b]{2}{*}{$\begin{array}{l}\text { Pupários } \\
\text { (n) }\end{array}$} & \multicolumn{2}{|c|}{ Moscas emergidas (n) } \\
\hline & & & $\mathrm{n}$ & $\begin{array}{l}\text { Peso } \\
(\mathrm{kg})\end{array}$ & & & & $\begin{array}{c}C . \\
\text { capitata }\end{array}$ & $\begin{array}{l}\text { Anastrepha } \\
\text { spp. }\end{array}$ \\
\hline \multicolumn{10}{|l|}{ Rosaceae } \\
\hline 21. P. persica (L.) Batsch & Pêssego & $\mathrm{E}$ & 1099 & 34,88 & 13 & 141 & 4222 & 1807 & 712 \\
\hline $\begin{array}{l}\text { 22. Prunus x Mume Sieb } \\
\text { e Zucc }\end{array}$ & Umê & $\mathrm{E}$ & 397 & 3,76 & 1 & 6 & 995 & 202 & 361 \\
\hline \multicolumn{10}{|l|}{ Rutaceae } \\
\hline $\begin{array}{l}\text { 23. Clausena lansium } \\
\text { (Lour) Skeels }\end{array}$ & Wampi & $\mathrm{E}$ & 244 & 0,87 & 1 & 2 & 5 & 0 & 0 \\
\hline Solanaceae & & & & & & & & & \\
\hline $\begin{array}{l}\text { 24. Solanum americanum } \\
\text { Mill. }\end{array}$ & $\begin{array}{l}\text { Maria } \\
\text { preta }\end{array}$ & $\mathrm{N}$ & 983 & 4,31 & 4 & 147 & 832 & 2 & 430 \\
\hline
\end{tabular}


Tabela 5. Espécies de plantas hospedeiras, número de amostras, parasitóides e moscas-das-frutas no Estado de São Paulo (agosto/1997 a fevereiro /2003)

\begin{tabular}{|c|c|c|c|c|c|c|c|c|c|}
\hline \multirow[b]{2}{*}{ Famílias/ espécies } & \multirow[b]{2}{*}{$\begin{array}{l}\text { Nomes } \\
\text { comuns }\end{array}$} & \multirow[b]{2}{*}{ Origens } & \multicolumn{2}{|c|}{ Frutos } & \multirow[b]{2}{*}{$\begin{array}{l}\text { Amostras } \\
\text { (n) }\end{array}$} & \multirow{2}{*}{$\begin{array}{l}\text { Parasitóides } \\
\text { emergidos } \\
\text { (n) }\end{array}$} & \multirow[b]{2}{*}{$\begin{array}{l}\text { Pupários } \\
\text { (n) }\end{array}$} & \multicolumn{2}{|c|}{ Moscas emergidas (n) } \\
\hline & & & $\mathrm{n}$ & $\begin{array}{l}\text { Peso } \\
(\mathrm{kg})\end{array}$ & & & & $\begin{array}{c}\text { C. } \\
\text { capitata }\end{array}$ & $\begin{array}{c}\text { Anastrepha } \\
\text { spp. }\end{array}$ \\
\hline \multicolumn{10}{|l|}{ Sapotaceae } \\
\hline $\begin{array}{l}\text { 25. Pouteria caimito } \\
\text { (Ruiz e Pav.) }\end{array}$ & Abiu & $\mathrm{N}$ & 471 & 12,10 & 4 & 103 & 439 & 1 & 208 \\
\hline \multicolumn{10}{|l|}{ Radlk } \\
\hline 26. ? Sapotaceae & Guapevinha & $?$ & 583 & 1,19 & 1 & 1 & 35 & 0 & 0 \\
\hline \multicolumn{10}{|l|}{ Verbenaceae } \\
\hline $\begin{array}{l}\text { 27. Citharexylum } \\
\text { myrianthum }\end{array}$ & Pombeiro & $\mathrm{N}$ & 11356 & 8,06 & 14 & 550 & 2964 & 0 & 1297 \\
\hline
\end{tabular}




\subsection{Chave para as espécies de parasitóides (Braconidae: Hymenoptera) de larvas frugívoras (Diptera: Tephritidae) coletadas}

1. Mandíbulas amplamente separadas (exodontes), ápices não se tocam quando fechadas; clípeo pequeno (Alysiinae) (Fig. 12B e 12C); nervelo (n) e pós-nervelo (Pn) ausentes (Fig. 14E)......................................................Asobara anastrephae (Muesebeck)

1'. Mandíbulas normais (endodontes), ápices se tocam quando fechadas; clípeo desenvolvido (Fig. 4B e 4C); carena prepectal ausente; presença de três células cubitais (Fig. 2B) (Opiinae) 2

2. Asa anterior com $2^{\underline{0}}$ segmento da nervura radial $\left(\mathrm{r}_{2}\right)$ igual ou menor que a $1^{\underline{a}}$ intercubital ( $\mathrm{i}_{1}$ ); nervura recurrente (rec) intersticial (Fig. 14A); asa posterior com pósnervelo (Pn) presente (Fig.14A).

2'. Asa anterior com $2^{\underline{0}}$ segmento da nervura radial $\left(\mathrm{r}_{2}\right)$ maior que a $1^{\underline{a}}$ intercubital $\left(\mathrm{i}_{1}\right)$ (Fig. 14D); asa posterior com pós-nervelo (Pn) ausente (Fig. 14D)

3. Coloração geral vermelho-amarelada (Fig. 15A); propódeo areolado (Fig. 5D); asas hialinas com nervuras e estigma escurecidos (Fig. 14A).

Doryctobracon areolatus (Szépligeti)

3’. Coloração geral escura (Fig. 15B); propódeo apresentando uma carena longitudinal mediana anteriormente (Fig. 7D); asas esfumaçadas com nervuras escurecidas e estigma amarelo (Fig. 14B). Doryctobracon brasiliensis (Szépligeti)

4. Asa anterior com nervura recurrente (rec) alcançando a $2^{2}$ célula cubital (Fig 14D); propódeo irregularmente reticulado (Fig. 11D); margem clipeal truncada ou côncava, formando uma distinta abertura entre o clípeo e a mandíbula fechada (Fig. 10C) Utetes anastrephae (Viereck) 
4'. Asa anterior com nervura recurrente (rec) alcançando a $1^{\underline{a}}$ célula cubital $\left(\mathrm{Cu}_{1}\right)$ (Fig. 14C); propódeo com carena médio-longitudinal bem desenvolvida (Fig. 9D); sem abertura entre as mandíbulas fechadas e clípeo (Fig. 8C)............................................5

5. Tíbias posteriores negras na base e no ápice (Fig. 15E).................. Opius bellus Gahan 5’. Tíbias posteriores vermelho-amareladas (Fig. 15F)..................................... Opius sp. 


\subsection{Caracterização das espécies de parasitóides (Hymenoptera: Braconidae) de larvas frugívoras (Diptera: Tephritidae)}

\subsubsection{Braconidae, Opiinae}

\section{Doryctobracon areolatus (Szépligeti, 1911)}

Biosteres areolatus Szépligeti, 1911

Opius cereus Gahan, 1919

Opius saopaulinensis Fisher, 1961

Doryctobracon areolatus (Szépligeti) (Wharton \& Marsh, 1978).

Cabeça. Mais larga $(1,05-1,44 \mathrm{~mm})$ que alta $(0,75-0,98 \mathrm{~mm})$; face brilhante apresentando largo sulco mediano inferiormente, carena occipital ausente; clípeo com a margem apical ligeiramente sinuosa (Figura 4C) com espaço entre o clípeo e as mandíbulas quando fechadas (Figura 4C).

Mesossoma. Mais alto $(1,11-1,60 \mathrm{~mm})$ que largo $(0,83-1,21 \mathrm{~mm})$; comprimento $(1,45-$ 1,98mm); mesonoto brilhante com notáulices completas e não crenulado (Figura 5B); sulco pré-escutelar com uma carena mediana transversal (Figura 5B); mesopleura lisa (Figuras 4A e 5C); esternelo não crenulado (Figura 5C); propódeo coberto por pêlos amarelos, com distinta e curta carena médio-anterior e areolado posteriormente (Figura 5D).

Asa anterior. Comprimento 3,62 a 5,32mm; célula radial larga, com a extremidade terminando antes do ápice da asa; segundo segmento da nervura radial (0,22 a 0,44mm), igual ou menor que a primeira nervura intercubital $(0,35-0,54 \mathrm{~mm})$; presença da nervura recurrente intersticial (Figura 14A).

Asa posterior. Pós-nervelo presente (Figura 14A).

Comprimento do ovipositor. Comprimento $3,15 \mathrm{~mm}$ a 4,59mm.

Comprimento do corpo. Macho: 3,51 a 4,84mm; fêmea: 3,69 a 5,46mm. 
Coloração. Coloração geral vermelho-amarelada. Antenas, ápice das mandíbulas, olhos, triângulo ocelar, tégula, metade distal da tíbia posterior, tarsos, bainha do ovipositor e dorso do ápice do abdome pretos ou enegrecidos; fêmures, tíbias anteriores e medianas amareladas; asas hialinas com nervuras e estigma escurecidos (Figura 15A).

Discussão. $D$. areolatus parasitou o maior número de espécies de moscas-das-frutas na maioria das espécies frutíferas, concordando com os dados de Canal Daza, 1993. Neste estudo, foi encontrada parasitando A. fraterculus, A. obliqua, e A. amita, e obtida pela primeira vez de larvas nas fruteiras wampi (Clausena lansium) e canela-batalha (Cryptocarya aschersoniana). Como observado por Leonel Júnior (1991), houve variação no tamanho do corpo do parasitóide emergido de diferentes fruteiras e variações na coloração entre alguns espécimens (de vermelho amarelado a marrom). Observou-se ainda uma pequena variação na asa anterior de um único exemplar (ausência da nervura 2r-m). Estas modificações observadas podem estar relacionadas com o inseto hospedeiro. Como são parasitóides obrigatórios, estão sujeitos às alterações fisiológicas do hospedeiro e, assim, pode ocorrer mudanças morfológicas (Lawrence, et al., 1976). Hospedeiros muito pequenos podem afetar a morfologia dos parasitóides, podendo emergir indivíduos pequenos ou adultos com apêndices desproporcionais (Salt, 1941, citado por Lawrence et al., 1976). O regime alimentar da fase larval é determinante para o tamanho de parasitóides adultos (Clausen et al., 1965).

Material examinado. BRASIL. SÃO PAULO: Atibaia, 30.IX.1999, 2 machos e 2 fêmeas (M. F. Souza Filho col.); Campinas, 30.VIII.1998, 1 macho e 1 fêmea (José Paduanelo col.); 15.XII.1999, 1 macho e 1 fêmea (Aline Cristina Previdel col.); 02.III.2000, 1 macho e 1 fêmea (Gabriel B. da Silva col.); 04.X.2000, 1 macho e 1 fêmea (Gabriel B. da Silva col.); 12.I.2001, 1 macho e 1 fêmea (Gabriel B. da Silva col.); Cordeirópolis, 27.XII.1999, 1 macho e 1 fêmea (Adalton Raga col.); Juquiá, 14.I.2000, 1 macho e 1 fêmea (M. F. Souza Filho col.); Monte Mor, 16.XI.1999, 1 fêmea (Adalton Raga col.); Nazaré Paulista, 22.VII.1999, 1 macho e 1 fêmea (M. F. Souza Filho col.); Pariquera Açú, 13.V.2002, 1 macho e 1 fêmea (Antonio A. Costa); Piracicaba, 02.II.2003, 2 machos e 2 fêmeas (Cláudia F. Marinho col.); Pindorama, 
11.I.2001, 1 macho e 1 fêmea (M. F. Souza Filho col.); Ubatuba, 02.II.2000, 1 fêmea (Adalton Raga col.).

Distribuição geográfica. Argentina, Costa Rica, México, Panamá, Trinidad, Venezuela in Leonel Júnior, 1991; Brasil (AM, BA, DF, ES, GO, MA, MS, MG, PA, PR, PI, RN, RS, RJ, SC, SP) in Leonel Júnior, 1991; in Canal \& Zucchi, 2000; Colômbia, El Salvador, USA (Flórida), Guatemala in Ovruski et al., 2000. No Havaí, Porto Rico e Austrália, foi introduzida e estabelecida in Wharton \& Gilstrap, 1983.

Hospedeiros. Anastrepha bistrigata Bezzi, 1919; A. bejamini Lima, 1938; A. consobrina (Loew, 1873); A. fraterculus (Wied., 1830); A. obliqua (Macquart, 1835); A. pseudoparallela (Loew, 1873); A. pickeli Lima, 1934; A. serpentina (Wied., 1830); A. sororcula Zucchi, 1979; A. suspensa (Loew, 1862); A. montei Lima, 1934 in Leonel Júnior, 1991; A. amita Zucchi, 1979; A. distincta Greene, 1934; A. striata Schiner, 1868 in Zucchi, 2000; A. alveata Stone, 1942; A. bahiensis Lima, 1937 in López et al., 1999; A. leptozona Hendel, 1914 in Aguiar-Menezes \& Menezes, 2001; A. ludens (Loew, 1873) in Canal Daza, 1993; A. zenildae Zucchi, 1979 in Araújo, 2002; A. crebra Stone 1942 in Hernández-Ortiz et al., 1994; Ceratitis capitata (Wied., 1824) in Souza Filho, 1999; Rhagoletotrypeta pastranai Aczél, 1954 in Leonel Júnior, 1991. 

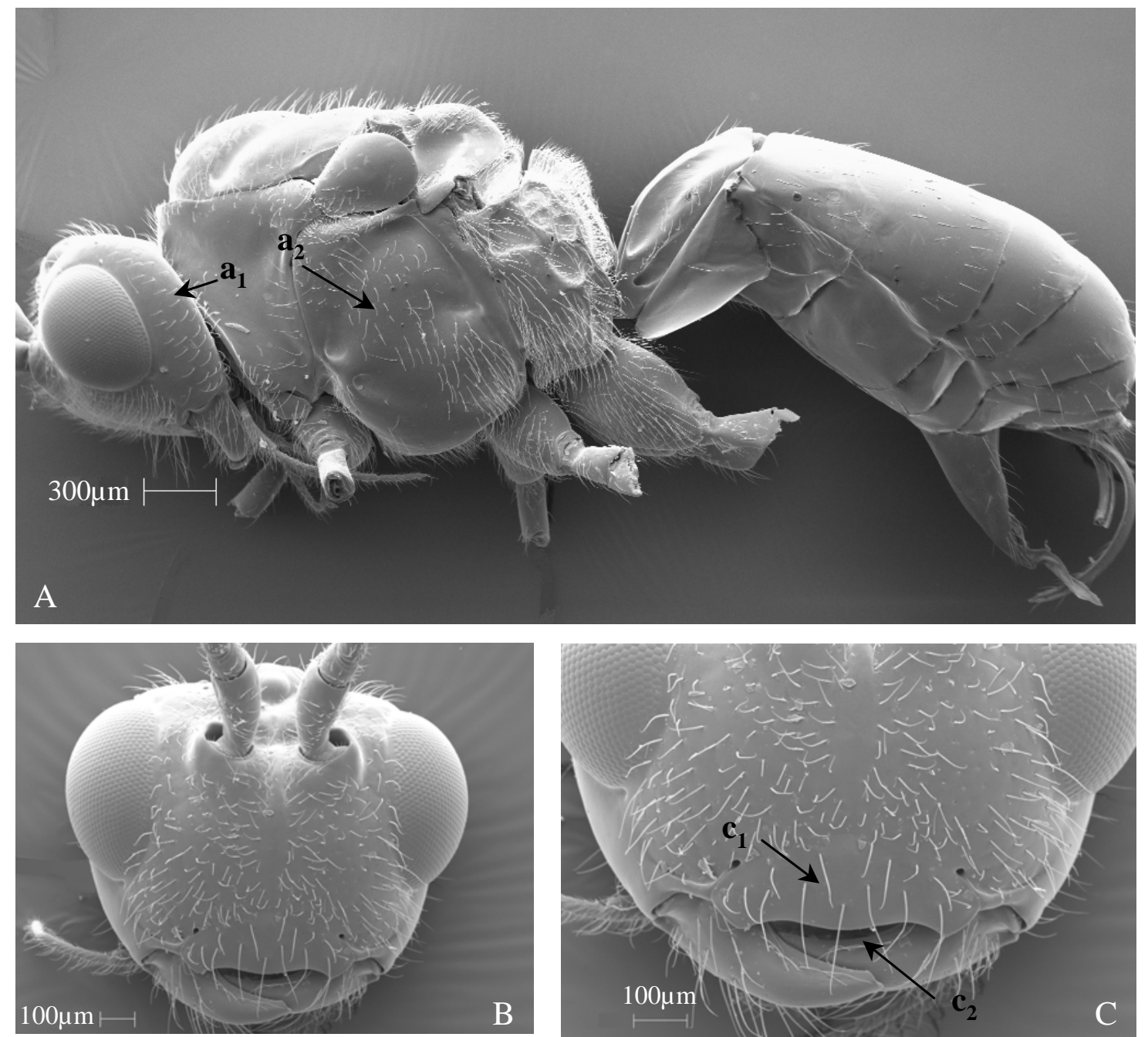

Figura 4 - Doryctobracon areolatus. A. Cabeça, mesossoma e metassoma, vista lateral (a $a_{1}$ têmpora; $a_{2}$. mesopleura lisa) (68x); B. Cabeça, vista frontal (170x); C. Cabeça, vista parcial ( $c_{1}$. Clípeo; c2. espaço entre o clípeo e mandíbulas) (272x) 

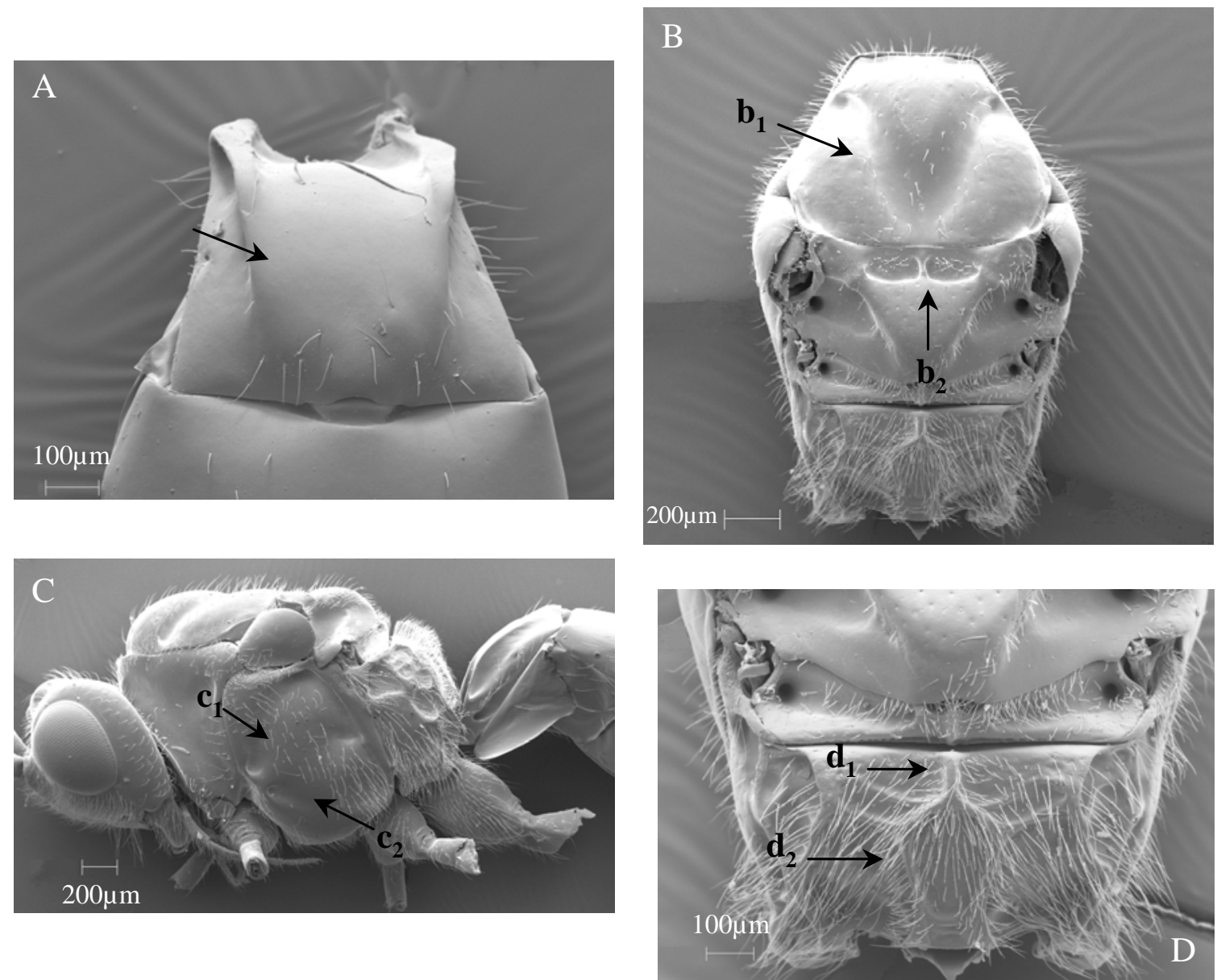

Figura 5 - Doryctobracon areolatus. A. Base do gáster (seta), vista dorsal (263x); B. Mesossoma, vista dorsal ( $b_{1}$. notáulices completas e não crenulada; $\mathrm{b}_{2}$. sulco pré-escutelar com uma carena mediana transversal) (105x); C. Cabeça e mesossoma, vista lateral ( $c_{1}$. mesopleura lisa; $c_{2}$. esternelo não crenulado) (87x); D. Propódeo ( $\mathrm{d}_{1}$. carena médio-anterior curta; $\mathrm{d}_{2}$. aréola) (263x) 


\section{Doryctobracon brasiliensis (Szépligeti, 1911)}

Biosteres brasiliensis Szépligeti, 1911

Coeloides anastrephae Brèthes, 1924

Opius (Diachasma) brasilianus Fischer, 1963

Parachasma brasilianus (Szépligeti) Fisher, 1967

Doryctobracon brasiliensis (Szépligeti) Fischer, 1977

Cabeça. Mais larga $(0,93-1,29 \mathrm{~mm})$ que alta $(0,64-0,98 \mathrm{~mm})$; face brilhante, com grande quantidade de pêlos amarelos, com uma carena mediana da metade superior até a base das antenas (Figura 6C); clípeo com a margem anterior ligeiramente sinuosa, com espaço entre o clípeo e as mandíbulas quando fechadas (Figura 6C).

Mesossoma. Mais alto $(0,86-1,45 \mathrm{~mm})$ que largo $(0,67-1,11 \mathrm{~mm})$; comprimento $(1,30$ 1,92mm); mesoescuto brilhoso, com notáulises incompletas (Figura 7B); sulco préescutelar com uma carena mediana transversal (Figura 7B); mesopleura lisa (Figuras 6A e 7C). Propódeo com distinta e curta carena médio-anterior (Figura 7D).

Asa anterior. Comprimento 3,65 a 5,62mm; asas esfumaçadas com nervuras pretas e estigma amarelo; segundo segmento da nervura radial $(0,21-0,41 \mathrm{~mm})$ menor ou igual à primeira nervura intercubital $(0,32-0,57 \mathrm{~mm})$; nervura recurrente intersticial ou iniciando-se na primeira célula cubital $\left(\mathrm{Cu}_{1}\right)$ (Figura 14B).

Asa posterior. Pós-nervelo presente (Figura 14B).

Comprimento do ovipositor. Comprimento 4,07mm a 6,04mm.

Comprimento do corpo. Macho: 3,51 a 4,90mm; fêmea: 4,10 a 5,55mm.

Coloração. Coloração geral vermelho-amarelada. Olhos, ocelos e estigma amarelos; antenas marrons; cabeça, antenômeros basais, tarsômeros apicais e pernas posteriores de coloração preta; asas esfumaçadas com nervuras enegrecidas (Figura 15B).

Discussão. Esta espécie foi obtida de larvas de $A$. fraterculus em ameixa japonesa (Prunus salicina Lindl.) (primeira referência de planta associada). Apresentou o comprimento do ovipositor relativamente maior comparado às outras espécies, não 
foram observadas alterações de cor entre os espécimens, fato também comentado por Leonel Júnior (1991). A maioria das fêmeas era relativamente maior que os machos.

Material examinado. SÃO PAULO: Atibaia, 12.XI.1999, 4 machos e 3 fêmeas; 30.IX.1999, 1 macho e 1 fêmea (M. F. Souza Filho col.); Campinas, 23.IX.1997, 1 macho e 1 fêmea (José Paduanelo col.); 24.XI.1997, 1 fêmea (Luis Otávio Siqueira col.); 04.X.2000, 1 macho e 1 fêmea; 18.I.2000, 1 macho; 09.III.2000, 1 fêmea; Cordeirópolis, 27.XII.1999, 1 fêmea (Gabriel B. da Silva col.); 12.III.2001, 1 macho (Adalton Raga col.); Monte Mor, 16.XI.1999, 1 macho e 1 fêmea (Adalton Raga col.); $\underline{\text { Monte Alegre do }}$ Sul, 16.VI.2000, 3 machos e 1 fêmea (M. F. Souza Filho col.); 26.III.2001, 1 macho (Joaquim A. de Azevedo Filho); São Bento do Sapucaí, 14.IV.1998, 1 macho e 1 fêmea (Adalton Raga); 03.II.2000, 1 fêmea (M. F. Souza Filho col.); Vargem, 02.III.2000, 2 fêmeas (Adalton Raga).

Distribuição geográfica. Argentina in Leonel Júnior, 1991; in Ovruski et al., 2000; e Brasil (PR, RS, RJ, SC, SP) in Canal \& Zucchi, 2000.

Hospedeiros. Anastrepha amita Zucchi, 1979 in Zucchi, 2000; A. fraterculus (Wied, 1830); A. serpentina (Wied, 1830); A. sororcula (Zucchi, 1979) in Leonel Júnior et al., 1995; Ceratitis capitata (Wied., 1824); Rhagoletotrypeta pastranai, Aczél 1954 in Leonel Júnior, 1991. 

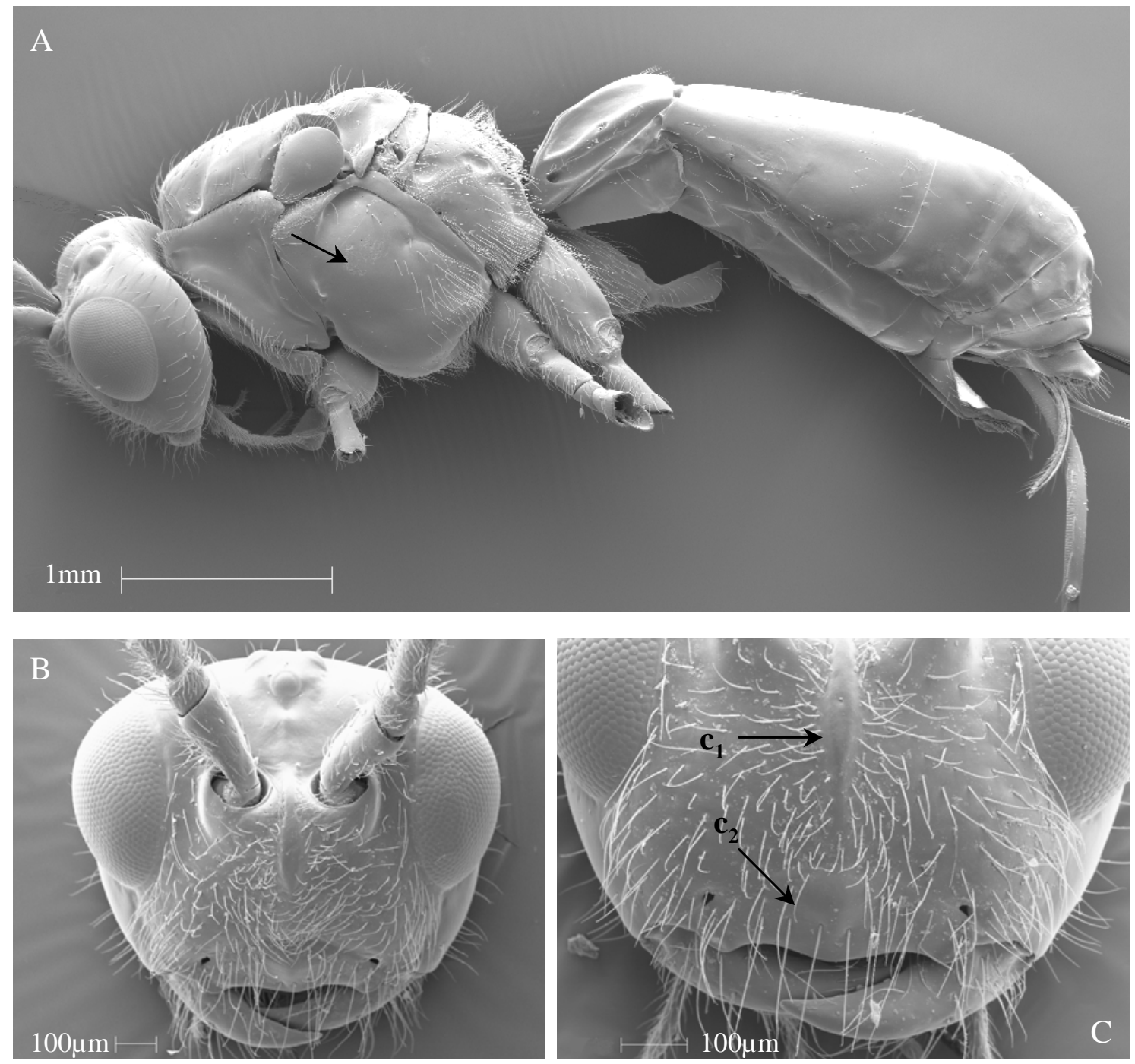

Figura 6 - Doryctobracon brasiliensis. A. Cabeça, mesossoma e metassoma, vista lateral (seta indica mesopleura lisa) (60x); B. Cabeça, vista frontal (187x); C. Cabeça, vista parcial (c1. carena mediana; c2. clípeo) (338x) 

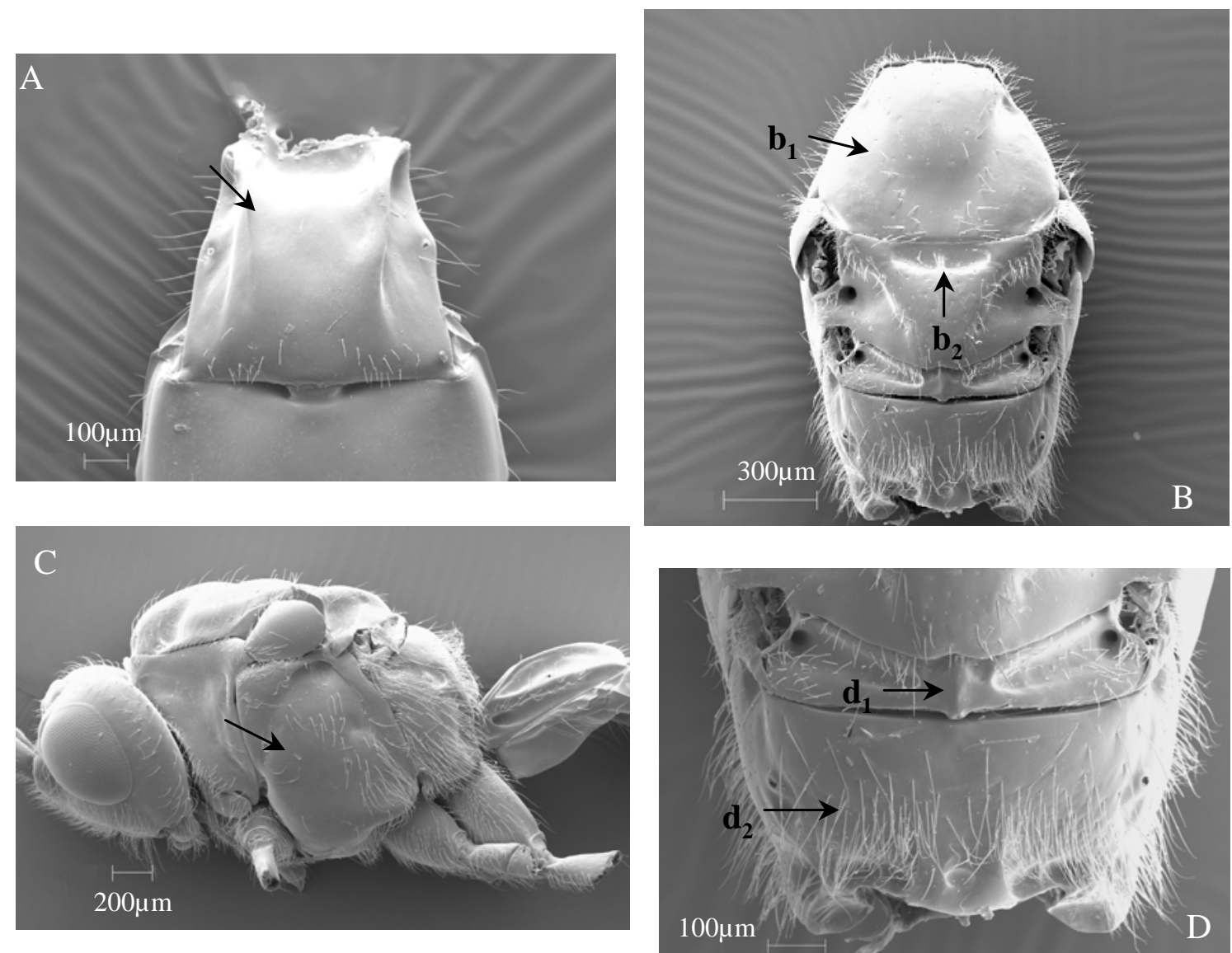

Figura 7 - Doryctobracon brasiliensis. A. Base do gáster (seta), vista dorsal (212x); B. Mesossoma, vista dorsal $\left(b_{1}\right.$. notáulices incompletas; $b_{2}$. sulco préescutelar com uma carena mediana) (124x); C. Cabeça e mesossoma, vista lateral (seta indica mesopleura lisa) (95x); D. Mesossoma, vista parcial (dorsal) ( $\mathrm{d}_{1}$. carena mediana anterior; $\mathrm{d}_{2}$. propódeo) (316x) 


\section{Opius bellus Gahan, 1930}

Opius gomesi Lima, 1938

Opius turicai Blanchard, 1966

Cabeça. Mais larga $(0,92-1,28 \mathrm{~mm})$ que alta $(0,69-0,89 \mathrm{~mm})$; face brilhante densamente pilosa (Figura 8B) com uma protuberância mediana acima do clípeo terminando na base das antenas (Figura 8C); margem anterior do clípeo sinuosa (Figura 8C), sem espaço entre o clípeo e as mandíbulas quando fechadas (Figura 8C).

Mesossoma. Mais alto (0,88-1,36mm) que largo (0,70-1,11mm), comprimento (1,171,86mm); mesoescuto brilhante sem notáulices (Figura 9B); sulco pré-escutelar profundo, com três carenas transversais (Figura 9B). Mesopleura lisa, sem impressão crenulada (Figuras 8A e 9C). Propódeo com pêlos densos, com uma carena médiolongitudinal desenvolvida, que se bifurca posteriormente, cada ramificação unindo-se a uma carena latero-longitudinal (Figura 9D).

Asa anterior. Comprimento 3,09 a 4,59mm; segundo segmento da nervura radial $(0,42-$ $0,63 \mathrm{~mm})$, maior que a primeira nervura intercubital $(0,32-0,44 \mathrm{~mm})$; nervura recurrente iniciando na primeira célula cubital $\left(\mathrm{Cu}_{1}\right)$ (Figura 14C).

Asa posterior. Pós-nervelo ausente (Figura 14C).

Comprimento do ovipositor. Comprimento $0,93 \mathrm{~mm}$ a $1,66 \mathrm{~mm}$.

Comprimento do corpo. Macho: 2,76 a 3,97mm; fêmea 2,87 a 4,07mm.

Coloração. Coloração vermelho-amarelada. Antenas, olhos, triângulo ocelar, extremidade das mandíbulas, metade posterior da tégula e bainha do ovipositor pretas; tíbias posteriores enegrecidas na base e no ápice; tarsômeros apicais pretos. Mesoescuto freqüentemente com uma mancha anterior e outra lateral no ângulo posterior preta ou enegrecida; asas esfumaçadas com nervuras escurecidas (Figura 15E).

Discussão. Não foi possível associar O. bellus com nenhum hospedeiro. Entretanto, parasita larva de quatro espécies de moscas-das-frutas em cinco famílias de plantas hospedeiras (Ovruski, et al., 2000). Na região Norte (Amazonas), O. bellus ataca principalmente espécies de Anastrepha em Spondias mombim (Anacardiaceae). Na 
região central do Brasil, parasita A. fraterculus em Mirtáceas e Anastrepha spp. em Prunus persicae (Rosaceae) (Canal et al., 1994, 1995; Leonel et al., 1995, 1996; Kovaleski, 1997).

Material examinado. SÃO PAULO: Atibaia, 06.X.1999, 4 machos e 3 fêmeas; 30.IX.1999, 3 machos e 3 fêmeas (M. F. Souza Filho col.); Bertioga, 18.I.2001, 2 machos (Adalton Raga. col.); Campinas, 08.X.1998, 2 fêmeas (Luiz Otávio Siqueira col.); 15.XII.1999, 1 fêmea (Aline Cristina Previdel col.); Juquiá, 14.I.2000, 1 fêmea (M. F. Souza Filho col.); Monte Alegre do Sul, 06.X.1999, 1 macho e 1 fêmea (Adalton Raga col.); 16.VI.2000, 1 macho; 24.III.2000, 2 fêmeas (M. F. Souza Filho col.); 26.IV.2001, 1 macho e 1 fêmea (Joaquim A. de Azevedo Filho col.); São Paulo, 05.11.1998, 1 fêmea (Adalton Raga col.).

Distribuição geográfica. Argentina, Belize, Costa Rica, Panamá, Trinidad, Venezuela (Wharton \& Marsh, 1978); Brasil (AM, DF, GO, MS, PA, RS, RJ, SC, SP) in Canal \& Zucchi, 2000. Foi introduzida no Havaí, Porto Rico e Austrália, mas não se estabeleceu in Wharton \& Gilstrap, 1983.

Hospedeiros. Anastrepha fraterculus (Wied., 1830); A. montei Lima, 1934; A. obliqua (Macquart, 1835); A. serpentina (Wied, 1830) in Leonel Júnior, 1991; A. distincta Greene, 1934; A. manihoti Lima, 1934 in Zucchi, 2000; A. sororcula Zucchi, 1979 in Aguiar-Menezes \& Menezes, 2001; Ceratitis capitata (Wied, 1824) in Leonel Júnior, 1991; Rhagholetis ferruginea Hendel, 1927; Rhagoletotrypeta pastranai Aczél, 1954 in Leonel Júnior, 1991. 

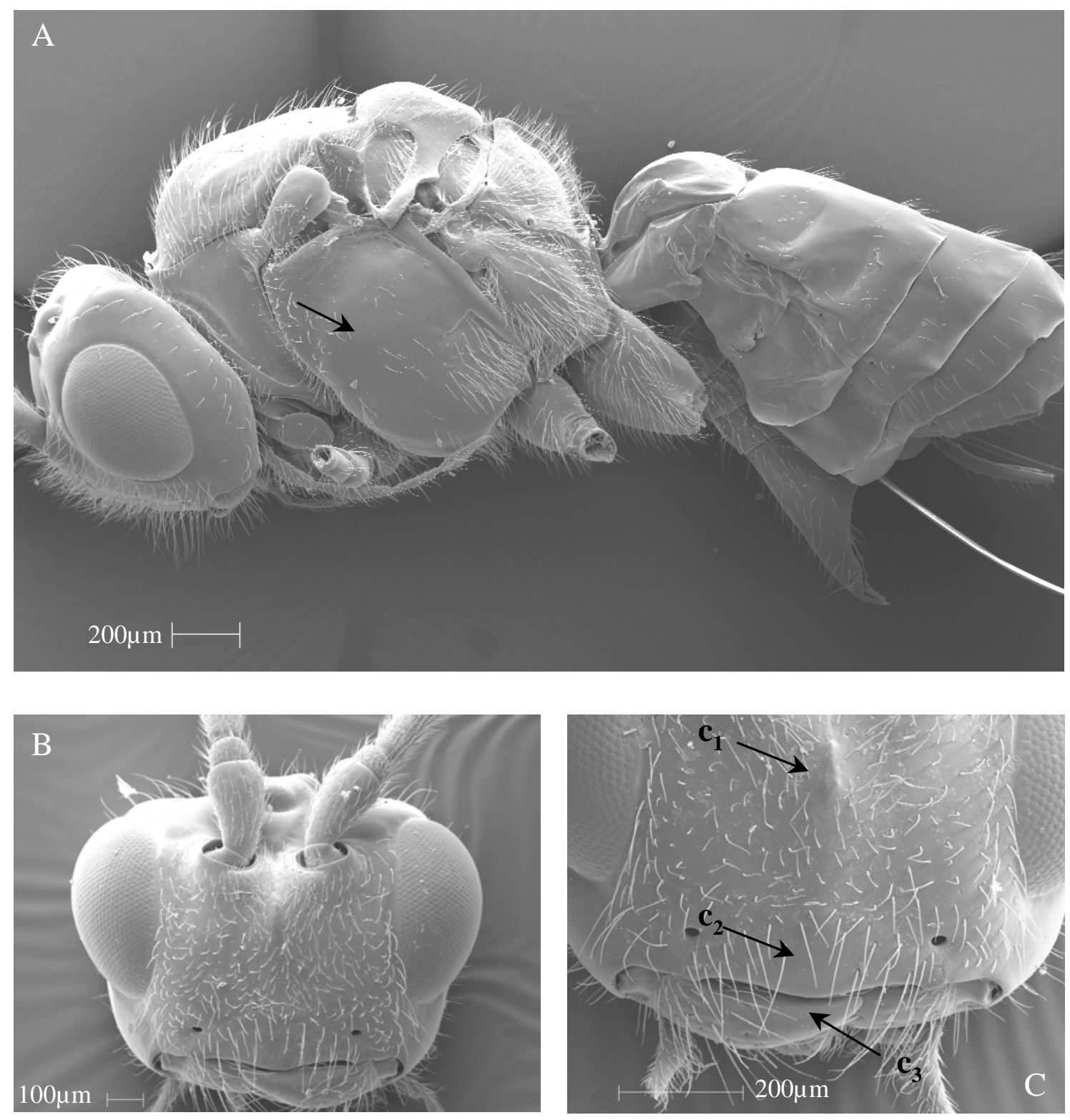

Figura 8 - Opius bellus. A. Cabeça, mesossoma e metassoma, vista lateral (seta indica mesopleura lisa) (101x); B. Cabeça, vista frontal (192x); C. Cabeça, vista parcial ( $c_{1}$. protuberância mediana; $c_{2}$. clípeo; $c_{3}$. abertura entre clípeo e mandíbulas ausente) (304x) 

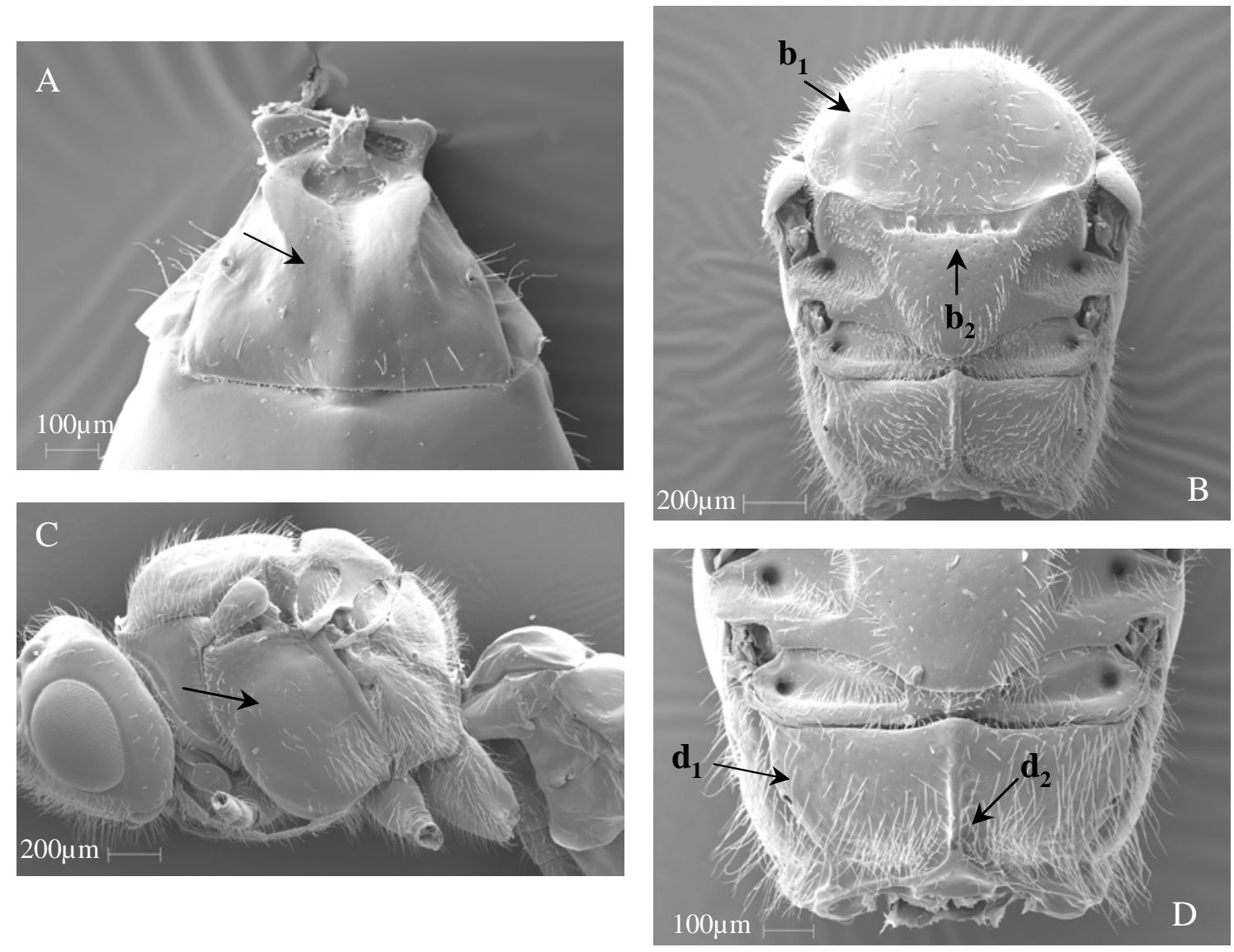

Figura 9 - Opius bellus. A. Base do gáster (seta), vista dorsal (252x); B. Mesossoma, vista dorsal $\left(b_{1}\right.$. notáulices ausentes; $b_{2}$. sulco pré-escutelar com três carenas transversais) (123x); C. Cabeça e mesossoma, vista lateral (seta indica mesopleura lisa) (135x); D. Mesossoma, vista parcial (dorsal) ( $\mathrm{d}_{1}$. propódeo; $\mathrm{d}_{2}$. carena médio-longitudinal) (275x) 


\section{Opius sp.}

Discussão. Opius sp. foi referida pela primeira vez por Leonel Júnior (1991), que atendeu à recomendação de Wharton (comunicação pessoal), definindo-a como espécie próxima a $O$. bellus pela semelhança na morfologia externa (diferenciação apenas na coloração das tíbias posteriores) (Figuras 15E e 15F). Não está ainda esclarecido se Opius sp. corresponde realmente à uma espécie ou se é apenas variação intra-específica de Opius bellus. Há necessidade de estudos biológicos e moleculares para o esclarecimento da identidade dessa espécie (Ovruski et al., 2000). Opius sp. foi a espécie menos freqüente. Entretanto, em Manaus (área urbana) - AM, é a espécie mais comum (Canal Daza, 1993). Não foi possível associar esta espécie com nenhum hospedeiro. Foi obtida em canela-batalha (Cryptocarya aschersoniana Mez) (primeira referência de planta associada).

Material examinado. SÃO PAULO: Atibaia, 30.III.1999, 7 machos e 9 fêmeas; 12.XI.1999, 1 macho (M. F. Souza Filho col.); Monte Alegre do Sul, 26.IV.2001, 1 macho e 1 fêmea (Joaquim A. de Azevedo Filho col.).

Distribuição geográfica. Brasil (AM, BA, GO, MS, PA, PI, RJ, SC, SP) in Leonel Júnior, 1991; in Canal \& Zucchi, 2000, Venezuela e México in Ovruski et al. 2000.

Hospedeiros. Anastrepha distincta Greene, 1934; A. leptozona Hendel, 1914; A. obliqua (Macquart, 1835) in Canal Daza, 1993.

WHARTON, R. A. (Texas A \& M University. College Station, Department of Entomology, Texas) Comunicação pessoal, 1993. 


\section{Utetes anastrephae (Viereck, 1913)}

Opius (Utetes) anastrephae Viereck, 1913

Opius anastrephae (Viereck) Gahan, 1915

Bracanastrepha argentina Brèthes, 1924

Opius mombinpraeoptans Fisher, 1966

Bracanastrepha anastrephae (Viereck) Fisher, 1977

Utetes (Bracanastrepha) anastrephae (Viereck) Wharton, 1988

Cabeça. Mais larga $(0,73-1,24 \mathrm{~mm})$ que alta $(0,53-0,84 \mathrm{~mm})$; Face brilhante com poucos pêlos distintos, com uma carena mediana acima do clípeo, mais larga anteriormente e afilada na linha da base das antenas (Figura 10B); margem anterior do clípeo côncava com espaço entre este e as mandíbulas quando fechadas (Figura 10C); ausência de carena occipital.

Mesossoma. Mais alto $(0,69-1,34 \mathrm{~mm})$ que largo $(0,54-1,04 \mathrm{~mm})$; comprimento $(1,00-$ 1,76mm); mesoescuto brilhante, com pêlos esparsos; notáulices incompletas com uma depressão médio-longitudinal (Figuras 11B); sulco pré-escutelar profundo com três carenas transversais (Figura 11B); esternelo crenulado (Figuras 10A e 11C); propódeo irregularmente reticulado com pêlos amarelos (Figura 11D).

Asa anterior. Comprimento 2,68 a 4,39mm; segunda nervura radial $(0,40-0,76 \mathrm{~mm})$ maior que a primeira nervura intercubital $(0,26-0,45 \mathrm{~mm})$; nervura recurrente iniciandose na segunda célula cubital $\left(\mathrm{Cu}_{2}\right)$, raramente intersticial (Figura 14D).

Asa posterior. Pós-nervelo ausente ou inconspícuo (Figura 14D)

Comprimento do ovipositor. Comprimento 0,85 a 1,87mm.

Comprimento do corpo. Macho: 2,29 a 4,24mm; fêmea: 2,86 a 4,23mm.

Coloração. Coloração geral vermelho-amarelada. Antenas, olhos, ocelos, extremidade distal das mandíbulas, tarsômeros apicais do primeiro e segundo pares de pernas e bainha do ovipositor pretos ou enegrecidos; extremidade dos tarsos apicais da perna posterior enegrecida; asas hialinas com nervuras e estigma marrons (Figura 15D). 
Discussão. Não foi possível associar Utetes anastrephae às espécies de moscas-dasfrutas. Observou-se variação na coloração de alguns espécimens como descrito nos trabalhos originais (Viereck, 1913) e nas observações de Leonel Júnior (1991). Houve variação no tamanho de alguns espécimens, provavelmente em razão do regime alimentar na fase larval, e da disponibilidade de alimento no hospedeiro, que determina o tamanho do parasitóide (Clausen et al., 1965).

Material examinado. SÃO PAULO: Araraquara, 21.X.1998, 2 machos (Adalton Raga col.); Atibaia, 30.IX.1999, 1 macho e 1 fêmea; 06.X.1999, 1 macho (M. F. Souza Filho col.); Bertioga, 18.I.2001, 1 fêmea (M. F. Souza Filho col.); Campinas, 03.IX.1997, 1 macho e 1 fêmea; 09.IX.1997, 1 macho e 1 fêmea; 12.XI.1997, 1 fêmea (José Paduanelo col.); 15.XII.1999, 1 macho e 3 fêmeas (Daniela A. de O. Prestes col.); 15.VII.1999, 1 fêmea (José Maria Breda Júnior col.); 02.III.2000, 2 machos e 1 fêmea (Gabriel B. da Silva); Florínia, 29.X.1998, 2 machos e 1 fêmea (Adalton Raga col.); $\underline{\text { Monte Alegre do }}$ Sul, 06.X.1999, 2 machos e 2 fêmeas (M. F. Souza Filho col.); Neves Paulista, 22.X.1998, 1 macho e 1 fêmea (Adalton Raga col.); Pindorama, 06.I.2000, 1 fêmea (M. F. Souza Filho col.); 11.I.2001, 1 macho (Adalton Raga col.).

Distribuição geográfica. Argentina, Oeste da Índia (Wharton e Marsh, 1978); Costa Rica, Colômbia, El Salvador, Guatemala, México, Porto Rico, USA (Flórida), Venezuela in Ovruski et al., 2000; Brasil (AM, BA, MS, MG, PA, PR, RN, RS, RJ, SC, SP) in Canal \& Zucchi, 2000. Esta espécie foi introduzida no Havaí, porém não se estabeleceu (Wharton \& Marsh, 1978).

Hospedeiros. Anastrepha fraterculus (Wied., 1830); A. sororcula Zucchi, 1979; A. suspensa Loew, 1862 in Leonel Júnior, 1991; A. obliqua (Macquart, 1835); A. manihoti Lima 1934) in Canal Daza, 1993; A. striata Schiner, 1868; A. alveata Stone, 1942 in López et al., 1999; A. crebra Stone, 1942 in Hernández-Ortiz et al., 1994; A distincta Greene, 1934 in Zucchi, 2000; A. zenildae Zucchi, 1979 in Araújo, 2002; Ceratitis capitata (Wied, 1824) in Souza Filho, 1999; Rhagoletotrypeta pastranai Aczél, 1954 in Leonel Júnior et al., 1995. 

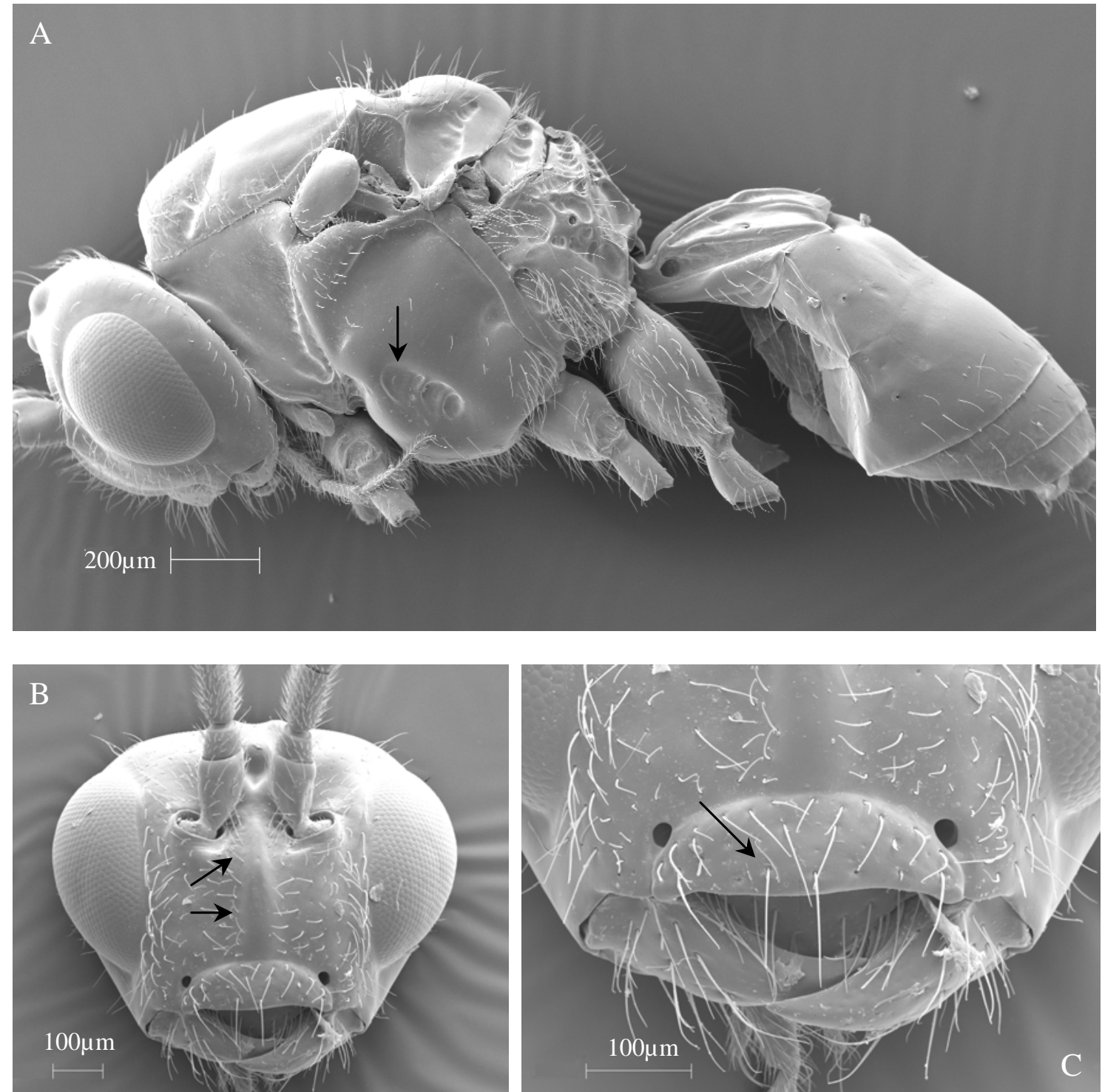

Figura 10 - Utetes anastrephae. A. Cabeça, mesossoma e metassoma, vista lateral (seta indica o esternelo crenulado) (129x); B. Cabeça, vista frontal (setas indicam a carena mediana acima do clípeo) (254x); C. Cabeça, vista parcial (seta indica o clípeo com margem anterior côncava) (534x) 

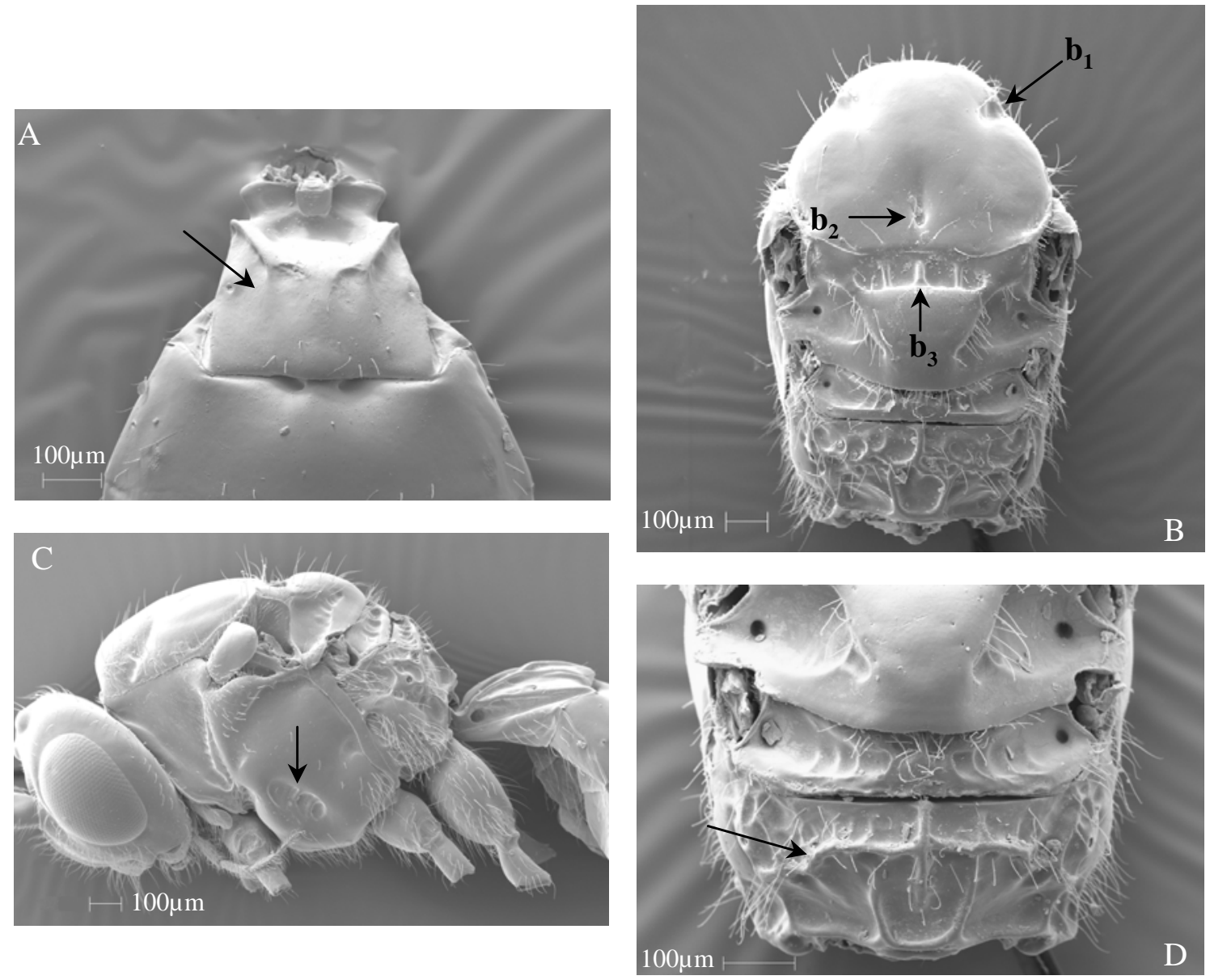

Figura 11 - Utetes anastrephae. A. Base do gáster (seta), vista dorsal (288x); B. Mesossoma, vista dorsal ( $b_{1}$. notáulices incompletas; $b_{2}$. depressão médio-longitudinal; $b_{3}$. sulco pré-escutelar com três carenas transversais) (158x); C. Cabeça e mesossoma, vista lateral (seta indica esternelo crenulado) (166x); D. Propódeo irregularmente reticulado (seta) (396x) 


\subsubsection{Braconidae, Alysiinae}

\section{Asobara anastrephae Muesebeck, 1958}

Aphaereta anastrephae (Muesebeck, 1958)

Phaenocarpa anastrephae Muesebeck, 1958

Cabeça. Mais larga $(0,99-1,27 \mathrm{~mm})$ que alta $(0,61-0,85 \mathrm{~mm})$; olhos grandes (Figura 12B); sulco médio-longitudinal do triângulo ocelar até o occipício; face curta com pêlos e uma protuberância mediana acima do clípeo, sendo este pequeno (Figuras 12C); espaço malar ausente (Figura 12C).

Mesossoma. Mais alto $(0,89-1,22 \mathrm{~mm})$, que largo $(0,62-0,85 \mathrm{~mm})$; comprimento $(1,11-$ 1,48mm); com notáulices incompletas (Figura 13B), marcadas apenas por uma depressão látero-anterior, com depressão mediana no mesoescuto (Figura 13B); sulco pré-escutelar profundo com uma carena transversal mediana (Figura 13B); esternelo crenulado (Figura 12A e 13C). Propódeo (Figura 13D) com uma carena médio-basal curta e carenas marginais (Figura 13D).

Asa anterior. Comprimento 3,45 a 4,24mm; segundo segmento da nervura radial (0,53$0,82 \mathrm{~mm})$ maior que o primeiro segmento da nervura intercubital $(0,22-0,37 \mathrm{~mm})$; célula braquial pouco definida posterior e distalmente; nervura recurrente iniciando-se na primeira célula cubital $\left(\mathrm{Cu}_{1}\right)$ (Figura 14E).

Asa posterior. Estreita com pós-nervelo ausente e radiela incompleta (Figura 14E).

Comprimento do ovipositor. Comprimento: 2,49mm a 3,28mm.

Comprimento do corpo. Macho: 3,32 a 4,04mm; fêmea: 2,61 a 3,91mm.

Coloração. Coloração geral vermelho-amarelada. Olhos, triângulo ocelar, flagelo (exceto a base do primeiro flagelômero), extremidade das mandíbulas, tarsos, tíbias posteriores, bainha do ovipositor e estigma enegrecidos ou pretos. Asas enfuscadas com nervuras enegrecidas (Figura 15C).

Discussão. Esta espécie foi referida pela primeira vez no Brasil por Leonel Júnior (1991). Não foram observadas variações entre os espécimes, porém como observado em 
D. areolatus, um exemplar não possuía a nervura 2r-m. Os machos apresentaram os tergitos finais do abdome enegrecidos como nas descrições originais (Muesebeck, 1958). Material examinado. SÃO PAULO: Avaré, 26.VI.1999, 1 fêmea (Adalton Raga col.); Campinas, 22.XII.1998, 1 fêmea (Daniela A. de O. Prestes); 15.XII.1999, 1 fêmea (Aline Cristina Previdel col.); Monte Mor, 30.I.2001, 2 machos e 1 fêmea (M. F. Souza Filho col.); Monte Alegre do Sul, 26.IV.2001, 1 macho e 2 fêmeas (Joaquim A. de Azevedo Filho col.); Pindorama, 06.I.2000, 2 machos e 2 fêmeas; 11.I.2001, 9 machos e 4 fêmeas (M. F. Souza Filho col.); São Bento do Sapucaí, 18.II.1999, 1 fêmea (Adalton

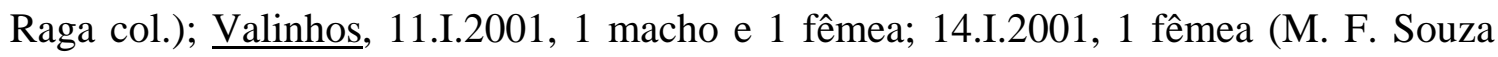
Filho col.).

Distribuição geográfica. Brasil (AM, GO, MS, RN, SP) in Canal \& Zucchi, 2000, Colômbia in Ovruski et al., 2000 e Panamá in Leonel Júnior, 1991.

Hospedeiros. Anastrepha obliqua (Macquart, 1835) in Canal Daza, 1993; A. zenildae Zucchi, 1979 in Araújo, 2002; Ceratitis capitata (Wied., 1824) in Souza Filho, 1999. 

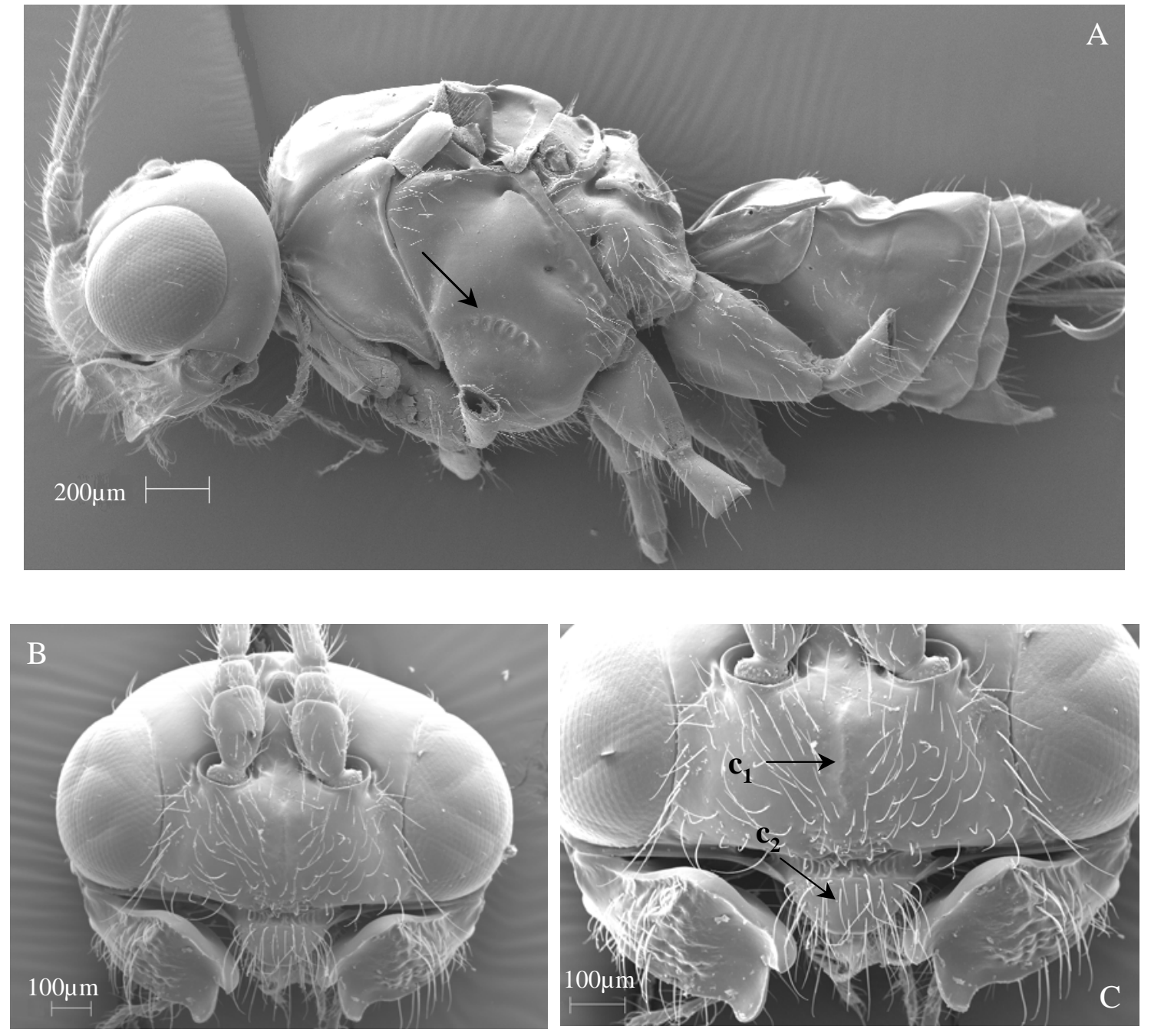

Figura 12 - Asobara anastrephae. A. Cabeça, mesossoma e metassoma, vista lateral (seta indica o esternelo crenulado) (91x); B. Cabeça, vista frontal (197x); C. Cabeça, vista parcial ( $c_{1}$. protuberância mediana; $c_{2}$. clípeo pequeno) (258x) 

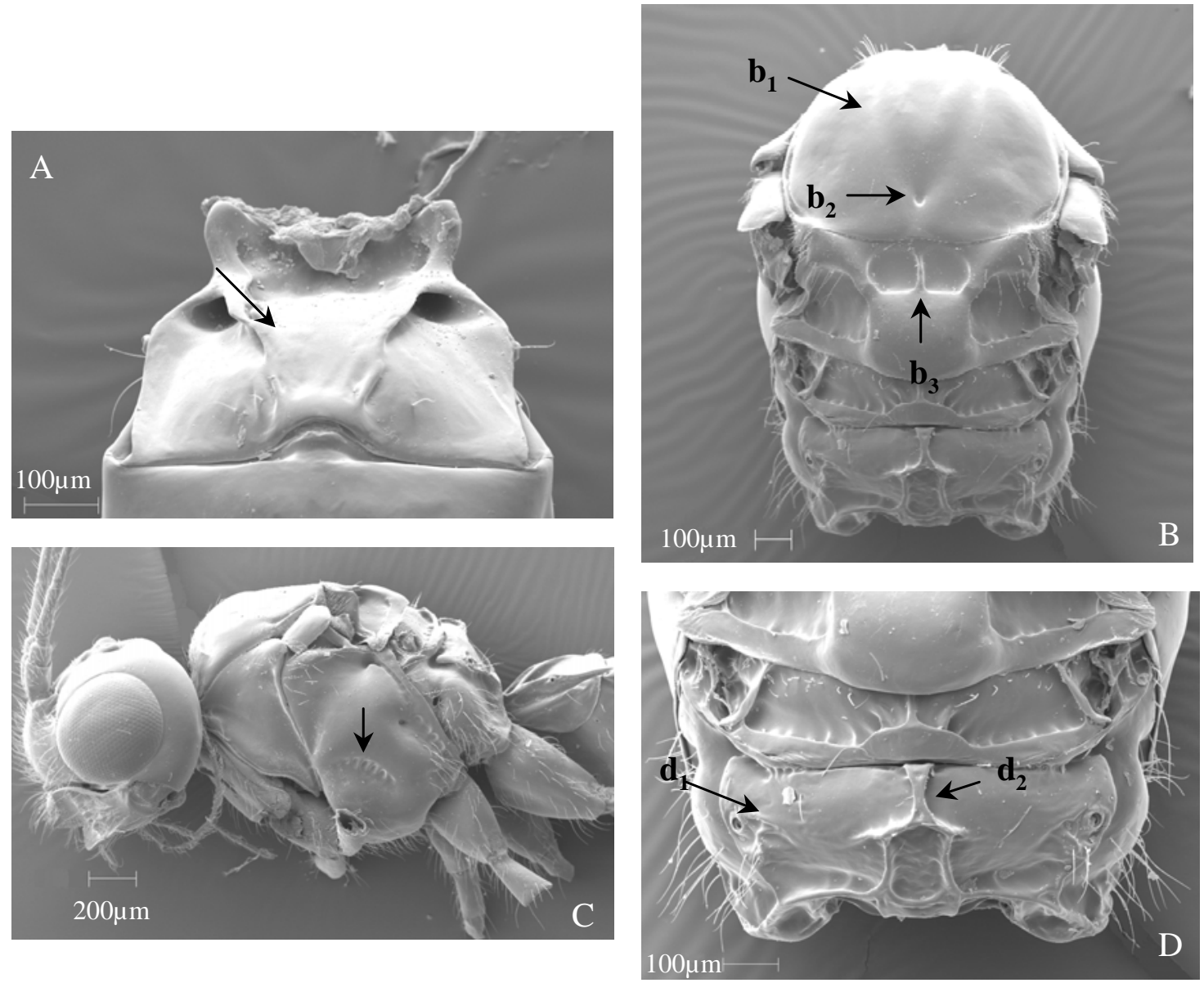

Figura 13 - Asobara anastrephae. A. Base do gáster (seta), vista dorsal (339x); B. Mesossoma, vista dorsal $\left(b_{1}\right.$. notáulices incompletas; $b_{2}$. mesoescuto com depressão mediana; $b_{3}$. sulco pré-escutelar com uma carena transversal mediana) (132x); C. Cabeça e mesossoma, vista lateral (seta mostra o esternelo crenulado) (115x); D. Mesossoma, vista parcial ( $\mathrm{d}_{1}$. propódeo; $\mathrm{d}_{2}$. carena médio-basal curta) (307x) 

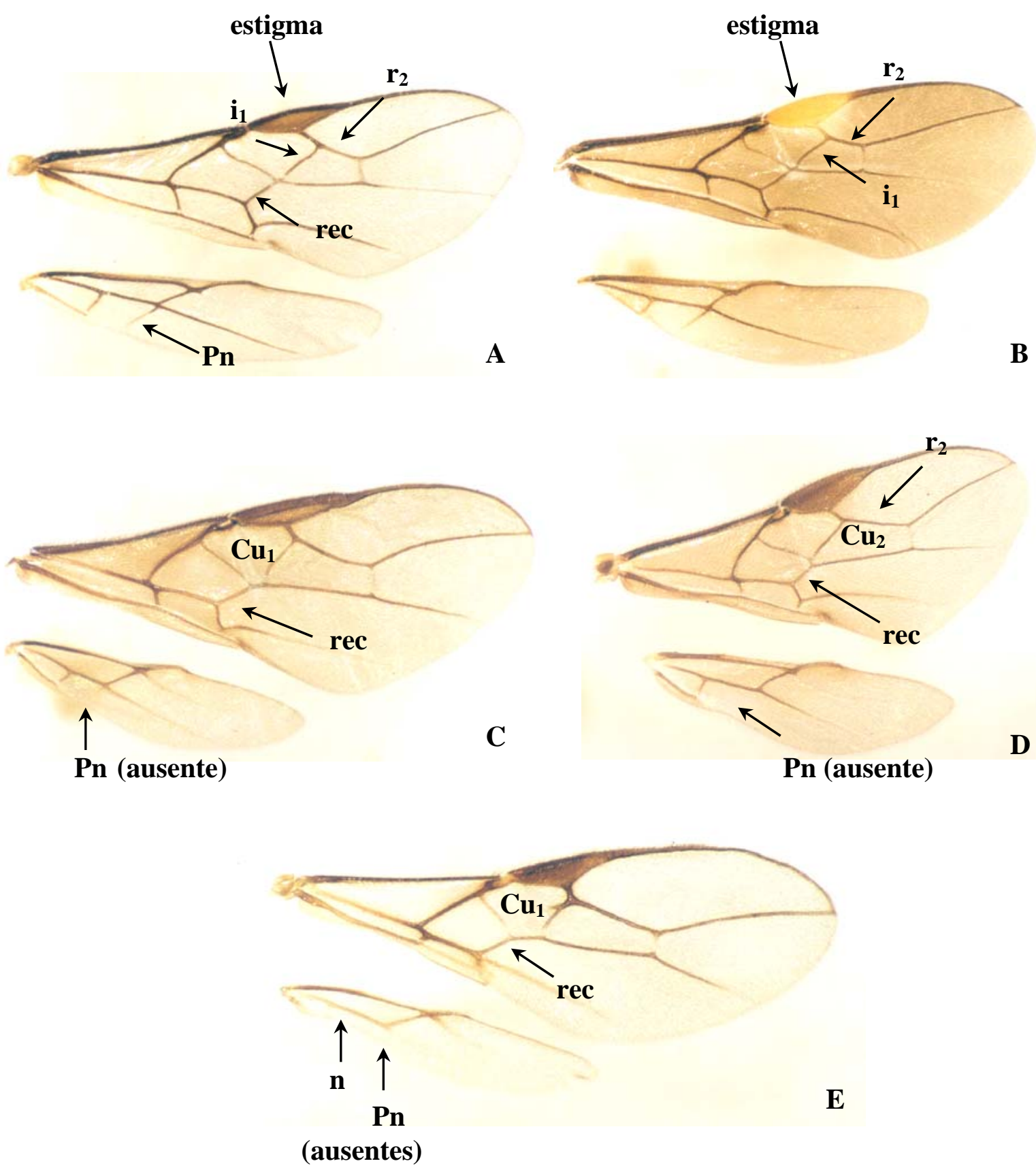

Figura 14 - Asas de braconídeos parasitóides de moscas-das frutas. A - Doryctobracon areolatus; B - D. brasiliensis; C - Opius bellus; D - Utetes anastrephae; E - Asobara anastrephae ( $\mathrm{i}_{1}$ - intercubital $1 ; \mathrm{r}_{2}$ - radial 2; rec - nervura recurrente; $\mathrm{n}$ - nervelo; $\mathrm{Pn}$ - pós-nervelo; $\mathrm{Cu}_{1}$ e $\mathrm{Cu}_{2}$ - células cubitais 1 e 2) (as figuras não estão em uma mesma escala) 

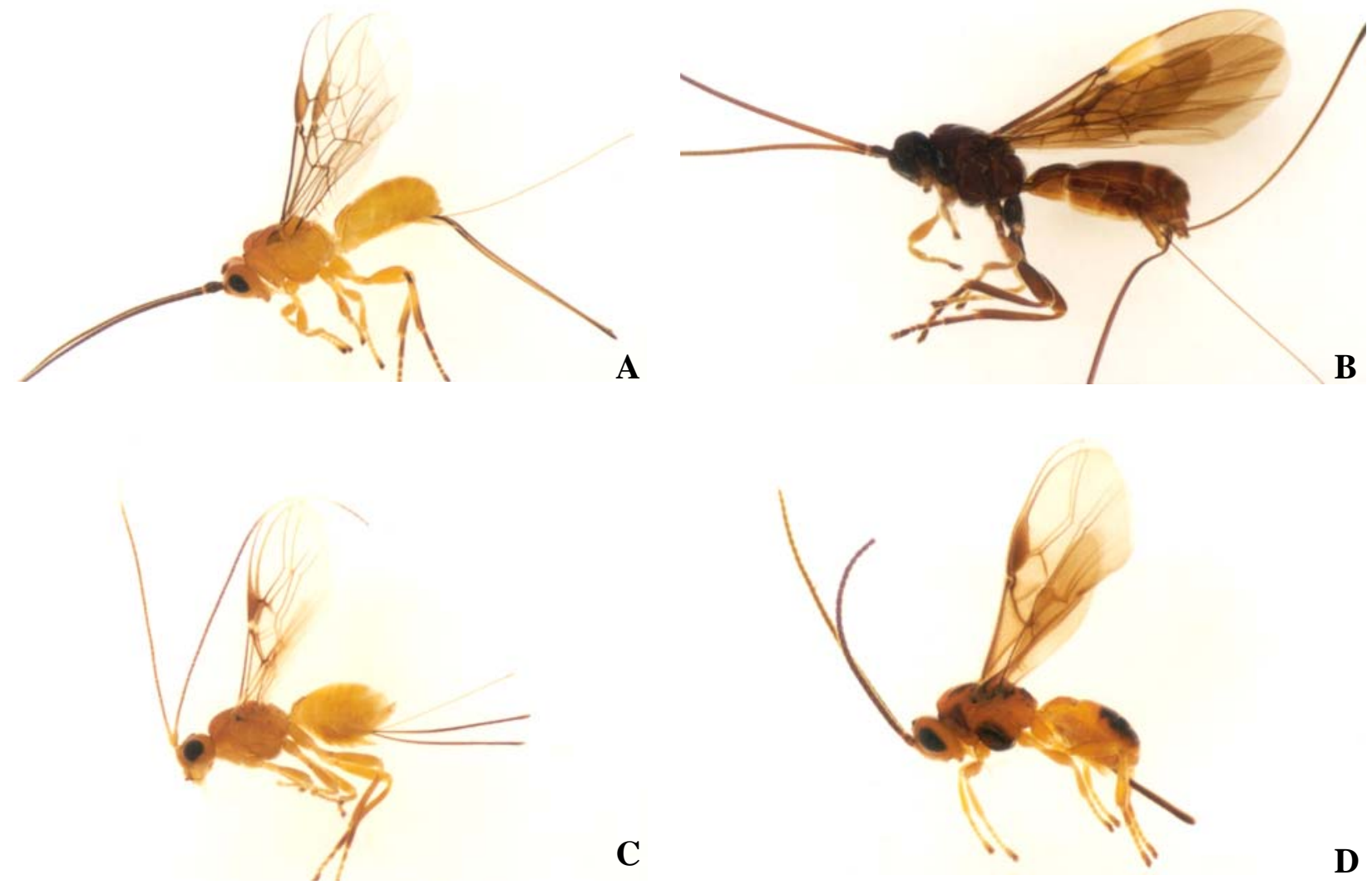

C

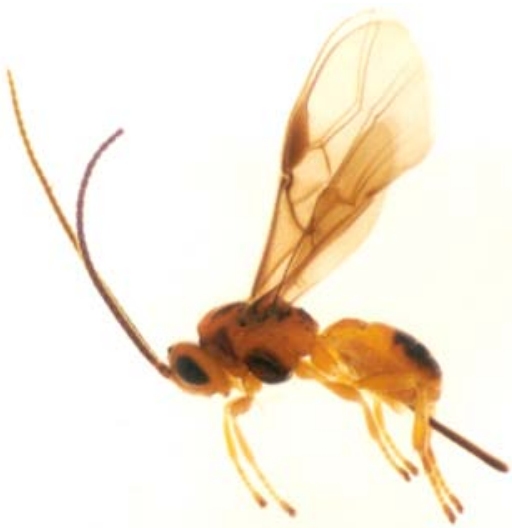

D
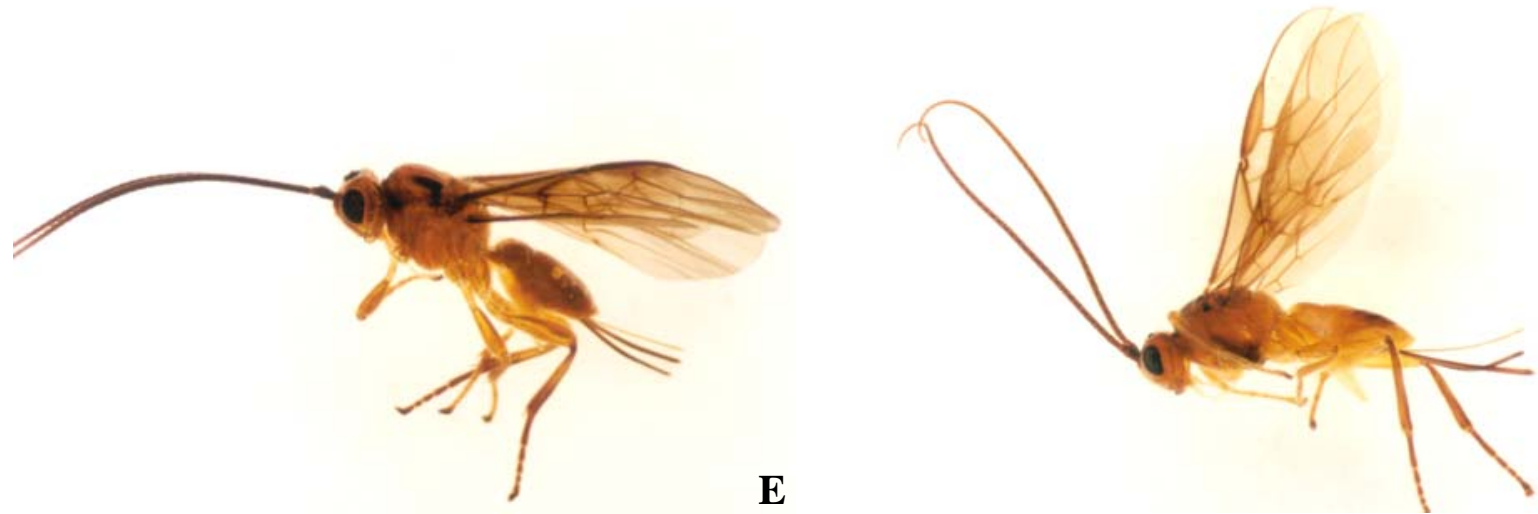

$\mathbf{F}$

Figura 15 - Braconídeos parasitóides de moscas-das-frutas (fêmeas). A - Doryctobracon areolatus; B - D. brasiliensis; C - Asobara anastrephae; D - Utetes anastrephae; E - Opius bellus; F - Opius sp. (as figuras não estão em uma mesma escala) 


\subsection{Associação parasitóides/insetos hospedeiros/plantas associadas}

Doryctobracon areolatus foi obtido de larvas/pupas de A. fraterculus, A. obliqua e A. amita (Quadro 1). Esta espécie apresentou o maior número de associações com as espécies de frutíferas, quando da associação com o inseto hospedeiro (12), sendo obtido em maior número em carambola, pombeiro e serigüela (Quadro 1). Em pitanga, apesar do pequeno número associado a $A$. fraterculus, a percentagem de emergência do parasitóide foi alta (21,35\%), inferior apenas a obtida em pombeiro (22,68\%) (Tabela 6). Resultados semelhantes também foram obtidos em diversas regiões brasileiras. No município de Seropédica-RJ, houve associação de $D$. areolatus a cinco espécies de Anastrepha (A. fraterculus, A. obliqua, A. sororcula, A. serpentina e A. distincta) em todas as espécies de plantas amostradas (12) (Aguiar-Menezes et al., 2001). Ainda no Rio de Janeiro, em Itaguaí, foi constatada parasitando larvas de A. fraterculus em pitanga e goiaba e A. obliqua em carambola, uvaia, manga e serigüela (Aguiar-Menezes \& Menezes, 1997). Em Mossoró/Assú-RN, região de semi-árido, foi obtida em maior número em larvas/pupas de A. obliqua, A. zenildae e C. capitata em goiaba, cajarana e juá, respectivamente (Araújo, 2002) e, no norte de Minas Gerais, ataca larvas de $A$. obliqua e A. zenildae em cajarana e juá, respectivamente (Canal Daza, 1997). Nos municípios de Limeira/Piracicaba-SP, foi associada a todas as espécies de moscas-dasfrutas obtidas em todas as fruteiras amostradas (Leonel Junior et al., 1996). Ainda no Estado de São Paulo, parasitou quatro espécies de moscas-das-frutas (A. amita, A. fraterculus, A. obliqua e C. capitata) em 16 espécies frutíferas (Souza Filho, 1999).

Doryctobracon brasiliensis foi obtido apenas de larvas/pupas de A. fraterculus em ameixa japonesa (primeira referência de planta associada) (Quadro 1). Esta espécie foi uma das mais coletadas em larvas de moscas em nêspera, pêssego e cereja-da-terra com percentagem de emergência de 23,47\%; 19,13\% e 17,39\%, respectivamente (Tabela 6). Em 21 Estados brasileiros, também foi verificado o parasitismo deste braconídeo em várias espécies de moscas-das-frutas em diversas fruteiras, por exemplo, em larvas/pupas de A. fraterculus, A. serpentina, A. sororcula além de Rhagoletotrypeta pastranai em pêssego, pitanga e esporão-de-galo (Leonel Júnior et al., 1995). Em 
Limeira e Piracicaba, foi coletada a partir de larvas/pupas de A. fraterculus em café, pêssego, pitanga e serigüela (Leonel Junior et al., 1996). Na província de Misiones na Argentina, foi associada a A. fraterculus em seis espécies de frutíferas pertencente a três famílias (Ovruski et al., 2001).

Neste trabalho, foram observados os primeiros registros no Brasil de ocorrência de moscas-das-frutas e parasitóides em wampi (Clausena lansium) e canela-batalha (Cryptocarya aschersoniana). Porém em wampi, apenas foi constatado o parasitismo por $D$. areolatus, mas não houve emergência de moscas-das-frutas. Em canela-batalha, ocorreu infestação por A. fraterculus com parasitismo de duas espécies de braconídeos, D. areolatus e Opius sp.

As fruteiras que apresentaram as menores percentagens de emergência de parasitóides foram, ameixa $(0,1 \%)$, bacupari $(0,13 \%)$, cambucá $(0,17 \%)$, canela-batalha $(0,23 \%)$, guabiroba $(0,03 \%)$, grumixama $(0,07 \%)$, umê $(0,19 \%)$, wampi $(0,07 \%)$ e guapevinha $(0,03 \%)$. Estas baixas percentagens podem estar relacionadas ao pequeno número de amostras de frutos que foram coletados, os quais não mostrariam o real número de parasitóides emergidos, além de outros fatores como a fase de amadurecimento dos frutos e a retirada deles, antes que as larvas pudessem ser parasitadas (Van Driesche, 1983; Bressan \& Telles, 1991) (Tabela 6).

Apesar de ter sido associado a um pequeno número espécies de moscas-dasfrutas, $D$. areolatus tem sido referido como parasitóide em diversas espécies de tefritídeos em várias frutíferas (Leonel et al., 1995). A estreita relação deste parasitóide com várias espécies de moscas demonstra o quanto é generalista em relação aos seus hospedeiros (Leonel Júnior, 1991; Katiyar et al., 1995). D. areolatus foi obtido tanto em fruteiras exóticas como nativas. Todavia as mirtáceas apresentaram a maior concentração destes parasitóides, 40,30\% dos espécimens de D. areolatus e 50\% dos espécimens de $D$. brasiliensis, provavelmente em razão do maior número de espécies frutíferas amostradas nesta família (Tabelas 5 e 6). É conhecida a preferência de Anastrepha spp. pelas espécies de Myrtaceae (Jirón \& Hedströn, 1988; Aguiar-Menezes \& Menezes, 1996), onde foram constatados os maiores índices de parasitismo (Eskafi, 1990; Leonel Junior et al., 1996; Aguiar-Menezes \& Menezes, 1997). 
Apesar de ter havido associação apenas para as espécies do gênero Anastrepha, especialmente com $A$. fraterculus, já foi constatado o parasistimo de braconídeos em larvas de C. capitata (e.g. Souza Filho, 1999), demonstrando a adaptação dos parasitóides nativos às espécies exóticas de tefritídeos. A ocorrência deste fato talvez possa ser explicada pela existência do maior número de Anastrepha spp. em relação a $C$. capitata, ou ainda, pelas formas imaturas de Anastrepha spp. apresentarem-se mais apropriadas nutricionalmente que as de C. capitata (Jirón \& Mexzon, 1989). Porém, mais do que a preferência pelos hospedeiros, existe uma forte associação entre as características físicas do fruto (peso, cor e tamanho), além de químicas como o odor na atração de parasitóides. A relação tritrófica entre braconídeo, larva hospedeira e planta associada apenas tem início com a captação dos voláteis químicos emitidos a partir de frutos maduros, estando infestados ou não (Leyva, et al. 1991; Hernández-Ortiz et al. 1994). Com relação às demais espécies de braconídeos não foi possível fazer nenhuma associação, haja vista que mais de uma espécie de mosca e parasitóide emergiram no mesmo frasco. 


\begin{tabular}{|c|c|c|c|}
\hline PARASITÓIDES & HOSPEDEIROS & FRUTOS HOSPEDEIROS & FAMÍLIAS \\
\hline \multirow{12}{*}{$\begin{array}{c}\text { Doryctobracon } \\
\text { areolatus }\end{array}$} & \multirow{9}{*}{ A. fraterculus } & $\begin{array}{l}\text { Araçá Psidium cattleianum } \\
\text { sabine }(2)^{*}\end{array}$ & Myrtaceae \\
\hline & & $\begin{array}{l}\text { Acerola Malpighia glabra } \\
\text { (6) }\end{array}$ & Malpighiaceae \\
\hline & & $\begin{array}{l}\text { Cabeluda Plinia glomerata } \\
\text { (Berg.) Amsh (3) }\end{array}$ & Myrtaceae \\
\hline & & $\begin{array}{l}\text { Jabuticaba Myrciaria } \\
\text { cauliflora (Mart.) (8) }\end{array}$ & Myrtaceae \\
\hline & & $\begin{array}{l}\text { Jambo Syzygium jambos L. } \\
\text { (20) }\end{array}$ & Myrtaceae \\
\hline & & Manga (2) & Myrtaceae \\
\hline & & $\begin{array}{l}\text { Nêspera Eriobotrya } \\
\text { japonica (Thunb.) (3) }\end{array}$ & Rosaceae \\
\hline & & $\begin{array}{l}\text { Pitanga Eugenia uniflora } \\
\text { (12) }\end{array}$ & Myrtaceae \\
\hline & & $\begin{array}{l}\text { Uvaia Eugenia Pyriformis } \\
\text { (7) }\end{array}$ & Myrtaceae \\
\hline & \multirow[b]{2}{*}{ A. obliqua } & $\begin{array}{l}\text { Carambola Averrhoa } \\
\text { carambola (221) }\end{array}$ & Oxalidaceae \\
\hline & & $\begin{array}{l}\text { Seriguela Spondias } \\
\text { purpúrea L. (31) }\end{array}$ & Anacardiaceae \\
\hline & A. amita & $\begin{array}{l}\text { Pombeiro Citharexylum } \\
\text { myrianthum Cham. (37) }\end{array}$ & Verbenaceae \\
\hline $\begin{array}{c}\text { Doryctobracon } \\
\text { brasiliensis }\end{array}$ & A. fraterculus & $\begin{array}{l}\text { Ameixa japosena Prunus } \\
\text { salicina (3) }\end{array}$ & Rosaceae \\
\hline
\end{tabular}

* Número de parasitóides emergidos na associação com a mosca.

Quadro 1 - Associação entre as espécies de parasitóides, frutíferas e moscas-das-frutas 
Tabela 6. Número de braconídeos emergidos e associação de frutos hospedeiros de larvas frugívoras (Dip. Tephritidae) do Estado de São Paulo

\begin{tabular}{|c|c|c|c|c|c|c|c|}
\hline \multirow[b]{2}{*}{$\begin{array}{l}\text { Frutos hospedeiros } \\
\text { das larvas frugívoras }\end{array}$} & \multicolumn{7}{|c|}{ PARASITÓIDES } \\
\hline & $\begin{array}{c}D . \\
\text { areolatus }\end{array}$ & $\begin{array}{c}D . \\
\text { brasiliensis }\end{array}$ & $\begin{array}{l}\text { Opius } \\
\text { bellus }\end{array}$ & $\begin{array}{l}\text { Opius } \\
\text { sp. }\end{array}$ & $\begin{array}{c}U . \\
\text { anastrephae }\end{array}$ & $\begin{array}{c}\text { A. } \\
\text { anastrephae }\end{array}$ & Total \\
\hline \multicolumn{8}{|l|}{ ANACARDIACEAE } \\
\hline $\begin{array}{l}\text { Mangifera indica L. } \\
\text { (Manga) }\end{array}$ & 16 & 0 & 0 & 0 & 4 & 1 & 21 \\
\hline \multicolumn{7}{|l|}{ L. (Serigüela) } & 112 \\
\hline \multicolumn{8}{|l|}{ CLUSIACEAE } \\
\hline \multicolumn{8}{|l|}{ Mart. (Bacupari) } \\
\hline \multicolumn{8}{|l|}{ LAURACEAE } \\
\hline $\begin{array}{l}\text { Cryptocarya } \\
\text { aschersoniana Mez } \\
\text { (Canela-Batalha) }\end{array}$ & 5 & 0 & 0 & 2 & 0 & 0 & 7 \\
\hline \multicolumn{8}{|l|}{ MALPIGHIACEAE } \\
\hline $\begin{array}{l}\text { Malpighia glabra L. } \\
\text { (Acerola) }\end{array}$ & 14 & 2 & 0 & 0 & 2 & 0 & 18 \\
\hline \multicolumn{8}{|l|}{ MIMOSACEAE } \\
\hline $\begin{array}{l}\text { Inga sp. } \\
\text { (Ingá) }\end{array}$ & 22 & 1 & 0 & 0 & 0 & 0 & 23 \\
\hline \multicolumn{8}{|l|}{ MYRTACEAE } \\
\hline \multicolumn{8}{|l|}{ guaviroba (DC.) } \\
\hline \multicolumn{8}{|l|}{ Kiaersk (Guabiroba) } \\
\hline Eugenia involucrata & 73 & 40 & 22 & 16 & 10 & 0 & 161 \\
\hline DC (cereja-da-terra) & & & & & & & \\
\hline
\end{tabular}


Tabela 6. Número de braconídeos emergidos e associação de frutos hospedeiros de larvas frugívoras (Dip. Tephritidae) do Estado de São Paulo

\begin{tabular}{|c|c|c|c|c|c|c|c|}
\hline \multirow[b]{2}{*}{$\begin{array}{l}\text { Frutos hospedeiros } \\
\text { das larvas frugívoras }\end{array}$} & \multicolumn{7}{|c|}{ PARASITÓIDES } \\
\hline & $\begin{array}{c}\text { D. } \\
\text { areolatus }\end{array}$ & $\begin{array}{c}D . \\
\text { brasiliensis }\end{array}$ & $\begin{array}{l}\text { Opius } \\
\text { bellus }\end{array}$ & $\begin{array}{l}\text { Opius } \\
\text { sp. }\end{array}$ & $\begin{array}{c}U . \\
\text { anastrephae }\end{array}$ & $\begin{array}{c}\text { A. } \\
\text { anastrephae }\end{array}$ & Total \\
\hline \multicolumn{8}{|l|}{ MYRTACEAE } \\
\hline $\begin{array}{l}\text { Plinia glomerata } \\
\text { (Cabeluda) }\end{array}$ & 4 & 25 & 0 & 0 & 9 & 0 & 38 \\
\hline $\begin{array}{l}\text { Eugenia brasiliensis } \\
\text { Lam. (Grumixama) }\end{array}$ & 2 & 0 & 0 & 0 & 0 & 0 & 2 \\
\hline $\begin{array}{l}\text { Eugenia uniflora L. } \\
\text { (Pitanga) }\end{array}$ & 498 & 22 & 6 & 1 & 77 & 0 & 604 \\
\hline $\begin{array}{l}\text { Eugenia pyriformis } \\
\text { (Uvaia) }\end{array}$ & 44 & 15 & 0 & 0 & 0 & 0 & 59 \\
\hline $\begin{array}{l}\text { Psidium cattleianum } \\
\text { Sabine (Araçá) }\end{array}$ & 147 & 9 & 0 & 0 & 0 & 0 & 156 \\
\hline $\begin{array}{l}\text { Psidium guajava L. } \\
\text { (goiaba) }\end{array}$ & 16 & 1 & 0 & 0 & 0 & 0 & 17 \\
\hline $\begin{array}{l}\text { Syzygium jambos } \\
\text { (L.) Alston } \\
\text { (Jambo) }\end{array}$ & 91 & 2 & 1 & 0 & 0 & 3 & 97 \\
\hline $\begin{array}{l}\text { Plinia edulis } \\
\text { (Cambucá) }\end{array}$ & 5 & 0 & 0 & 0 & 0 & 0 & 5 \\
\hline $\begin{array}{l}\text { Myrciaria cauliflora } \\
\text { (Mart.) Berg } \\
\text { (Jabuticaba) }\end{array}$ & 59 & 1 & 1 & 0 & 8 & 0 & 69 \\
\hline
\end{tabular}


Tabela 6. Número de braconídeos emergidos e associação de frutos hospedeiros de larvas frugívoras (Dip. Tephritidae) do Estado de São Paulo

\begin{tabular}{|c|c|c|c|c|c|c|c|}
\hline \multirow[b]{2}{*}{$\begin{array}{l}\text { Frutos hospedeiros } \\
\text { das larvas frugívoras }\end{array}$} & \multicolumn{7}{|c|}{ PARASITÓIDES } \\
\hline & $\begin{array}{c}\text { D. } \\
\text { areolatus }\end{array}$ & $\begin{array}{c}D . \\
\text { brasiliensis }\end{array}$ & $\begin{array}{l}\text { Opius } \\
\text { bellus }\end{array}$ & $\begin{array}{l}\text { Opius } \\
\text { sp. }\end{array}$ & $\begin{array}{c}U . \\
\text { anastrephae }\end{array}$ & $\begin{array}{c}\text { A. } \\
\text { anastrephae }\end{array}$ & Total \\
\hline \multicolumn{8}{|l|}{ OXALIDACEAE } \\
\hline $\begin{array}{l}\text { Averrhoa carambola } \\
\text { L. (Carambola) }\end{array}$ & 260 & 0 & 0 & 0 & 1 & 78 & 339 \\
\hline ROSACEAE & & & & & & & \\
\hline $\begin{array}{l}\text { Eriobotrya japonica } \\
\text { (Thunb.) Lindl. }\end{array}$ & 125 & 54 & 9 & 3 & 127 & 5 & 323 \\
\hline (Nêspera) & & & & & & & \\
\hline $\begin{array}{l}\text { Prunus salicina } \\
\text { Lindl. }\end{array}$ & 0 & 3 & 0 & 0 & 0 & 0 & 3 \\
\hline (Ameixa japonesa) & & & & & & & \\
\hline Prunus persica (L.) & 96 & 44 & 0 & 1 & 0 & 0 & 141 \\
\hline $\begin{array}{l}\text { Batsch } \\
\text { (Pêssego) }\end{array}$ & & & & & & & \\
\hline $\begin{array}{l}\text { Prunus x Mume Sieb } \\
\text { e Zucc (Umê) }\end{array}$ & 2 & 2 & 2 & 0 & 0 & 0 & 6 \\
\hline RUTACEAE & & & & & & & \\
\hline $\begin{array}{l}\text { Clausena lansium } \\
\text { (Lour) Skeels }\end{array}$ & 2 & 0 & 0 & 0 & 0 & 0 & 2 \\
\hline (Wampi) & & & & & & & \\
\hline SOLANACEAE & & & & & & & \\
\hline $\begin{array}{l}\text { Solanum } \\
\text { americanum Mill. } \\
\text { (Maria Preta) }\end{array}$ & 129 & 2 & 0 & 0 & 16 & 0 & 147 \\
\hline
\end{tabular}


Tabela 6. Número de braconídeos emergidos e associação de frutos hospedeiros de larvas frugívoras (Dip. Tephritidae) do Estado de São Paulo

\begin{tabular}{|c|c|c|c|c|c|c|c|}
\hline \multirow[b]{2}{*}{$\begin{array}{l}\text { Frutos hospedeiros } \\
\text { das larvas frugívoras }\end{array}$} & \multicolumn{7}{|c|}{ PARASITÓIDES } \\
\hline & $\begin{array}{c}D . \\
\text { areolatus }\end{array}$ & $\begin{array}{c}\text { D. } \\
\text { brasiliensis }\end{array}$ & $\begin{array}{l}\text { Opius } \\
\text { bellus }\end{array}$ & $\begin{array}{l}\text { Opius } \\
\text { sp. }\end{array}$ & $\begin{array}{c}U . \\
\text { anastrephae }\end{array}$ & $\begin{array}{c}\text { A. } \\
\text { anastrephae }\end{array}$ & Total \\
\hline \multicolumn{8}{|l|}{ SAPOTACEAE } \\
\hline $\begin{array}{c}? \\
\text { (Guapevinha) }\end{array}$ & 1 & 0 & 0 & 0 & 0 & 0 & 1 \\
\hline & 100 & 2 & 1 & 0 & 0 & 0 & 103 \\
\hline $\begin{array}{l}\text { (Ruiz e Pav.) Radlk } \\
\text { (Abiu) }\end{array}$ & & & & & & & \\
\hline VERBENACEAE & & & & & & & \\
\hline $\begin{array}{l}\text { Citharexylum } \\
\text { myrianthum Cham } \\
\text { (Pombeiro) }\end{array}$ & 529 & 5 & 3 & 0 & 11 & 2 & 550 \\
\hline TOTAL & 2332 & 230 & 45 & 23 & 265 & 114 & 3009 \\
\hline
\end{tabular}




\subsection{Percentagem de parasitismo}

O parasitismo total das larvas/pupas de tefritídeos foi de 7,75\% nos 33 municípios amostrados. Entre os municípios paulistas, o parasitismo é bastante variável, sendo 2,9\% em Limeira e Piracicaba (Leonel Júnior, 1991) e de 1,1\% a 63,4\%, em 94 municípios (Souza Filho, 1999). No presente estudo, as maiores percentagens foram observadas em wampi (40\%), abiu (23,46\%) e pombeiro (18,55\%) e as menores em umê $(0,6 \%)$, goiaba $(2,22 \%)$ e acerola (2,69\%) (Figura 16). Entretanto, deve-se ter cautela entre os valores de parasitismo apresentado, pois alguns podem estar superestimados pela variação do número de amostras, como ocorrido com wampi. Esta apresentou o maior valor de parasitismo, no entanto, o número das amostras foi bastante pequeno (1) e estava parasitada. Desse modo, não se pode afirmar que o parasitismo neste fruto foi maior, pois o fato do número de amostras ser pequeno, mascara o resultado do que estaria ocorrendo em campo (Figura 16).

Com relação às espécies de braconídeos, as percentagens variaram de acordo com os locais de coleta e dos frutos hospedeiros das larvas frugívoras, sendo que $D$. areolatus apresentou variações nos índices de parasitismo de 0,002 a 40\%, D. brasiliensis de $0,09 \%$ a 7,50\%, $U$. anastrephae de $0,02 \%$ a $1,92 \%$, A. anastrephae de $0,05 \%$ a $2,30 \%$ e $O$. bellus de $0,05 \%$ a 1,29\%. Para Opius sp., a percentagem variou de 0,03\% (em nêspera) a 3,84\% (em canela-batalha) (Tabela 7). Estes valores certamente foram influenciados por fatores que interferiram no parasitismo, por exemplo, a retirada de frutos hospedeiros do campo para o laboratório. Esta ação impede as larvas presentes nos frutos de serem parasitadas, contribuindo negativamente para o resultado do impacto de parasitóides, sobre as populações de seus hospedeiros (Van Driesche, 1983). A característica morfológica dos frutos é outro fator que favorece ou não o parasitismo, porém já foi constatado que em frutos menores com polpa rasa, os índices são maiores que em frutos grandes com polpa espessa (Sivinski et al., 1997, Hickel, 2002). De acordo com os resultados obtidos, não houve correlação entre peso médio de fruto (g) e parasitismo (\%), porém, verifica-se uma tendência dos frutos menores apresentarem as maiores percentagens de parasitismo, como observado em pombeiro (0,70g; 18,55\%) e 
pitanga (1,76g; 14,79\%). Para os frutos maiores, ocorre o inverso, por exemplo, manga (126,9g; 4,52\%), goiaba (62,20g; 2,22\%) e carambola (37,07g; 9,57\%) (Figura 17). Estas observações são semelhantes às obtidas por vários autores (Hernández-Ortiz, 1994; Sivinski, et al. 1997; Souza Filho, 1999). Como observado por Matrangolo et al. (1998), no Recôncavo Baiano, as larvas em manga apresentaram um parasitismo superior às larvas em goiaba, talvez em razão da presença do caroço, que poderia ter impossibilitado as larvas de aprofundarem-se na polpa, ficando ao alcance dos parasitóides. No México, o índice de parasitismo de larvas em goiaba também foi baixo (2,1\%) (Hernández-Ortiz, 1994).

Em relação ao parâmetro intensidade de infestação (I.I.), foram constatadas as maiores intensidades para cereja-da-terra e pitanga, seguido de pombeiro, araçá, cabeluda, uvaia e maria preta, e as menores em wampi, bacupari, guabiroba, manga e guapevinha (Figura 16). De modo geral, há uma tendência dos frutos menores serem mais infestados que os maiores (Figura 17), concordando com os dados de Malavasi e Morgante (1980), pois o fruto menor apresenta uma maior relação superfície/volume. As variações ocorridas provavelmente estejam relacionadas com os locais e época de coleta dos frutos, uma vez que as amostras foram coletadas, sem periodicidade, em diversas regiões do Estado de São Paulo, dependendo apenas da disponibilidade de frutos, com diferentes mudanças sazonais, que poderiam estar atuando nos locais. 


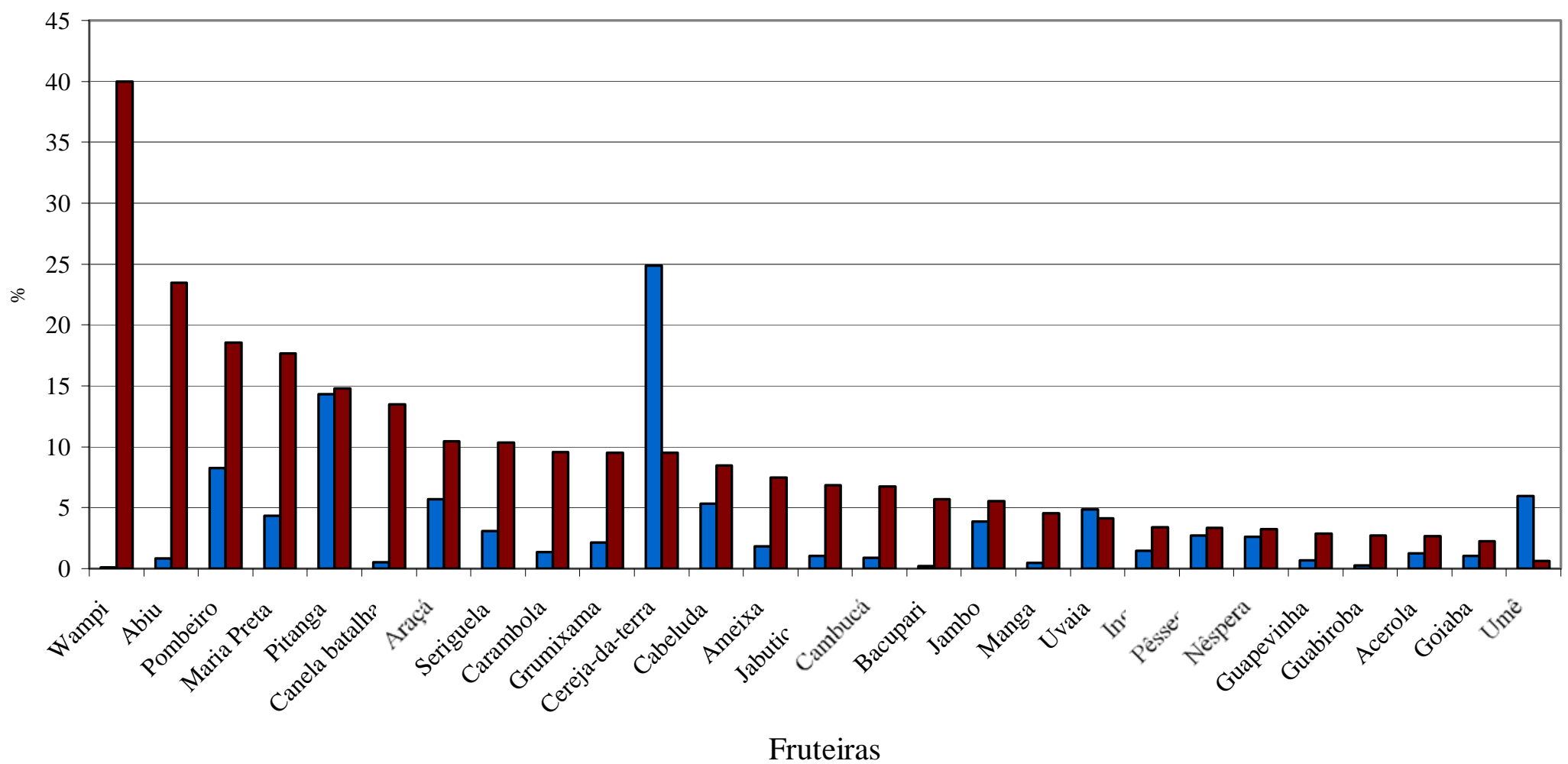

Figura 16 - Percentagem de intensidade de infestação de moscas-das-frutas (\%I.I.) e percentagem de parasitismo (Braconidae) 
Tabela 7. Percentagem de parasitismo de larvas frugívoras por braconídeos em frutos de 33 municípios do Estado de São Paulo (agosto/1997 a fevereiro/2003)

\begin{tabular}{|c|c|c|c|c|c|c|c|c|c|c|c|c|}
\hline \multirow{3}{*}{$\begin{array}{c}\text { Frutíferas } \\
\text { hospedeiras } \\
\text { das larvas } \\
\text { (№ de pupários) }\end{array}$} & \multicolumn{12}{|c|}{ PARASITÓIDES } \\
\hline & \multicolumn{2}{|c|}{$\begin{array}{c}\text { Doryctobracon } \\
\text { areolatus }\end{array}$} & \multicolumn{2}{|c|}{$\begin{array}{c}\text { Doryctobracon } \\
\text { brasiliensis }\end{array}$} & \multicolumn{2}{|c|}{$\begin{array}{l}\text { Opius } \\
\text { bellus }\end{array}$} & \multicolumn{2}{|c|}{ Opius sp. } & \multicolumn{2}{|c|}{$\begin{array}{c}\text { Utetes } \\
\text { anastrephae }\end{array}$} & \multicolumn{2}{|c|}{$\begin{array}{c}\text { Asobara } \\
\text { anastrephae }\end{array}$} \\
\hline & $\mathrm{N}$ & $\%$ & $\mathrm{~N}$ & $\%$ & $\mathrm{~N}$ & $\%$ & $\mathrm{~N}$ & $\%$ & $\mathrm{~N}$ & $\%$ & $\mathrm{~N}$ & $\%$ \\
\hline $\begin{array}{c}\text { Acerola } \\
\text { (669) }\end{array}$ & 14 & 2,09 & 2 & 0,29 & 0 & 0 & 0 & 0 & 2 & 0,29 & 0 & 0 \\
\hline $\begin{array}{c}\text { Ameixa } \\
\text { (40) }\end{array}$ & 0 & 0 & 3 & 7,50 & 0 & 0 & 0 & 0 & 0 & 0 & 0 & 0 \\
\hline $\begin{array}{l}\text { Araçá } \\
(1490)\end{array}$ & 147 & 9,86 & 9 & 0,60 & 0 & 0 & 0 & 0 & 0 & 0 & 0 & 0 \\
\hline $\begin{array}{l}\text { Abiu } \\
(439)\end{array}$ & 100 & 22,7 & 2 & 0,45 & 1 & 0,22 & 0 & 0 & 0 & 0 & 0 & 0 \\
\hline $\begin{array}{c}\text { Bacupari } \\
\text { (70) }\end{array}$ & 4 & 5,71 & 0 & 0 & 0 & 0 & 0 & 0 & 0 & 0 & 0 & 0 \\
\hline $\begin{array}{c}\text { Cereja-da-terra } \\
\qquad \text { (1696) }\end{array}$ & 73 & 4,30 & 40 & 2,35 & 22 & 1,29 & 16 & 0,94 & 10 & 0,58 & 0 & 0 \\
\hline $\begin{array}{c}\text { Carambola } \\
\text { (3542) }\end{array}$ & 260 & 7,34 & 0 & 0 & 0 & 0 & 0 & 0 & 1 & 0,02 & 78 & 2,2 \\
\hline $\begin{array}{l}\text { Canela batalha } \\
\qquad(52)\end{array}$ & 5 & 9,61 & 0 & 0 & 0 & 0 & 2 & 3,84 & 0 & 0 & 0 & 0 \\
\hline $\begin{array}{c}\text { Cabeluda } \\
\text { (448) }\end{array}$ & 4 & 0,89 & 25 & 5,58 & 0 & 0 & 0 & 0 & 9 & 2,0 & 0 & 0 \\
\hline $\begin{array}{c}\text { Cambucá } \\
\text { (74) }\end{array}$ & 5 & 6,75 & 0 & 0 & 0 & 0 & 0 & 0 & 0 & 0 & 0 & 0 \\
\hline
\end{tabular}


Tabela 7. Percentagem de parasitismo de larvas frugívoras por braconídeos em frutos de 33 municípios do Estado de São Paulo (agosto/1997 a fevereiro/2003)

\begin{tabular}{|c|c|c|c|c|c|c|c|c|c|c|c|c|}
\hline \multirow{3}{*}{$\begin{array}{c}\text { Frutíferas } \\
\text { hospedeiras } \\
\text { das larvas } \\
\text { (№ de pupários) }\end{array}$} & \multicolumn{12}{|c|}{ PARASITÓIDES } \\
\hline & \multicolumn{2}{|c|}{$\begin{array}{c}\text { Doryctobracon } \\
\text { areolatus }\end{array}$} & \multicolumn{2}{|c|}{$\begin{array}{c}\text { Doryctobracon } \\
\text { brasiliensis }\end{array}$} & \multicolumn{2}{|c|}{$\begin{array}{l}\text { Opius } \\
\text { bellus }\end{array}$} & \multicolumn{2}{|c|}{ Opius sp. } & \multicolumn{2}{|c|}{$\begin{array}{c}\text { Utetes } \\
\text { anastrephae }\end{array}$} & \multicolumn{2}{|c|}{$\begin{array}{c}\text { Asobara } \\
\text { anastrephae }\end{array}$} \\
\hline & $\mathrm{N}$ & $\%$ & $\mathrm{~N}$ & $\%$ & $\mathrm{~N}$ & $\%$ & $\mathrm{~N}$ & $\%$ & $\mathrm{~N}$ & $\%$ & $\mathrm{~N}$ & $\%$ \\
\hline $\begin{array}{c}\text { Guapevinha } \\
\text { (35) }\end{array}$ & 1 & 2,85 & 0 & 0 & 0 & 0 & 0 & 0 & 0 & 0 & 0 & 0 \\
\hline $\begin{array}{c}\text { Grumixama } \\
\text { (21) }\end{array}$ & 2 & 9,52 & 0 & 0 & 0 & 0 & 0 & 0 & 0 & 0 & 0 & 0 \\
\hline $\begin{array}{c}\text { Goiaba } \\
\text { (764) }\end{array}$ & 16 & 2,09 & 1 & 0,13 & 0 & 0 & 0 & 0 & 0 & 0 & 0 & 0 \\
\hline $\begin{array}{c}\text { Guabiroba } \\
\text { (37) }\end{array}$ & 1 & 2,70 & 0 & 0 & 0 & 0 & 0 & 0 & 0 & 0 & 0 & 0 \\
\hline $\begin{array}{l}\text { Ingá } \\
\text { (677) }\end{array}$ & 22 & 3,24 & 1 & 0,14 & 0 & 0 & 0 & 0 & 0 & 0 & 0 & 0 \\
\hline $\begin{array}{c}\text { Jabuticaba } \\
\text { (1004) }\end{array}$ & 59 & 5,87 & 1 & 0,09 & 1 & 0,09 & 0 & 0 & 8 & 0,79 & 0 & 0 \\
\hline $\begin{array}{l}\text { Jambo } \\
\text { (1759) }\end{array}$ & 91 & 5,17 & 2 & 0,11 & 1 & 0,05 & 0 & 0 & 0 & 0 & 3 & 0,17 \\
\hline $\begin{array}{l}\text { Maria preta } \\
\text { (832) }\end{array}$ & 129 & 15,5 & 2 & 0,24 & 0 & 0 & 0 & 0 & 16 & 1,92 & 0 & 0 \\
\hline $\begin{array}{l}\text { Manga } \\
(464)\end{array}$ & 16 & 3,44 & 0 & 0 & 0 & 0 & 0 & 0 & 4 & 0,86 & 1 & 0,21 \\
\hline
\end{tabular}


Tabela 7. Percentagem de parasitismo de larvas frugívoras por braconídeos em frutos de 33 municípios do Estado de São Paulo (agosto/1997 a fevereiro/2003)

\begin{tabular}{|c|c|c|c|c|c|c|c|c|c|c|c|c|}
\hline \multirow{3}{*}{$\begin{array}{c}\text { Frutíferas } \\
\text { hospedeiras } \\
\text { das larvas } \\
\text { (№ de pupários) }\end{array}$} & \multicolumn{12}{|c|}{ PARASITÓIDES } \\
\hline & \multicolumn{2}{|c|}{$\begin{array}{c}\text { Doryctobracon } \\
\text { areolatus }\end{array}$} & \multicolumn{2}{|c|}{$\begin{array}{c}\text { Doryctobracon } \\
\text { brasiliensis }\end{array}$} & \multicolumn{2}{|c|}{$\begin{array}{l}\text { Opius } \\
\text { bellus }\end{array}$} & \multicolumn{2}{|c|}{ Opius sp. } & \multicolumn{2}{|c|}{$\begin{array}{c}\text { Utetes } \\
\text { anastrephae }\end{array}$} & \multicolumn{2}{|c|}{$\begin{array}{c}\text { Asobara } \\
\text { anastrephae }\end{array}$} \\
\hline & $\mathrm{N}$ & $\%$ & $\mathrm{~N}$ & $\%$ & $\mathrm{~N}$ & $\%$ & $\mathrm{~N}$ & $\%$ & $\mathrm{~N}$ & $\%$ & $\mathrm{~N}$ & $\%$ \\
\hline $\begin{array}{l}\text { Nêspera } \\
\text { (9898) }\end{array}$ & 125 & 1,26 & 54 & 0,54 & 9 & 0,09 & 3 & 0,03 & 127 & 1,28 & 5 & 0,05 \\
\hline $\begin{array}{l}\text { Pombeiro } \\
\text { (2964) }\end{array}$ & 529 & 17,84 & 5 & 0,16 & 3 & 0,10 & 0 & 0 & 11 & 0,37 & 2 & 0,06 \\
\hline $\begin{array}{l}\text { Pêssego } \\
\text { (4222) }\end{array}$ & 96 & 2,27 & 44 & 1,04 & 0 & 0 & 1 & 0,02 & 0 & 0 & 0 & 0 \\
\hline $\begin{array}{l}\text { Pitanga } \\
\text { (4082) }\end{array}$ & 498 & 12,19 & 22 & 0,53 & 6 & 0,14 & 1 & 0,02 & 77 & 1,88 & 0 & 0 \\
\hline $\begin{array}{c}\text { Serigüela } \\
\text { (1084) }\end{array}$ & 87 & 8,02 & 0 & 0 & 0 & 0 & 0 & 0 & 0 & 0 & 25 & 2,30 \\
\hline $\begin{array}{l}\text { Uvaia } \\
\text { (1422) }\end{array}$ & 44 & 3,09 & 15 & 1,05 & 0 & 0 & 0 & 0 & 0 & 0 & 0 & 0 \\
\hline $\begin{array}{l}\text { Umê } \\
\text { (995) }\end{array}$ & 2 & 0,20 & 2 & 0,20 & 2 & 0,20 & 0 & 0 & 0 & 0 & 0 & 0 \\
\hline $\begin{array}{c}\text { Wampi } \\
\text { (5) }\end{array}$ & 2 & 40,0 & 0 & 0 & 0 & 0 & 0 & 0 & 0 & 0 & 0 & 0 \\
\hline
\end{tabular}




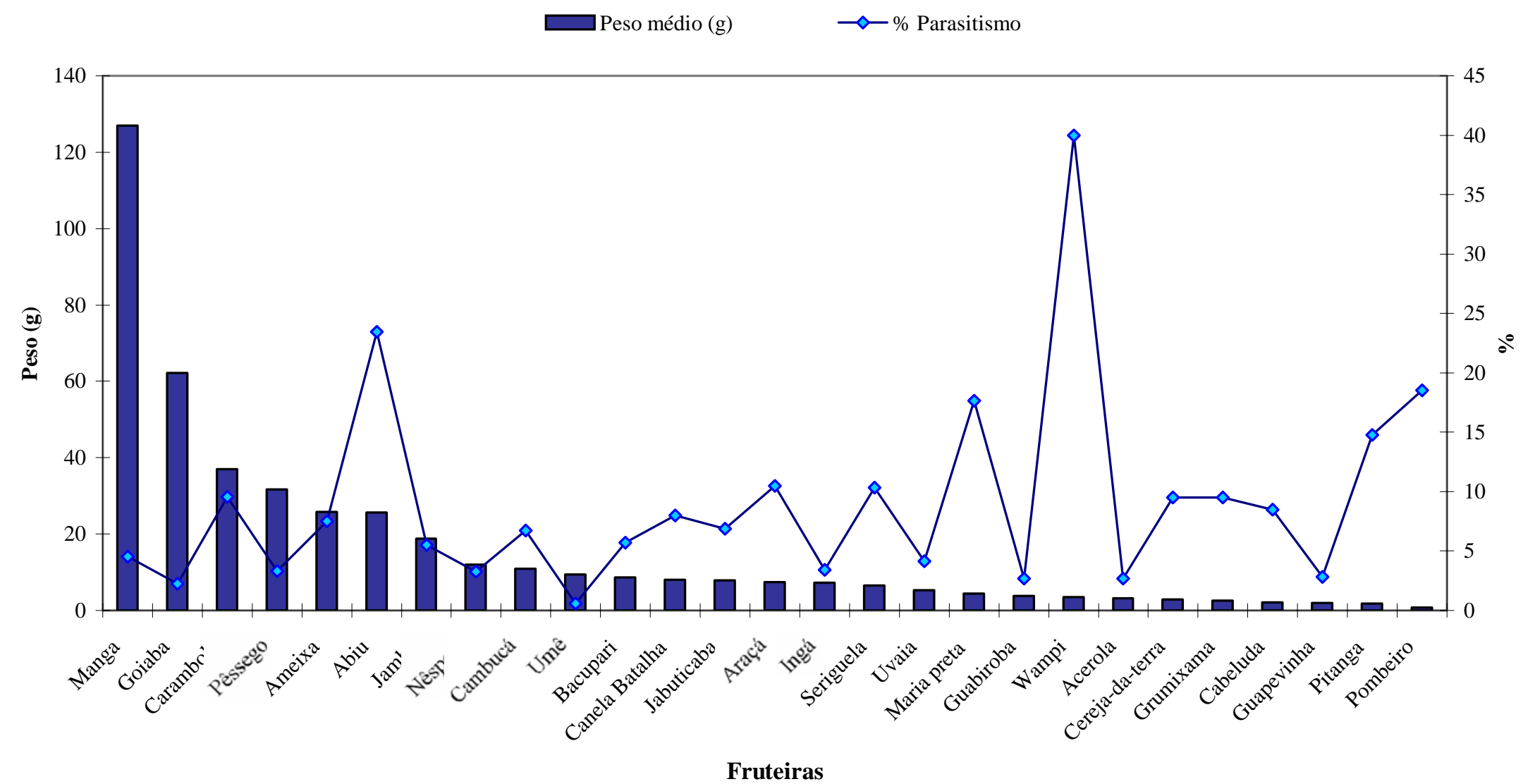

Figura 17 - Relação entre percentagem de parasitismo (\%) de braconídeos e peso do fruto (g) 


\section{CONCLUSÕES}

- Os parasitóides da subfamília Opiinae são mais comuns (96,2\%);

- Doryctobracon areolatus (Szépligeti) é a espécie mais comum (77,5\%) e ocorre na maioria dos municípios;

- Doryctobracon areolatus (Szépligeti) parasita larvas/pupas de moscas em 26 espécies frutíferas e está associada a Anastrepha fraterculus (Wied.), A. obliqua (Macquart) e A. amita Zucchi;

- Doryctobracon areolatus (Szépligeti) é associado pela primeira vez com larvas/pupas de moscas em wampi, Clausena lansiun (Lour) Skeels e com larvas/pupas de Anastrepha fraterculus em frutos de canela-batalha (Cryptocarya aschersoniana Mez);

- Opius sp. é registrado pela primeira vez em larvas/pupas de Anastrepha fraterculus em frutos de canela-batalha (Cryptocarya aschersoniana Mez);

- Doryctobracon brasiliensis é registrado pela primeira vez em larvas/pupas de mosca em ameixa-japonesa (Prunus salicina Lindl.);

- O parasitismo total de braconídeos em larvas de tefritídeos é de 7,75\% e o parasitismo entre as espécies de parasitóides variou de 0,02\% a 40\%. 


\section{REFERÊNCIAS BIBLIOGRÁFICAS}

ACHTERBERG, C. Van. A preliminar key to the subfamilies of the Braconidae (Hymenoptera). Tijdschrift voor Entomologie, v. 119, p. 33-78, 1976.

ACHTERBERG, C. Van Essay on the phylogeny of Braconidae (Hymenoptera: Ichneumonoidea). Entomologisk Tidskrift, v. 105, p. 41-58, 1984.

ARAÚJO, E.L. Dípteros frugívoros (Tephritidae e Loncheidae) na região de Mossoró/Assu, Estado do Rio Grande do Norte. Piracicaba, 2002. 112p. Tese (Doutorado) - Escola Superior de Agricultura "Luiz de Queiroz”, Universidade de São Paulo.

AGUIAR-MENEZES, E. L. Aspectos ecológicos de populações de parasitóides Braconidae (Hymenoptera) de Anastrepha spp. Schiner, 1868 (Diptera: Tephritidae) no município de Seropédica, RJ. Rio de Janeiro, 2000. 133p. Tese (Doutorado) Universidade Federal Rural do Rio de Janeiro.

AGUIAR-MENEZES, E.L.; MENEZES, E.B. Flutuação populacional das moscas-dasfrutas e sua relação com a disponibilidade hospedeira em Itaguaí-RJ. Anais da Sociedade Entomológica do Brasil, v. 25, n. 2, p. 223-232, 1996.

AGUIA-MENEZES, E. L; MENEZES E. B. Natural occurrence of parasitoids of Anastrepha spp. Schiner, 1868 (Diptera: Tephritidae) in the different host plants, in Itaguaí (RJ), Brazil. Biologic Control, v. 8, p. 1-6, 1997. 
AGUIAR-MENEZES, E.L.; MENEZES, E. B. Parasitismo sazonal e flutuação de Opiinae (Hymenoptera: Braconidae), parasitóides de espécies de Anastrepha (Diptera: Tephritidae), em Seropédica, RJ. Neotropical Entomology, v. 30, n. 4, p. 613-623, 2001.

AGUIAR-MENEZES, E.L.; MENEZES, E.B.; SILVA, P.S.; BITTAR, A.C.; CASSINO, P.C.R. Native Hymenopteran parasitoids associated with Anastrepha spp. (Diptera: Tephritidae) in Seropedica city, Rio de Janeiro, Brazil. Florida Entomologist, v. 84, n. 4, p. 465-751, 2001.

BARANOWSKI, R. H. Release Opius longicaudatus against Anastrepha suspensa in Florida. Fruit Fly News, v. 3, p. 17, 1974.

BLANCHARD, E.E. Dos nuevos opiinos (Hym. Braconidae) parasitos de tripétidos (Dipt.) Del gênero Anastrepha. Revista de investigaciones Agropecuarias, série 5, Patología Vegetal, v. 3, p. 21-25, 1966.

BENNETT, F. D.; YASEEN, M.; BERG, M. N. SOMMERIJER, M. J. Anastrepha spp. - Investigations on their natural enemies and establishment of Bioteres longicaudatus in Trinidad, West Indies. Commonwealth Institute of Biological Control Technical Bulletin, v.18, p. 1-12, 1977.

BESS, H.A. Status of Ceratitis in Hawaii following the introduction of Dacus dorsalis and its parasites. Proceedings Hawaiian Entomological Society. v.15, p. 221-234, 1953.

BRESSAN, S.; TELLES, M.C. Lista de hospedeiros e índices de infestação de algumas espécies do gênero Anastrepha Schiner, 1868 (Diptera: Tephritidae) na região de Ribeirão Preto - SP. Anais da Sociedade Entomológica do Brasil, v. 20, n. 1, p. 115, 1991. 
BRÈTHES, J. Vários himenópteros de la América del Sur. Nunquam Otiosus, v. 2, p. 10-11, 1924.

CANAL DAZA, N.A. Espécies de parasitóides (Hymenoptera: Braconidae) de moscasdas-frutas (Diptera: Tephritidae) em quatro locais do Estado do Amazonas. Piracicaba, 1993. 93p. Dissertação (Mestrado) - Escola Superior de Agricultura “Luiz de Queiroz”, Universidade de São Paulo.

CANAL DAZA, N.A. Levantamento, flutuação populacional e análise faunística das espécies de moscas-das-frutas (Dip. Tephritidae) em quatro municípios do Norte de Minas Gerais. Piracicaba, 1997. 113p. Tese (Doutorado) - Escola Superior de Agricultura “Luiz de Queiroz”, Universidade de São Paulo.

CANAL DAZA, N. A.; ZUCCHI, R. A. Chave ilustrada para a identificação das espécies de Braconidae (Hymenoptera), assinaladas no Brasil, parasitóides de moscas-das-frutas (Diptera: Tephritidae). In: SIMPÓSIO DE CONTROLE BIOLÓGICO 5., Foz do Iguaçu, 1996. Anais. Foz do Iguaçu, PR: Cobrafi, Embrapa Soja, 1996. p. 336.

CANAL DAZA, N.A.; ZUCCHI, R.A. Parasitóides-Braconidae. In: MALAVASI, A.; ZUCCHI, R.A. (Ed.) Moscas-das-frutas de importância econômica no Brasil. Conhecimento básico e aplicado. Ribeirão Preto: Holos-FAPESP, 2000, cap. 15, p. 119-126.

CANAL DAZA, N. A.; ZUCCHI, R. A.; SILVA, N. M. Análise faunística dos parasitóides (Hymenoptera: Braconidae) de Anastrepha spp. (Diptera: Tephritidae) em Manaus e Iranduba, Estado do Amazonas. Acta Amazonica, v. 25, p. 235-246, 1995. 
CANAL DAZA, N.A.; ZUCCHI, R.A.; SILVA, N.M. da; LEONEL JUNIOR, F.L. Reconocimiento de las especies de parasitóides (Hym.; Braconidae) de moscas de las frutas (Dip.: Tephritidae) em dos municipios del Estado de Amazonas, Brasil. Boletin Del Museo de Entomologia de la Universidad Del Valle, v. 2, n. 1/2, p. 1$17,1994$.

CARVALHO, R. da S.; NASCIMENTO A. S. Avaliação do controle biológico de moscas-das-frutas no Brasil utilizando o Parasitóide exótico Diachasmimorpha longicaudata (Hymenoptera: Braconidae). In: SIMPÓSIO DE CONTROLE BIOLÓGICO 7., Poços de Caldas, 2001. Resumos. Poços de Caldas: Universidade Federal de Lavras, 2001. p. 625-630. 1 CD

CARVALHO, R.S.; NASCIMENTO, A.S.; MATRANGOLO, W.J.R. Controle Biológico. In: MALAVASI, A.; ZUCCHI, R.A. (Ed.) Moscas-das-frutas de Importância econômica no Brasil. Conhecimento básico e aplicado. Ribeirão Preto: Holos-FAPESP, 2000, cap. 14, p.113-117.

CANALE, A.; RASPI, A. Host location and oviposition behaviour in Opius concolor (Hymenoptera: Braconidae). Entomological Problems, v. 31, n. 1, p. 25-32, 2000.

CAPEK, M. An attempt at a natural classification of the family Braconidae based on various unconventional characters (Hymenoptera). Proceedings of the Entomological Society of Washington, v. 71, n. 3, p. 304-312, 1969.

CAPEK, M. A new classification of the Braconidae (Hymenoptera) based on the cephalic structures of the final instar larva and biological evidence. The Canadian Entomologist, v. 102, p. 846-875, 1970.

CLAUSEN, C. P. Biological control of fruit flies. Journal of Economic Entomology, v. 49, n. 2, p. 176-178, 1956. 
CLAUSEN, C. P., CLANCY, D.W., CHOCK, Q.C. Biological control of the oriental fruit fly (Dacus dorsalis Hendel) and other fruit flies in Hawaii. Washington: USDA, 1965. 102p. USDA. (Technical Bulletin, 1322).

ESKAFI, F.M. Parasitism of fruit flies Ceratitis capitata and Anastrepha spp. (Diptera: Tephritidae) in Guatemala. Entomophaga, v. 35, n. 3, p. 355-362, 1990.

FISCHER, M. Zur kenntnis de von Szépligeti beschriebenen Opius - arten. 1. teil. Polskie Pismo Entomogiczne, v. 31, p. 263-293, 1961.

FISCHER, M. Die Opius - arten der neotropischen region. Polskie Pismo Entomogiczne, v. 33, p. 253-409, 1963.

FISCHER, M. Neue neotropische Opius - arten aus dem U. S. National Museum Washington. Beiträge zur Entomologie, v. 16, p. 84-150, 1966.

FISCHER, M. Zusammen fassung der neotropischen Opiinae mit ausschluss der gattung Opius Wesm. (Hymenoptera, Braconidae). Beiträge zur Neotropischen Fauna, v. 5, p. 1-21, 1967.

FISCHER, M. Hymenoptera Braconidae (Opiinae I). Das Tierreich, v. 91, p. 1-602, 1972.

FISCHER, M. Die nearktischen Phaenocarpa-Arten. Revision der gruppe B (Hymenoptera, Braconidae, Alysiinae). Polskie pismo Entomologiczne, v. 44, p. 103-230, 1974.

FISCHER, M. Die nearktischen Phaenocarpa-Arten. Revision der gruppe A (Hymenoptera, Braconidae, Alysiinae). Polskie pismo Entomologiczne, v. 45, p. 279-356, 1975. 
FISCHER, M. Hymenoptera Braconidae (Opiinae II). Das Tierreich, Berlin, v. 96, p. 11001, 1977.

FULLAWAY, D. T. Review of the indo-australasian parasites of the fruit flies (Thephritidae). Proceedings of the Hawaiian Entomological Society, v. 14, n. 2, p. 243-250, 1951.

GAHAN, A.B. A revision of the North American ichneumon flies of the subfamily Opiinae. Proceedings of the United States National Museum, v. 49, p. 63-95, 1915.

GAHAN, A.B. Description of seven new species of Opius (Hymenoptera: Braconidae). Proceedings of the Entomological Society of Washington, v. 21, p. 161-170, 1919.

GAHAN, A.B. Synonymical and descriptive notes on parasitic Hymenoptera. Proceedings of the United States National Museum, v. 77, n. 8, p. 1-12, 1930.

GAUlD, I.; BOLTON, B. The Hymenoptera. London: British Museum, Oxford University Press, 1988. 332p.

GREANY, P. D.; HAWKE, S.D.; CARLYSLE, T.C.; ANTHONY, D. W. Sence organs in the ovipositor of Bioteres (Opius) longicaudatus, a parasite of the Caribbean fruit fly Anastrepha suspensa. Annals of the Entomological Society America, v. 70, p. 319-321, 1977.

GRIFFITHS, G. C. D. The Alysiinae (Hym., Braconidae) parasites of the Agromyzidae (Diptera). I. General questions of taxonomy, biology and evolution. Beitrage zur Entomologie, v. 14, p. 823 - 914, 1964. 
GUIMARÃES e SILVA, A. S. Interações de espécies de Anastrepha Schiner, 1868 (Diptera: Tephritidae) e parasitismo em abiu Pouteria caimito Ruiz \& Pav. (Sapotaceae) e taperebá Spondias mombin L. (Anacardiaceae) em Manaus. Amazonas, Brasil, 2002. 79p. Dissertação (Mestrado) - Instituto Nacional de Pesquisas da Amazônia - INPA/ Universidade do Amazonas - UA.

HICKEL, E.R. Espessura da polpa como condicionante do parasitismo de mosca-dasfrutas (Díptera: Tephritidae) por Hymenoptera: Braconidae. Ciência Rural, v. 32, n. 6, p. 1005-1009, 2002.

HERNÁNDEZ-ORTIZ, V.; PÉREZ-ALONSO, R.; WHARTON, R.A. Native parasitoids associated with the genus Anastrepha (Dipt.: Tephritidae) in los Tuxtlas, Veracruz, México. Entomophaga, v. 39, n. 2, p. 171-178, 1994.

JIMÉNEZ, A.; CASTILHO, E. Bioteres longicaudatus (Ashmead), un parasitóide de las moscas de la frutas. Su cría y posibilidad de empleo en control biológico. Boletín de Sanidad Vegetal, Plagas, v. 18, p. 139-148, 1992.

JIMÉNEZ-JIMÉNEZ, W. Resultados del combate de las moscas de la fruta en el Estado de Morelos. Fitófilo, v. 38, p. 35-37, 1963.

JIRON, L.F.; HEDSTRÖM, I. Occurrence of fruit flies of the genera Anastrepha and Ceratitis capitata (Diptera: Tephritidae) and their host plant availability in Costa Rica. Florida Entomologist, v. 71, n. 1, p. 62-73, 1988.

JIRÓN, L.F.; MEXZON, R.G. Parasitoids hymenopterans of Costa Rica: geographical distribution of the species associated with fruit flies (Diptera: Tephritidae). Entomophaga, v. 34, n. 1, p. 53-60, 1989. 
KATIYAR, K.P.; CAMACHO, M.J.; GERAULD, F.; MATHEUS, R. Parasitoides Hymenópteros de moscas de las frutas (Diptera: Tephritidae) em la región occidental de Venezuela. Revista de la Faculdad de Agronomia, v. 12, p. 303-312, 1995.

KIMANI-NJOGU, S. W.; WHARTON, R. A. Two new species of Opiinae (Hymenoptera: Braconidae) attacking fruit-infesting Tephritidae (Diptera) in Western Kenya. Proceedings of the Entomological Society of Washington, v. 104 n. 1, p. 79-90, 2002.

KOVALESKI, A. Processos adaptativos na colonização da macieira (Malus domestica L.) por Anastrepha fraterculus (Wiedmann) (Diptera: Tephritidae) na região de Vacaria, RS. São Paulo, 1997. 122p. Tese (Doutorado) - Instituto de Biociências, Universidade de São Paulo.

LAWRENCE, P.O.; BARANOWSK, R.M.; GREANY, P.D. Effect of host age on development of Biosteres longicaudatus, a parasitoid of the Caribbean fruit fly Anastrepha suspensa. The Florida Entomologist, v. 59, p. 33-39, 1976.

LEONEL JUNIOR, F.L. Espécies de Braconidae (Hymenoptera) parasitóides de moscas-das-frutas (Diptera: Tephritidae) no Brasil. Piracicaba, 1991. 83p. Dissertação (Mestrado) - Escola Superior de Agricultura "Luiz de Queiroz", Universidade de São Paulo.

LEONEL JUNIOR, F.L.; ZUCCHI, R.A.; WHARTON, R.A. Distribution and tephritid hosts (Diptera) of braconid parasitoids (Hymenoptera) in Brazil. International Journal of pest Management, v. 41, n. 4, p. 208-213, 1995. 
LEONEL JUNIOR, F.L.; ZUCCHI, R.A.; CANAL D., N. A. Parasitismo de moscasdas-frutas (Díptera: Tephritidae) por Braconidae (Hymenoptera) em duas localidades do Estado de São Paulo. Anais da Sociedade Entomológica do Brasil, v. 25, n. 2, p. 199-206, 1996.

LEYVA, J.L.; BROWHNING, H.W.; GILSTRAP, F.E. Effect of host fruit species, size, and color on parasitization of Anastrepha ludens (Diptera: Tephritidae) by Diachasmimorpha longicaudata (Hymenoptera: Braconidae). Environmental Entomology, v. 20, n. 5, p. 1469-1474, 1991.

LIMA, A.C. Vespa do gênero Opius, parasitas de larvas de moscas das frutas (Hymenoptera: Braconidae). O Campo, p. 22-24, set.; p. 29-32, out. 1937.

LIMA, A.C. Vespas parasitas de moscas das frutas (Hymenoptera: Braconidae). O Campo, v. 9, n. 99, p. 69-72, mar. 1938.

LÓPEZ, M.; ALUJA, M.; SIVINSKI, J. Hymenopterous laval-pupal and parasitoids of Anastrepha flies (Diptera: Tephritidae) in Mexico. Biological Control, v. 15, p. 119129, 1999.

MARSH, P.M. A key to the Neartic subfamilies of the family Braconidae (Hymenoptera). Annals of the Entomological Society of America, v. 56, p. 522527, 1963.

MALAVASI, A.; MORGANTE, J.L. Biologia de "moscas-das-frutas" (Diptera: Tephritidae). II Índices de infestação em diferentes hospedeiros e localidades. Revista Brasileira de Biologia. v. 40, n. 1, p.17-24, 1980. 
MATRANGOLO, W. J. R.; NASCIMENTO, A. S.; CARVALHO, R. S.; MELO, E. D.; de JESUS, M. Parasitóides de moscas-das-frutas (Diptera: Tephritidae) associados a fruteiras tropicais. Anais da Sociedade Entomologica do Brasil, v. 27, p. 593-603, 1998.

MESSING, R.H.; JANG, E.B. Response of the fruit fly parasitoid Diachasmimorpha longicaudata (Hym.: Braconidae) to host fruit Stimuli. Environmental Entomology, v.21, p. 1189-1195, 1992.

MUESEBECK, C. F. W. New Neotropical wasps of the family Braconidae (Hymenoptera) in the U. S. National Museum. Proceedings of the United States National Museum, v. 107, p. 405-461, 1958.

NORA, I.; CANAL D., N.A.; ZUCCHI, R.A.; BRANCO E.S. Levantamento de parasitóides (Hym. Braconidae) de Anastrepha (Dip., Tephritidae) na região do Vale do Rio do Peixe, SC. IN: CONGRESSO BRASILEIRO DE ENTOMOLOGIA 15., Caxambu, MG, 1995. Abstracts. Caxambu: 1995. p. 298.

OVRUSKI, S. M. Aganaspis pelleranoi (Hymenoptera: Eucoilidae) parasitóide de larvas de Ceratitis capitata (Diptera: Tephritidae). Revista de la Sociedad Entomologica Argentina, v. 53, n. 1/4, p. 121-127, 1994.

OVRUSKI, S.; ALUJA, M.; SIVINSKI, J.; WHARTON, R. Hymenopteran parasitoids on fruit-infesting Tephritidae (Diptera) in Latin America and the southern United States: Diversity, distribution, taxonomic status and their use in fruit fly biological control. Integrated Pest Management Reviews, v. 5, p. 81-107, 2000. 
OVRUSKI, S.M.; de COLL, O.R.; SCHLISERMAN, P.; TIETJEN, G. E. Parasitoids associated with Anastrepha fraterculus (Diptera: Tephritidae) in different host plants in missiones, Argentina. In: MEETING OF THE WORKING GROUP ON FRUIT FLIES OF THE WESTERN HEMISPHERE 4., Mendoza, 2001. Proceedings. Argentina: s. ed., 2001. p. 124.

PAPP, J. A synopsis of the Phaenocarpa Forst. Species of the Oriental Region (Hymenoptera, Braconidae, Alysiinae). Reichenbachia, v. 8, n. 20, p. 139-157, 1967.

PENTEADO-DIAS, A.M. Parasitismo de Tephritidae (Diptera) por Opiinae (Hymenoptera: Braconidae) na região de São Carlos, SP. In: CONGRESSO BRASILEIRO DE ENTOMOLOGIA, 11., Campinas, 1987. Resumos. Campinas: SEB, 1987. p. 481.

PURCELL, M. F.; JACKSON, C. G.; LONG, J. P.; BATCHELOR, M. A. Influence of guava ripening on parasitism of the oriental fruit fly, Bactrocera dorsalis (Hendel) (Diptera: Tephritidae), by Diachasmimopha longicaudata (Ashmead) (Hymenoptera: Braconidae) and other parasitoids. Biological Control, v. 4, p. 396-403, 1994.

QUICKE, D. L.; ACHTERBERG, C. van. Phylogeny of the subfamilies of the family Braconidae (Hymenoptera: Ichneumonoidea). Zoologische Verhandelinger, v. 258, p. 1-95, 1990.

SALLES, L. A. B. Parasitóides de Anastrepha fraterculus (Wield.) (Diptera: Tephritidae) por Hymenoptera na região de Pelotas, RS. Pesquisa Agrícola Brasileira, v. 31, n. 11, p. 769-774, 1996.

SIVINSKI, J. The influence of host fruit morphology on parasitism rates in Caribbean fruit fly Anastrepha suspensa (Loew). Entomophaga, v. 36, p. 447-454, 1991. 
SIVINSKI, J.; ALUJA, M.; LOPÉZ, M. Spatial and temporal distribution of parasitoids of mexican Anastrepha species (Diptera: Tephritidae). Within the canopies of fruit trees. Annals of the Entomological Society America, v. 90, n. 5, p. 604-618, 1997.

SIVINSKI, J.; ALUJA, M.; HOLLER, T.; EITAN, A. Phenological comparison of two braconid parasitoids of the Caribbean fruit fly (Diptera: Tephritidae). Environmental Entomology, v. 27, n. 2, p. 360-365, 1998.

SOUZA FILHO, M.F. Biodiversidade de moscas-das-frutas (Diptera: Tephritidae) e seus parasitóides (Hymenoptera) em plantas hospedeiras no Estado de São Paulo. Piracicaba, 1999. 173p. Dissertação (Mestrado) - Escola Superior de Agricultura “Luiz de Queiroz”, Universidade de São Paulo.

SNOWBALL, G. J. Status of introduced parasites of Queensland fruit fly (Strumeta tryoni), 1962-1965. The Australian Journal of Agricultural Reseach, v. 17, p. 719-739, 1966.

SZÉPLIGETI, G. Zwei neue braconiden aus brasilien. Bolletino Laboratório di Zoologia Generale della Faclta Agrária in Portici, v. 5, p. 285, 1911.

TOBIAS, V. I. A review of the classification, phylogeny and evolution of the family Braconidae (Hymenoptera). Entomological Review, v. 46, p. 387-399, 1967.

TOBIAS, V. I. The genus Opius Wesm. (Hymenoptera, Braconidae) as parasites of fruit flies (Diptera, Tephritidae). Entomological Review, v. 56, p. 132-139, 1977.

TROSTLE, M.; CARREJO, N. S.; MERCADO, I.; WHARTON, R. A. Two new species of Phaenocarpa Foerster (Hymenoptera: Braconidae: Alysiinae) from South America. Proceedings of the Entomological Society Washington, v. 101, n. 1, p. 197-207, 1999. 
UCHÔA F., M. F. Biodiversidade de moscas frugívoras (Díptera Tephritidae), seus frutos hospedeiros e parasitóides (Hymenoptera) em áreas de cerrado do Mato Grosso do Sul. Piracicaba, 1999. 104p. Tese (Doutorado) - Escola Superior de Agricultura “Luiz de Queiroz”, Universidade de São Paulo.

UCHÔA-FERNANDES, M.A.; MOLINA, R.M. da S.; OLIVEIRA, I. de; ZUCCHI, R.A.; CANAL, N.A.; DÍAZ, N.B. Larval endoparasitoids (Hymenoptera) of frugívorous flies (Díptera, Tephritoidea) reared from fruits of the cerrado of the State of Mato Grosso do Sul, Brazil. Revista Brasileira de Entomologia, v. 47, n. 2, p. 181-186, 2003.

VAN DRIESCHE, R.G. Meaning of "Percent parasitism" in studies of insect parasitoids. Environmental Entomology, v. 12, n. 6, p. 1611-1622, 1983.

VELOSO, V. R. S.; ZUCCHI R. A.; CANAL D., N. A.; SUGAYAMA, R. L. Espécies de parasitóides (Hymenoptera: Braconidae) de moscas de las frutas (Dip., Tephrtitidae) en el Estado de Goiás. In: MEETING OF THE WORKING GROUP ON FRUIT FLIES OF THE WESTERN HEMISPHERE, 2., Viña del Mar, Chile, 1996. Proceedings. Chile: 1996. p. 69.

VIERECK, H.L. Descriptions of ten new genera and twenty-t-three new species of ichneumon-flies. Proceedings of the United States National Museum, v. 44, n. 1968, p. 555-568, 1913.

VINSON, S.B. Host selection by insect parasitoids. Annual Review Entomology, v. 21, p. 109-133, 1976.

WHARTON, R. A. Review of the Neartic Alysiini (Hymenoptera: Braconidae) with discussion of generic relationships within the tribe. University of California, Publications in Entomology, Berkeley, v. 88, p. 1-112, 1980. 
WHARTON, R. A. Changes in nomenclature and classification of some Opiine Braconidae (Hymenoptera). Proceedings of the Entomological Society of Washington, v. 89, p. 61-73, 1987.

WHARTON, R. A. Classification of the Braconidae subfamily Opiinae (Hymenoptera). The Canadian Entomologist, v. 120, p. 333-360, 1988.

WHARTON, R. A. Classical biological control of Fruit infesting Tephritidae. In A. Robinson \& G. Hooper, (Ed.). Fruit Flies: their biology, natural enemies and control. Elsevier, Amsterdam, p. 303-312, 1989.

WHARTON, R.A. Bionomics of the Braconidae. Annual Review Entomology, v. 38, p. 121-143, 1993.

WHARTON, R.A., New genera, species, and records of new world Alysiinae (Hymenoptera: Braconidae). Proceedings of the Entomological Society of Washington, v. 16, n. 4, p. 630-664, 1994.

WHARTON, R. A. Manual of the New World Genera of the Family Braconidae (Hymenoptera) In: WHARTON, R. A.; MARSH, P. M.; SHAKEY, M. J. (Ed.), Manual of the New World Genera of the Family Braconidae (Hymenoptera). Lawrence: Allen Press, 1997. p. 1-15. (Special Publication of the International Society of Hymenopterists)

WHARTON, R. A. Subfamily Alysiinae, In: WHARTON, R. A.; MARSH, P. M.; SHAKEY, M. J. (Ed.), Manual of the New World Genera of the Family Braconidae (Hymenoptera). Lawrence: Allen Press, 1997a. p. 85-116. 
WHARTON, R. A. Subfamily Opiinae In: WHARTON, R. A.; MARSH, P. M.; SHAKEY, M. J. (Ed.), Manual of the New World Genera of the Family Braconidae (Hymenoptera). Lawrence: Allen Press, 1997b. p. 379-395.

WHARTON, R. A. Generic relationships of Opiinae Braconidae (Hymenoptera) parasitic on fruit-infesting Tephritidae (Diptera). Contributions of the American Entomological Institute, v. 30, n. 3, p. 1-53, 1997c.

WHARTON, R.A. A review of the Old World genus Fopius Wharton (Hymenoptera: Braconidae: Opiinae), with description of two new species reared from fruitinfesting Tephritidae (Diptera). Journal of Hymenoptera Reseach, v. 8, n. 1, p. 4864, 1999.

WHARTON, R. A. Revision of the Australian Alysiini (Hymenoptera: Braconidae). Invertebrate Systematics CSIRO, v. 16, p. 7-105, 2002.

WHARTON, R.A.; MARSH, P.M. New world Opiinae (Hymenoptera: Braconidae) parasitic on Tephritidae (Diptera). Journal of the Washington Academy of Sciences, v. 68, n. 4, p. 147-167, 1978.

WHARTON, R.A., GILSTRAP, F.E. Key to and status of Opiine Braconid (Hymenoptera) parasitoids used in biological control of Ceratitis capitata and Dacus s.l. (Diptera: Tephritidae). Annals of the Entomological Society America, v. 76, p. 721-742, 1983.

YAO, A. L. Recovery survey of small-scale field releases of Bioteres longicaudatus Ashmead (Hymenoptera: Braconidae) in Bai-chi area, Taiwan. Bulletin of the Institute of Zoology Academia Sinica, v. 28, p. 211-214, 1989. 
ZUCCHI, R.A. Espécies de Anastrepha, Sinonímias, Plantas Hospedeiras e Parasitóides. In: MALAVASI, A.; ZUCCHI, R.A. (Ed.). Moscas-das-frutas de Importância Econômica no Brasil. Conhecimento básico e aplicado. Ribeirão Preto: HolosFAPESP, 2000. cap. 4, p. 41-48. 